UNIVERSIDADE DE SÃO PAULO

INSTITUTO DE QUÍMICA

\title{
MAPEAMENTO E CARACTERIZAÇÃO DO DOMÍNIO ATIVATÓRIO DA TROPONINA T
}

\author{
DANIELA MARA DE OLIVEIRA
}

Tese de doutorado submetida ao

Departamento de Bioquímica do

Instituto de Química da Universidade de

São Paulo.

Orientador: Dr. Fernando C.Reinach

São Paulo

31 de agosto de 2000 
Oliveira, Daniela Mara de

048m Mapeamento e caracterização do domínio ativatório da troponina T / Daniela Mara de Oliveira. -- São Paulo, 2000.

86p.

Tese (doutorado) - Instituto de Química da Universidade de São Paulo. Departamento de Bioquímica.

Orientador : Reinach, Fernando de Castro

1. Troponina : Bioquímica I. T. II. Reinach, Fernando de Castro, orientador. 


\section{"Mapeamento e Cartacterização do Domínio Ativatório da Troponina T".}

\section{DANIELA MARA DE OLIVEIRA}

Tese de Doutorado submetida ao Instituto de Química da Universidade de São Paulo como parte dos requisitos necessários à obtenção do grau de Doutor em Ciências - Área: Bioquímica.

Aprovada por:

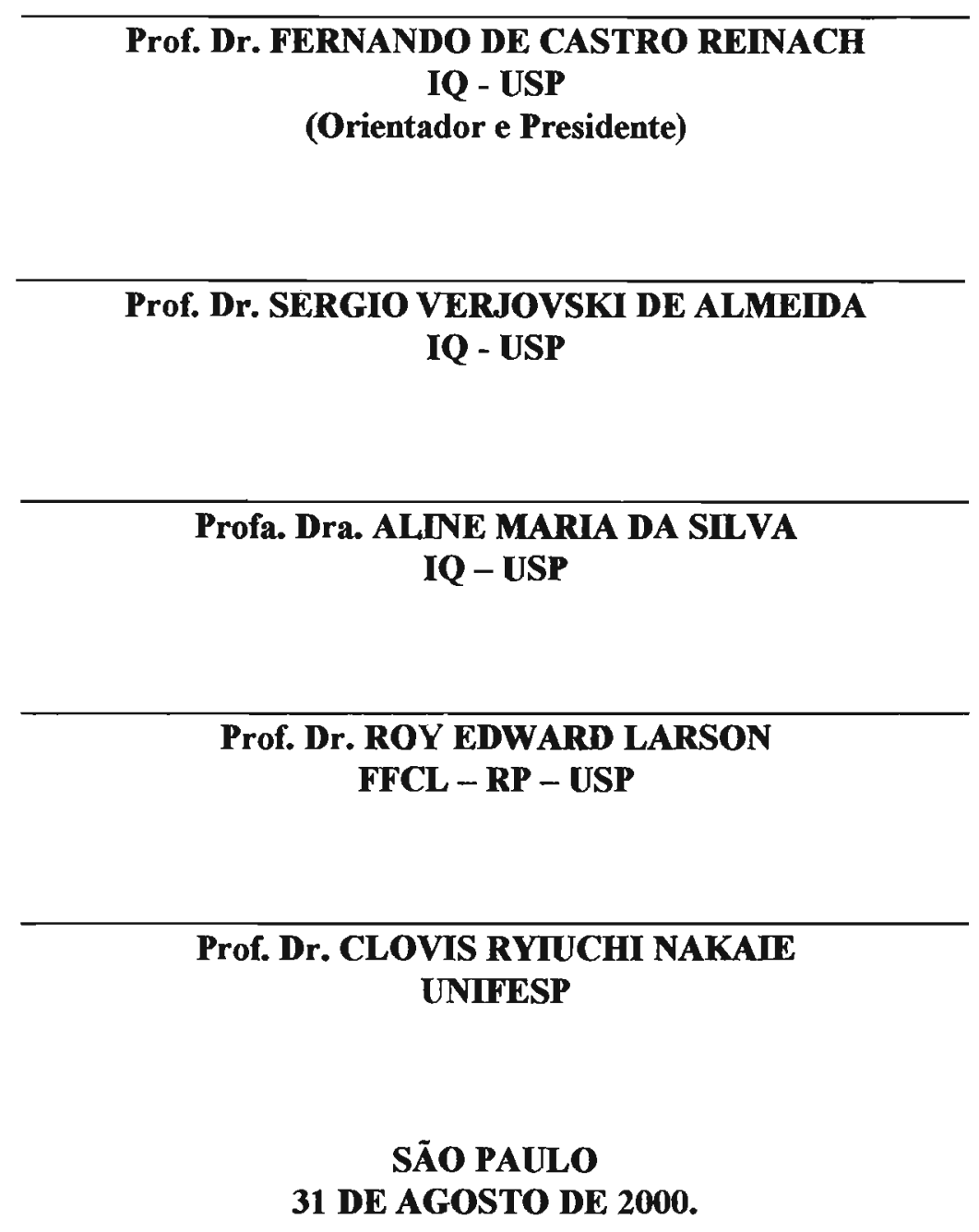




\section{AGRADECIMENTOS}

Ao Fernando C. Reinach pela orientação;

A todos membros do laboratório e do Instituto de Química que contribuíram direta ou indiretamente para a realização desse trabalho e para a minha formação científica;

Ao Prof. Dr. Clóvis R. Nakaie pela síntese e marcação do fragmento TnT158-191;

A Aurea D. de Sousa e Luís M. F. Holthauzen por terem cedido, respectivamente, as tropomiosinas $5 \mathrm{OH} 263 \mathrm{~W}$ e $5 \mathrm{OH} 122 \mathrm{~W}$;

À FAPESP e CNPq pelas bolsas concedidas;

À FAPESP, CNPq e Howard Hughes Medical Institute pelo suporte financeiro. 
ÍNDICE

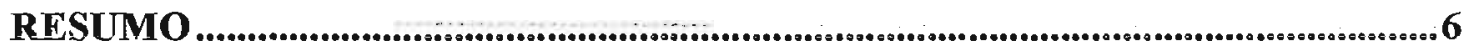

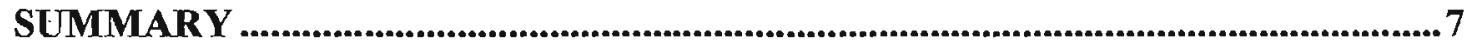

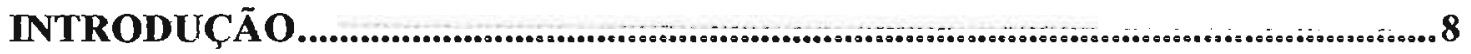

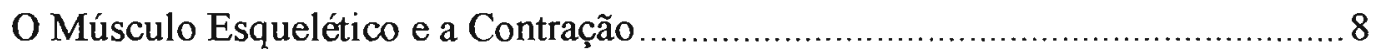

Regulação da Contração Muscular ..................................................................... 13

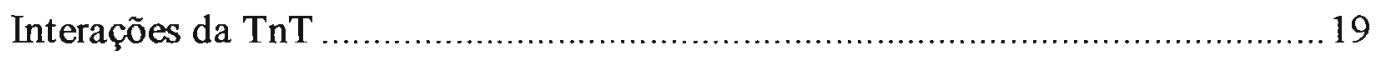

TnT e a Regulação da Contração Muscular.........................................................22

OBJETIVO...............................................................................................................25

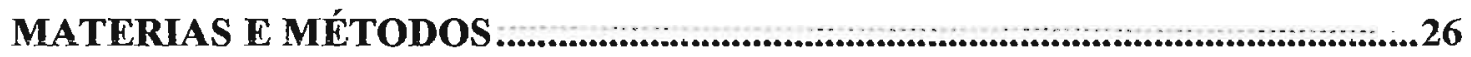

Produção dos Vetores de Expressão dos Fragmentos TnT1-157, TnT1-76,

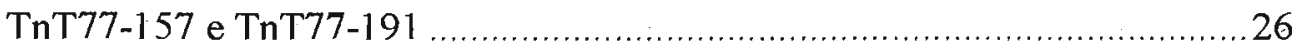

Expressão e Purificação dos Fragmentos TnT1-157, TnT1-76, TnT77-157 e

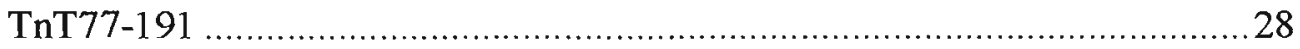

Síntese Química e Marcação do Fragmento TnT158-191 …….............................29

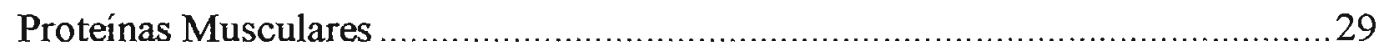

Dicroísmo Circular dos Fragmentos de TnT ….................................................29

Determinação da Atividade ATPásica da Acto-miosina ......................................30

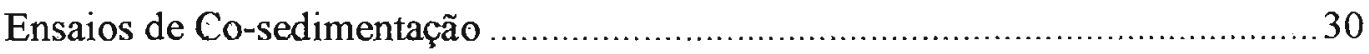

Estudo dos Efeitos do Complexo Troponina e dos Fragmentos de TnT no Espectro de Emissão das Tropomiosinas 5OH263W e 5OH122W ............... 31

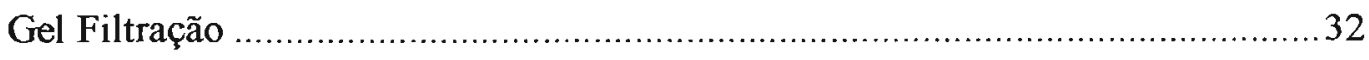

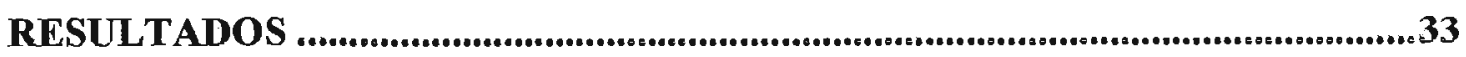

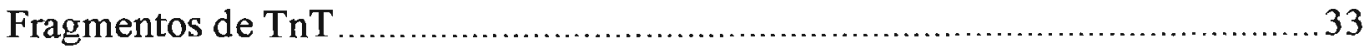

Dicró́smo Circular dos Fragmentos de TnT ……............................................ 35

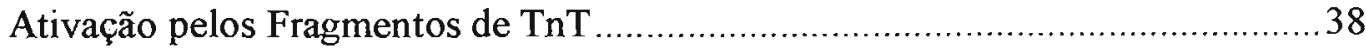

Interação dos Fragmentos de TnT com Actina e Tropomiosina............................42

Efeito do Complexo Troponina e Fragmentos de TnT no Espectro de

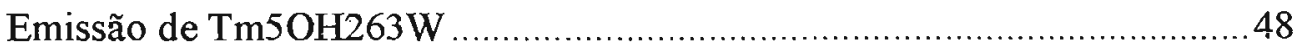


Efeito dos Fragmentos de TnT no Espectro de Fluorescência da

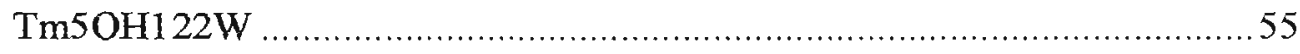

DISCUSSÃO

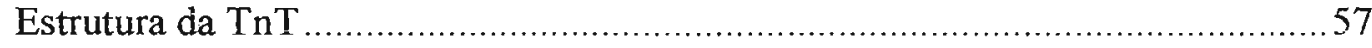

Interações da Região $\mathrm{NH}_{2}$-Terminal da Troponina $\mathrm{T}$.........................................5 58

Ativação da Atividade ATPásica da Acto-miosina pela TnT ..............................59

O Domínio Ativatório da Troponina T Altera a Posição da Tropomiosina no

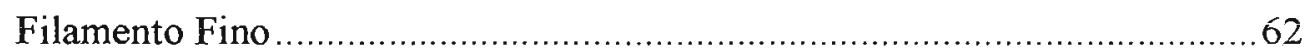

Interação da Região 77-157 da TnT com a Tropomiosina ..................................63

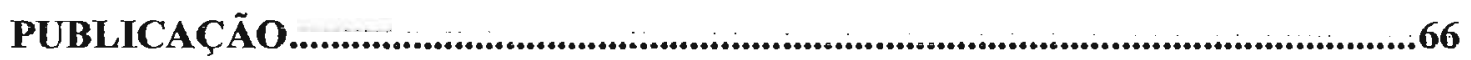

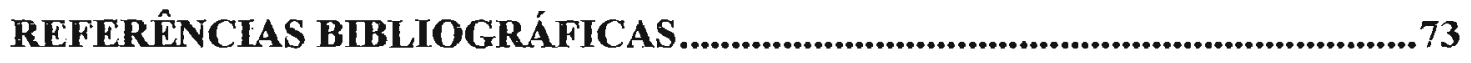

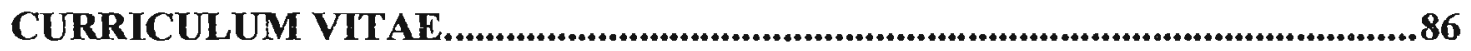




\section{ABREVIATURAS}

ABZ - ácido o-aminobenzóico

ADP - difosfato de adenosina

ATP - trifosfato de adenosina

BSA - albumina sérica bovina

CD - dicroísmo circular

cDNA - DNA complementar

CM - carbóxi metil

DEAE - dietilaminoetil

DO - densidade ótica

DTT - ditiotreitol

EDTA - ácido etileno-diamino-tetracético

EGTA - ácido etileno-glicol-bis( $\beta$-aminoetil-éter)-n, n, n', n'-tetracético

IPTG - isopropil- $\beta$-D-tiogalactopiranosídeo

$\mathrm{K}_{\mathrm{d}}$--constante de dissociação

MOPS - ácido 3-(N-morfolino) propanosulfônico

PCR - reação de polimerase em cadeia

$\mathrm{Pi}$ - pirofosfato inorgânico

$\mathrm{RF}$ - forma replicativa

S1- subfragmento 1 da miosina

SDS - dodecil sulfato de sódio

SDS-PAGE - eletroforese em gel de poliacrilamida e SDS

Tn -complexo troponina

$\mathrm{TnC}$ - troponina $\mathrm{C}$

TnI - troponina I

TnT-troponina $\mathrm{T}$

Tm - tropomiosina

Tris - Tris-(hidroximetil)-aminometano

$\mathrm{Wt}$ - tipo selvagem (wild type) 
Tm5OH122W- tropomiosina recombinante com a Glu ${ }^{122}$ substituída por 5hidroxitriptofano.

$\mathrm{Tm} 5 \mathrm{OH} 263 \mathrm{~W}$ - tropomiosina recombinante com a Gln ${ }^{263}$ substituída por 5hidroxitriptofano. 


\section{RESUMO}

A regulação dependente de $\mathrm{Ca}^{2+}$ da atividade ATPásica da acto-miosina em concentrações fisiológicas de actina, tropomiosina e troponina ocorre exclusivamente na presença de troponina $\mathrm{T}(\operatorname{Tn} \mathrm{T})$. Nosso grupo demonstrou que um polipeptídeo correspondente aos primeiros 191 aminoácidos da TnT ativa a atividade ATPásica da acto-miosina na presença de tropomiosina e na ausência das outras duas subunidades do complexo troponina ( $\mathrm{Tn} U / \mathrm{TnC})$. Com o objetivo de mapear e caracterizar esse domínio ativatório da TnT, construímos fragmentos de TnT correspondentes às regiões compreendidas entre os resíduos de aminoácidos: 1-157 (TnT1-157), 1-76 (TnT1-76), 77-157 (TnT77-57), 77-191 (TnT77-191) e 158-191 (TnT158-191). Estudos das interações desses fragmentos com actina e tropomiosina demonstraram que: i) o fragmento TnT1-76 não se liga à tropomiosina ou a actina; ii) a região da TnT correspondente aos resíduos 158-191 liga-se à actina cooperativamente, mas não se liga à tropomiosina; iii) a região correspondente seqüência de aminoácidos 77-157 é necessária para a interação da TnT com o resíduo de aminoácido 263 da tropomiosina; iv) TnT77-191 ativa a atividade ATPásica da acto-miosina com a mesma intensidade que TnT1-191. Também observamos que TnT1-157, TnT1-76, TnT77-157, TnT158-91 e combinações de TnT158-191 com TnT1-157 e TnT77-157 não afetam a atividade ATPásica da acto-mioina. Concluímos que a região da TnT delimitada pelos aminoácidos 77 e 191 é essencial para a ativação da atividade ATPásica da actomiosina e que essa ativação é mediada pelas interações dessa região da TnT com a tropomiosina e a actina. 


\section{SUMMARY}

The $\mathrm{Ca}^{2+}$-regulation of the actomyosin ATPase activity at physiological ratios of actin, tropomyosin and troponin occurs only in the presence of troponin T. Our group has previously demonstrated that a recombinant polypeptide corresponding to the first 191 amino acids of $\operatorname{TnT}(\operatorname{TnT} 1-191)$ activates the actomyosin $\mathrm{Mg}^{2+}$-ATPase activity in the presence of tropomyosin and in the absence of TnI/TnC. In order to further map and characterize this activation domain, we constructed a set of recombinant or synthetic TnT fragments, corresponding to amino acids 1-157 (TnT1-157), 1-76 (TnT1-76), 77-57 (TnT77157), 77-191 (TnT77-191) and 158-191 (TnT158-191). Binding assays using these fragments demonstrated that: i) amino acids 1-76 of TnT do not bind to tropomyosin or actin; ii) amino acids 158-191 bind to actin cooperatively, but not to tropomyosin; iii) the sequence $77-157$ is necessary for TnT's interaction with residue 263 of tropomyosin; iv) TnT77-191 on its own activates de actomyosin ATPase activity to the same extent as previously described for TnT1-191. TnT1157, TnT1-76, TnT77-157, TnT158-191 and combinations of TnT158-191 with TnT1-157 or TnT77-157 showed no effect on the ATPase activity. We conclude that interactions of amino acids 77-191 of TnT with tropomyosin and actin are essential for the activation of actomyosin ATPase activity, and that this activation may be mediated in part by a direct interaction between TnT residues 158-191 and actin. 


\section{INTRODUÇÃO}

O Músculo Esquelético e a Contração

O músculo esquelético é formado por células multinucleadas e alongadas denominadas fibras musculares. As fibras musculares possuem seus citoplasmas predominantemente preenchidos por miofibrilas, que são as estruturas responsáveis pela contração. As miofibrilas são constituídas de feixes de fibras altamente organizados. Essa organização gera padrões repetitivos de bandas claras (bandas $\mathrm{I}$, isotrópicas) e escuras (bandas $\mathrm{A}$, anisotrópicas) quando visualizadas em microscopia óptica. No centro das bandas $I$, existe uma região altamente refratária (alta densidade protéica) denominada linha $Z$. No centro da banda A, existe uma região menos densa denominada linha $H$ (Figura 1). Nos segmentos entre duas linhas $Z$, denominados sarcômeros, observa-se uma organização paralela de conjuntos de dois tipos de filamentos, filamentos finos e grossos, que se interdigitam parcialmente (Figura 1) (para revisão, ver Bagshaw, 1993).

O filamento fino é composto por actina, tropomiosina e complexo troponina na proporção 7:1:1 (Moore et al., 1970; Squire, 1973). O principal componente do filamento grosso é a miosina (para revisão, ver Huxley, 1969).

Quando o músculo contrai, a banda I (constituída de filamentos finos) sofre um decréscimo em seu comprimento enquanto o comprimento da banda A (constituída de filamentos finos e grossos) permanece inalterado. Essa observação levou a criação do modelo de deslizamento de filamentos (Huxley, 1969). De acordo com esse modelo, os filamentos finos e grossos deslizam um sobre o outro sem encurtar os seus comprimentos, levando ao encurtamento do sarcômero. Eletromicrografias de músculo em rigor revelaram a formação de conexões entre os filamentos fino e o grosso nas regiões de interdigitações. Essas conexões, denominadas pontes cruzadas, são partes integrais da molécula de miosina. 
A.

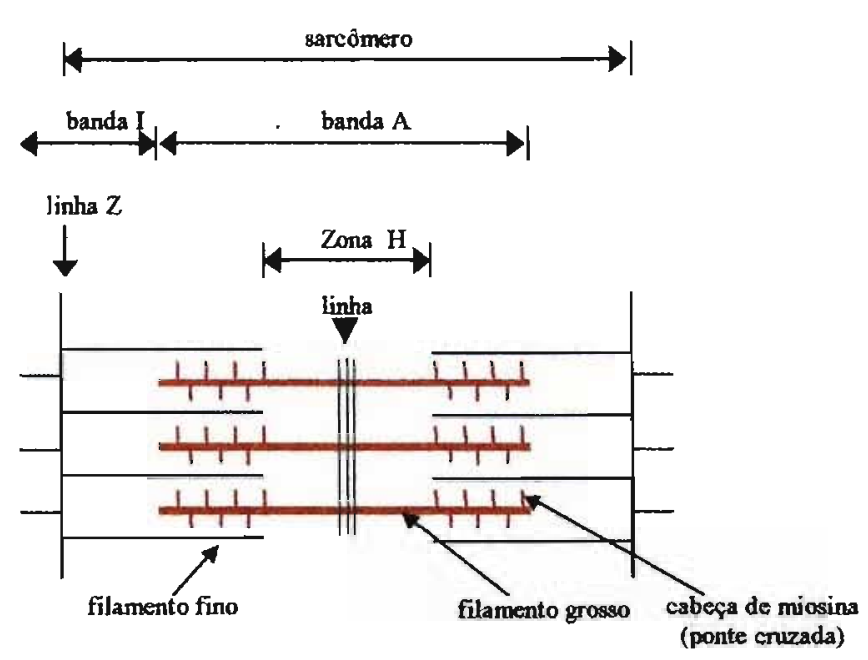

B.

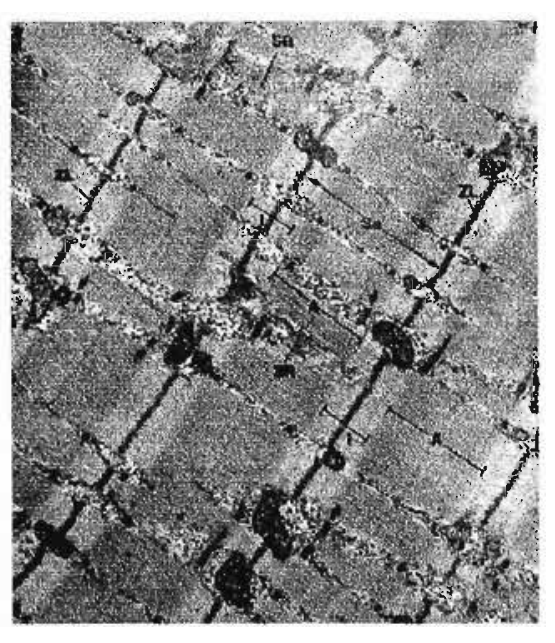

Figura 1. Microanatomia do músculo estriado esquelético. A. Esquema mostrando a organização do sarcômero. B. Eletromicrografia de um músculo estriado esquelético (Dr. Roger C. Wagner).

A contração muscular depende de interações cíclicas entre a miosina e a actina, que resultam no deslizamento do filamento fino em relação ao filamento grosso, acopladas com a hidrólise de ATP. A hidrólise de ATP pelas cabeças de miosina fornece a energia necessária para esse ciclo (Figura 2). As cabeças das misoina são ATPases ativadas por actina. Durante a contração muscular, a actina causa o deslocamento dos produtos da hidrólise do ATP (ADP e Pi) da cabeça da miosina, aumentando a atividade ATPásica da miosina aproximadamente 100 vezes (para revisão, ver Huxley, 1969). 


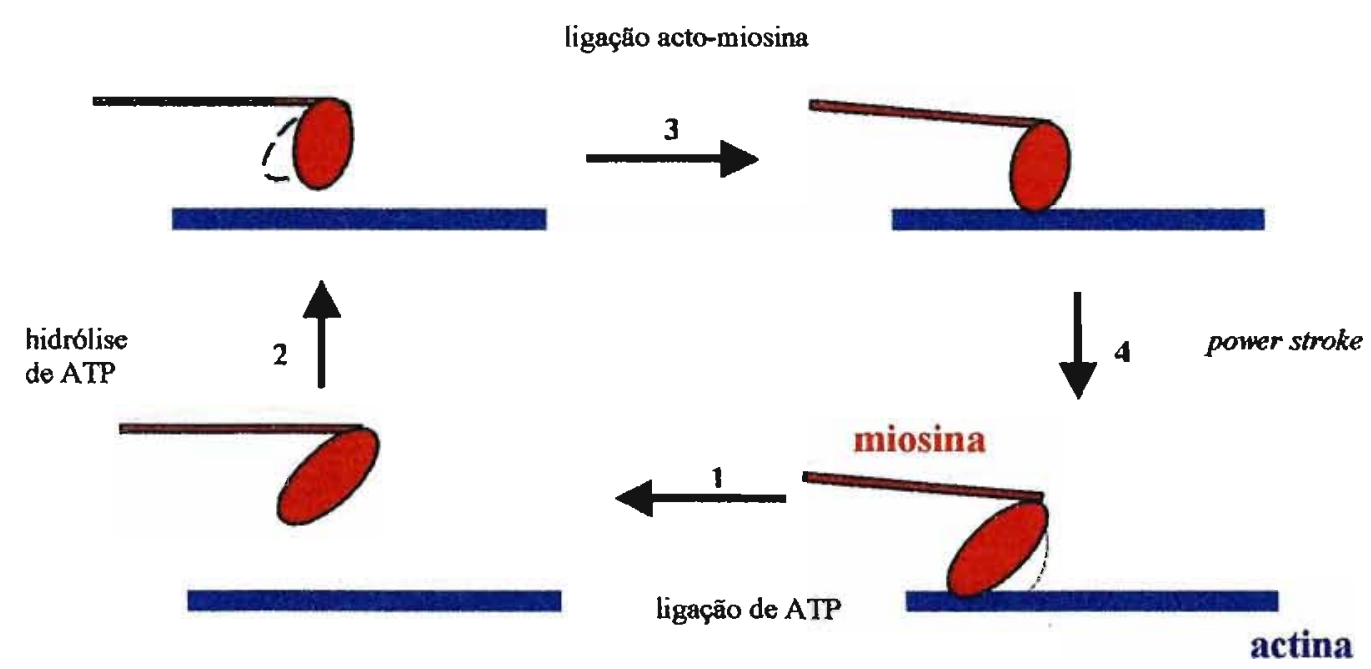

Figura 2: Modelo de contração muscular (ciclo de formação de pontes cruzadas). 1. A ponte cruzada acto-miosina rapidamente dissocia-se após a ligação de ATP à miosina. 2. A cabeça da misoina move-se para ligar-se à actina ao mesmo tempo em que o ATP é hidrolisado. 3. A cabeça da miosina, com os produtos da hidólise ( $\mathrm{ADP}+\mathrm{Pi}$ ) associados, ligase novamente ao filamento de actina. 4. A cabeça da miosina gera força para o "power stroke". Ocorre a dissociação de ADP e Pi da cabeça da miosina. Esse é o passo limitante da contração. A ponte cruzada acto-miosina está pronta para a ligação de ATP, iniciando assim outro ciclo.

A miosina é uma proteína com propriedades globulares e fibrosas. A miosina muscular $(520 \mathrm{kDa})$ é composta por quatro cadeias leves $(\sim 20 \mathrm{kDa}$ cada) e por duas cadeias pesadas (220 kDa) (Gazith et al., 1970). A miosina é suscetível à clivagem proteolítica por papaína e tripsina. Cada cadeia pesada consiste de uma cabeça globular (correspondente ao subfragmento S1 (S1) obtido após clivagem proteolítica) e uma cauda longa em alfa-hélice. Somente S1 foi cristalizada (Rayment et al., 1993a e b). S1 contém os sítios de ligação para o ATP e para a actina (Figura 3). As cadeias pesadas dimerizam-se em uma estrutura coiled coil. No músculo, a polimerização do filamento grosso occorre devido à associação de caudas de miosina. Na região denominada pescoço da miosina (região entre a cauda e a cabeça), existem sítios de ligação para as duas cadeias leves que, por 
razões históricas, são denominadas essencial e regulatória (para revisão, ver Bagshaw, 1993).

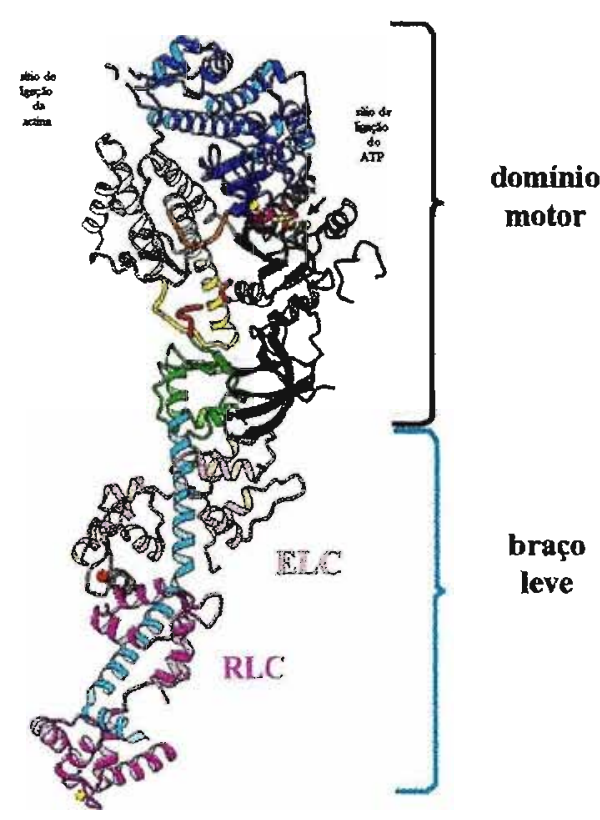

Figura 3: Modelo da estrutura de S1 (Houdusse et al., 1999). Os sítios de ligação do ATP e da actina estão indicados. A estrutura sugere uma possível via de comunicação entre os sítios de ATP e actina.

A actina é uma proteína conservada e presente em vários tipos celulares. Em baixa força iônica, a actina existe sob a forma de monômero (G-actina, 42 $\mathrm{kDa}$ ), mas em condições fisiológicas a actina polimeriza-se formando filamento (F-actina), em um processo dependente de hidrólise de ATP que envolve três passos seqüenciais: ativação dos monômeros, nucleação (passo limitante) e elongação (para revisão, ver Carlier, 1991).

A análise de cristais de actina-DNAse-1 (Kabsch et al., 1990) e actinagelsolina (McLaughilin et al., 1993) mostrou que a actina possui quatro domínios (Figura 4). De acordo com o modelo proposto para a estrutura do filamento de actina (Figura 4; Holmes et al., 1990; Steinmetz et al., 1998), ele pode ser definido como uma hélice dupla, contendo 13 monômeros por volta, em que o domínio pequeno está localizado distalmente em relação ao eixo do filamento, enquanto o domínio grande está localizado proximalmente (para revisão, ver Kabsch e Vandekerckhove, 1992). 
A.

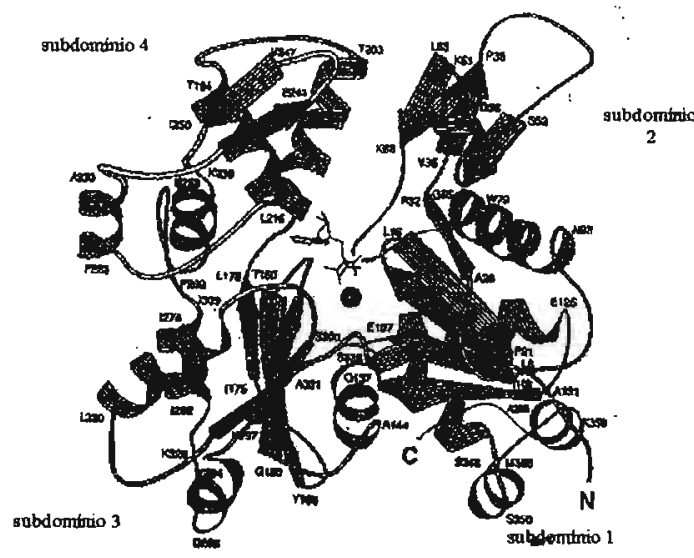

B.

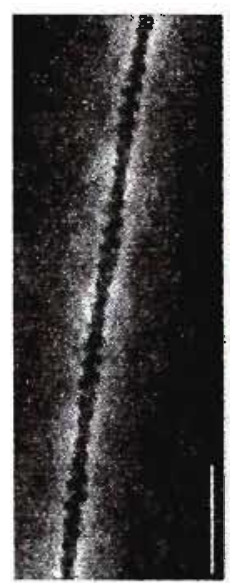

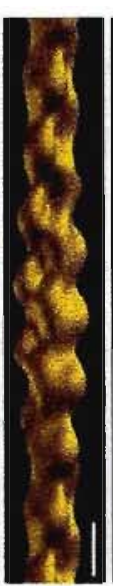

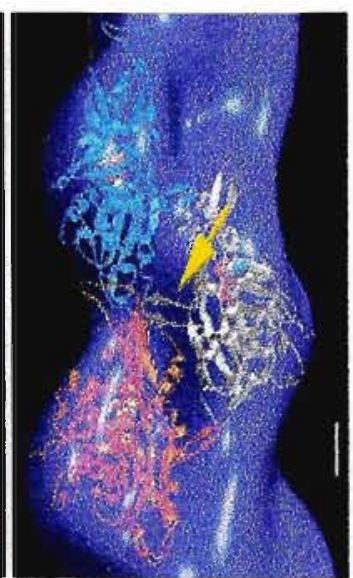

Figura 4 Esquema da estrutura da actina (Holmes e Kabsch, 1991). Um linha central imaginária dividiria a molécula de actina em dois domínios: o "grande" à esquerda e o "pequeno" à direita. O ATP e o $\mathrm{Ca}^{2+}$, que têm um papel essencial na estabilização da estrutura da molécula de actina, estão localizados na fenda entre os dois dominios. Esses domínios são subdivididos: o domínio pequeno em subdomínios 1 e 2 e o grande em subdomínios 3 e 4 . A nomeclatura grande e pequeno origina-se do fato que o subdomínio 2 tem uma massa significantemente menor que o os outros 3 subdomínios. A região da actina composta pelos subdomínios 1 e 3 é denominada "barbed end", e a região que compreende os subdomínios 2 e 4 é denominada "pointed end". B. Disposição dos subdomínios no filamento de actina. As imagens mostram a sobreposição da estutura obtida a partir do cristal actina-DNAse 1 com o mapa de densidade da actina obtido a partir de difração de raio $\mathrm{X}$ e microscopia eletrônica obtidos por Steinmetz et al. (1998) (retirado do sítio www.mih. unibas.ch/Homepages/stoffler/Slides/Actin/Actin.html). 
A interação entre a actina e a miosina, nos músculos esqueléticos, é

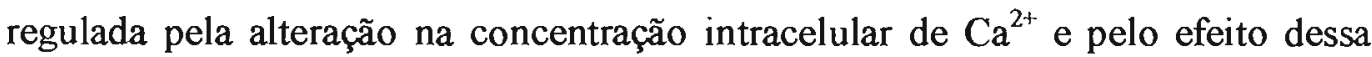
alteração nas interações das proteínas que constituem o filamento fino. Os outros dois componentes do filamento fino, a tropomiosina e o complexo troponina, regulam esse processo em músculos estriados (para revisão, ver Zot e Potter, 1987; Gordon et al., 2000).

A tropomiosina $(\mathrm{Tm})$ é uma molécula alongada que se apresenta sob a forma de dímero de aproximadamente $65 \mathrm{KDa}$. Duas isoformas de tropomiosina são encontradas nos músculos esqueléticos, $\alpha$ e $\beta$ (Cummins e Perry, 1973), sendo a subunidade $\alpha$ a mais freqüente (para revisão, ver Zot e Potter, 1987). O coração é formado somente por subunidade $\alpha$ (Bronson e Schachat, 1982).

A tropomioisna é composta por duas cadeias de $\alpha$-hélices associadas (33 $\mathrm{kDa}$ cada) em coiled coil e em registro (Jonhson e Smillie, 1975; Lehrer, 1975). A seqüência de 284 aminoácidos da $\alpha$-tropomiosina de músculo esquelético possui um padrão de repetição formado por uma série de sete resíduos, característica de estrutura coiled coil, perfazendo um total de 40 repetições por molécula (McLachlan e Stewart, 1975). Os resíduos presentes em cada repetição ocupam sete posições denominadas $\mathbf{a}, \mathbf{b}, \mathbf{c}, \mathbf{d}, \mathbf{e}, \mathbf{f}$ e $\mathbf{g}$. Os resíduos nas posições a e d tendem a ser hidrofóbicos e estão na face interna do dímero, estabilizando a estrutura coiled coil. Os resíduos e e $\mathbf{g}$ tendem a ser carregados. Pontes salinas entre os resíduos e e $\mathbf{g}$ também estabilizam a estrutura coiled coil. Os resíduos b, $\mathbf{c}$ ef tendem a ser polares (McLachlan e Stewart, 1975; Smillie, 1979).

No filamento fino, a tropomiosina estende-se por sete monômeros de actina e liga-se ao complexo troponina na proporção de 1:1 (para revisão, ver Zot e Potter, 1987; Gordon et al., 2000). As tropomiosinas formam filamentos por interações do tipo "cabeça-cauda" da extremidade $\mathrm{NH}_{2}$-terminal de uma molécula com a extremidade COOH-terminal da molécula adjacente (MacLachlan e Stewart, 1975). A tropomiosina está envolvida na transmissão das mudanças estruturais ao longo do filamento fino durante a regulação da contração muscular. 
Uma limitação encontrada para o estudo de tropomiosinas recombinantes expressas em bactérias é o fato que a acetilação da metionina inicial é fundamental para que a polimerização de tropomiosinas musculares ocorra. Nosso grupo contornou esse impedimento construindo uma $\alpha$-tropomiosina funcional com uma fusão dipeptídica em sua porção $\mathrm{NH}_{2}$-terminal (Monteiro et al., 1994).

O complexo troponina ( $\mathrm{Tn}$ ) apresenta-se ancorado ao filamento fino por interações com a tropomiosina e com a actina (para revisão, ver Farah e Reinach, 1995). Dessa forma, o filamento fino pode ser visto como uma estrutura formada por repetições de unidades reguladoras ou funcionais, cada unidade composta por sete actinas, uma tropomiosina e um complexo troponina (Figura 5).

O complexo troponina é formado por três subunidades (Greaser et al., 1973) que apresentam funções distintas. A troponina C (TnC) é a subunidade na qual os íons cálcio ligam-se; a troponina I (TnI) liga-se à actina inibindo a atividade $\mathrm{Mg}^{2+}$-ATPásica da acto-miosina; e a troponina $\mathrm{T}$ (TnT) liga-se fortemente à tropomiosina unindo o complexo troponina ao filamento fino (para revisão, ver Zot e Potter, 1987).

O complexo troponina apresenta um domínio globular e um domínio alongado (Flicker et al., 1982) (Figura 5). A TnC, a TnI e a parte COOH-terminal da TnT (T2) constituem o domínio globular. A parte $\mathrm{NH}_{2}$-terminal da $\mathrm{TnT}$, denominada T1, corresponde ao domínio alongado (Heeley et al. 1987) (Figura 5).

A TnC é a subunidade mais estudada e a única que teve sua estrutura cristalográfica resolvida dentre as três subunidades do complexo troponina. Ela possui dois domínios distintos separados por uma longa alfa-hélice (Figura 5). O domínio $\mathrm{NH}_{2}$-terminal contém dois sítios de baixa afinidade para cálcio (sítios regulatórios) e o domínio $\mathrm{COOH}$-terminal possui dois sítios $\mathrm{Ca}^{2+} / \mathrm{Mg}^{2+}$ de alta afinidade (sítios estruturais). Os sítios de alta afinidade não estão envolvidos na regulação e estão sempre ocupados por $\mathrm{Ca}^{2+}$ ou $\mathrm{Mg}^{2+}$ (Herzberg et al., 1986; Ohtsuki et al., 1986). Quando a concentração intracelular de $\mathrm{Ca}^{2+}$ aumenta, os sítios de baixa afinidade passam a ser ocupados por íons $\mathrm{Ca}^{2+}$, gerando alterações conformacionais na TnC (Herzberg et al., 1986). Essas alterações são propagadas para os outros componentes do filamento fino, removendo as interações inibitórias 
da TnI no filamento fino e levando à ativação da atividade $\mathrm{Mg}^{2+}$-ATPásica da acto-miosina (para revisão, ver Zot e Potter, 1987; Farah e Reinach, 1995; Tobacman, 1996).

A TnT (31-36 Kda) é a subunidade que se caracteriza pela sua afinidade pela tropomiosina, sendo essa interação de particular importância no posicionamento do complexo troponina no filamento fino. A TnT interage com a tropomiosina de uma maneira antiparalela. Ela é uma molécula em forma de bastão de aproximadamente $185 \AA$ com as extremidades $\mathrm{NH}_{2^{-}}$e $\mathrm{COOH}$-terminal em lados opostos.

Em termos de polaridade, a TnT é uma molécula assimétrica. A seqüência inicial, correspondente aproximadamente aos primeiros 20 aminoácidos, é altamente conservada e apresenta uma predominância de resíduos de aminoácidos ácidos. Adjacentemente à essa região da TnT, encontra-se uma região que pode originar-se a partir de vários splicings alternativos e que é responsável pelas várias isoformas de TnT presentes em um mesmo tecido muscular. $\mathrm{O}$ número de éxons envolvidos em splicing alternativos nessa região $\mathrm{NH}_{2}$-terminal da $\mathrm{TnT}$ varia com a espécie e tipo muscular. A região correspondente aproximadamente aos aminoácidos 70-150, caracterizada pelo alto conteúdo de $\alpha$-hélice e por ser um dos sítios de interação com a tropomiosina, apresenta uma alta similaridade entre as diferentes isoformas assim como a região $\mathrm{COOH}$-terminal da $\mathrm{TnT}$ (região que interage com o dímero TnI/TnC) (para revisão, ver Perry, 1998).

A inibição da atividade $\mathrm{Mg}^{2+}$-ATPásica da acto-miosina provocada pela TnI está relacionada com as interações da TnI no filamento fino. A TnI liga-se à actina, à tropomiosina, à $\mathrm{TnC}$ e à $\mathrm{TnT}$. Na ausência $\mathrm{Ca}^{2+}$, a TnI liga-se à actina e à tropomiosina inibindo a interação contrátil entre a actina e a miosina (para revisão, ver Farah e Reinach, 1995).

A tropomiosina potencializa o efeito inibitório da TnI (Syska et al., 1976). $\mathrm{Na}$ ausência das outras duas subunidades do complexo troponina e da tropomiosina, a TnI inibe a atividade $\mathrm{Mg}^{2+}$-ATPásica da acto-miosina independentemente de $\mathrm{Ca}^{2+}$ (Perry et al., 1972). Na presença de TnC, a inibição provocada pela $\mathrm{Tnl}$ é dependente da concentração intracelular de $\mathrm{Ca}^{2+}$. Em 1981 , 
Talbot e Hodges determinaram que a região da TnI correspondente aos resíduos de aminoácidos 104 a 115 contém a seqüência mínima necessária para a ligação na actina e para a propriedade inibitória da TnI.

$\mathbf{A}$

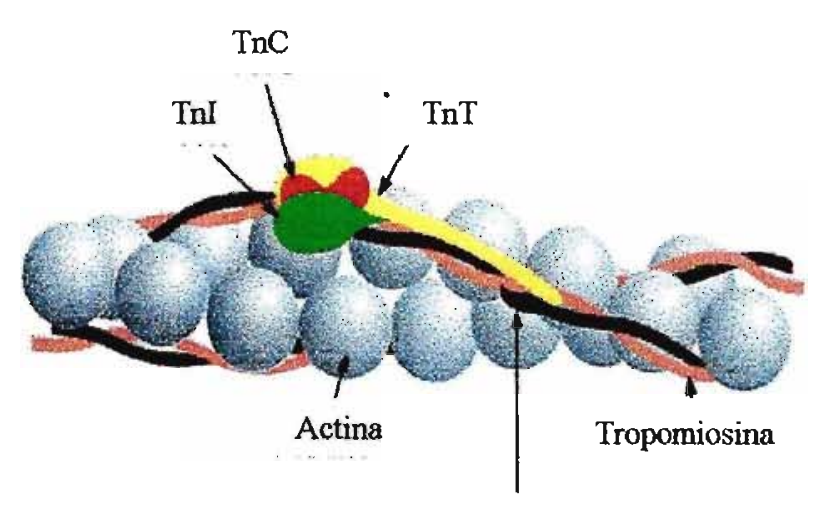

Região de sobreposição cabeça-cauda

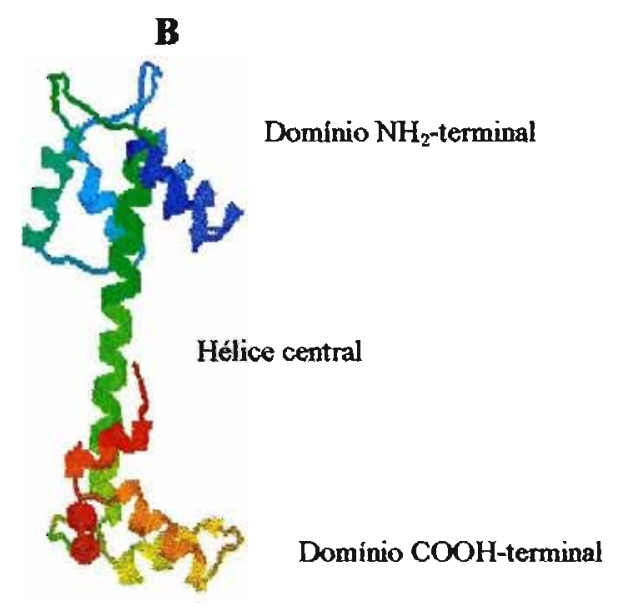

Figura 5: A. Modelo da organização do filamento fino no músculo esquelético (Heeley et al., 1987 modificado por Gordon et al., 2000). Os monômeros de actina encontram-se polimerizados, formando um filamento dupla-hélice sobre a qual está localizada o dímero de tropomiosina. A região $\mathrm{Tl}$ da $\mathrm{TnT}$ interage com a região de sobreposição entre tropomiosinas adjacentes. A região $\mathrm{T} 2$ da $\mathrm{TnT}$, juntamente com a $\mathrm{TnC}$ e com a $\mathrm{Tnl}$, faz parte do domínio globular do complexo troponina. B. Representação da estrutura cristalográfica da TnC (Herzberg e James, 1985). Os domínios $\mathrm{COOH}$ e $\mathrm{NH}_{2}$-terminal da $\mathrm{TnC}$ são conectados uma alfa-hélice central.

O modelo padrão utilizado para explicar a regulação da contração é o do bloqueio estérico da ligação da actina com a cabeça da miosina pela tropomiosina (Huxley, 1972; Haselgrove, 1972). Esse modelo propõe que, quando o músculo está relaxado (baixas concentrações de $\mathrm{Ca}^{2+}$ ), a tropomiosina estaria posicionada de uma maneira (posição off) que impediria fisicamente a ligação da cabeça da 
miosina à actina. A tropomiosina estaria mantida nessa posição por meio das interações da TnI com tropomiosina e actina. Durante a ativação do músculo, o $\mathrm{Ca}^{2+}$ ligaria-se à $\mathrm{TnC}$, o que levaria a uma alteração na posição da tropomiosina (posição on), permitindo a interação da acto-miosina (Huxley et al., 1972; Haselgrove, 1972).

Recentes observações de alterações da posição da tropomiosina no filamento fino, obtidas a partir de micrografias eletrônicas de actina-tropomiosinatroponina em altas e baixas concentrações de $\mathrm{Ca}^{2++}$, validam o modelo do bloqueio estérico (Lehman et al., 1994 e 1995; Poole et al. 1994).

Entretanto, foi demonstrado que o complexo troponina, em condições em que a atividade ATPásica da acto-miosina é sensível ao $\mathrm{Ca}^{2+}$ e tanto na presença quanto na ausência de $\mathrm{Ca}^{2+}$, não afeta a afinidade entre a miosina e tropomiosinaactina (Chalovich e Eisenberg, 1982), como previsto pelo modelo do bloqueio estérico. Essa observação sugere que a troponina e a tropomiosina não regulariam a atividade $\mathrm{Mg}^{2+}$-ATPásica pelo controle da interação da actina com a miosina, mas pela regulação do passo cinético limitante do ciclo da hidrólise de ATP, a liberação de $\mathrm{Pi}$ da cabeça da miosina. Uma outra observação experimental, que não pode ser explicada pelo modelo do bloqueio estérico, é que o complexo troponina pode ativar a atividade $\mathrm{Mg}^{2+}$-ATPásica da miosina, na presença de $\mathrm{Ca}^{2+}$, acima da ativação provocada pela actina (Bremel et al., 1972; Haselgrove, 1973; Malnic e Reinach, 1994; Malnic et al., 1998; Farah et al., 1995).

Mais recentemente, foi proposto por Mckillop e Geeves (1993) que a regulação da contração via alterações da posição da tropomiosina ao longo do filamento de actina pode ser interpretada em termos de um equilibrio $\mathrm{Ca}^{2+}$ dependente entre três estados da tropomiosina: bloqueado (blocked), fechado (closed) e aberto (open). Esse modelo, esquematizado na Figura 6, é utilizado para explicar a cooperatividade observada tanto na ligação de miosina ao filamento fino quanto na ativação da atividade $\mathrm{Mg}^{2+}$-ATPásica, relacionando as três posições da tropomiosina no filamento fino com dois diferentes tipos de ligação de S1 no filamento fino. Esse modelo propõe que o equilibrio entre os três estados é influenciado pela ligação de $\mathrm{Ca}^{2+}$ no complexo troponina, ligação de miosina no 
filamento de actina e também possivelmente por unidades reguladoras adjacentes (conjunto formado por sete actinas, uma tropomiosina e um complexo troponina). De acordo com esse modelo, o estado aberto é o mais ativo e pode ligar miosina fortemente em qualquer etapa do ciclo de contração. $O$ estado fechado (actina + $T m+T n$ na presença de $\mathrm{Ca}^{2+}$ ) pode ligar miosina fracamente e essa ligação pode ser tornar uma ligação forte, resultando na evolução desse estado para o estado ligado. No estado bloqueado (actina $+\mathrm{Tm}+\mathrm{Tn}$ na ausência de $\mathrm{Ca}^{2+}$ ), em que a tropomiosina está presa sobre o subdomínio 1 da actina por interações da troponina com a actina, não há ligação de miosina. Contudo, esse estado existe em equilíbrio com os estados fechado e ligado. A ligação de $\mathrm{Ca}^{2+}$ à troponina causaria um deslocamento no equilíbrio entre os estados. Embora o processo de ativação da atividade ATPásica da acto-miosina não seja completamente explicado por esse modelo, esse modelo sugere que a ativação seria tanto mediada pela ligação de $\mathrm{Ca}^{2+}$ à TnC quanto pela ligação de miosina ao filamento fino.

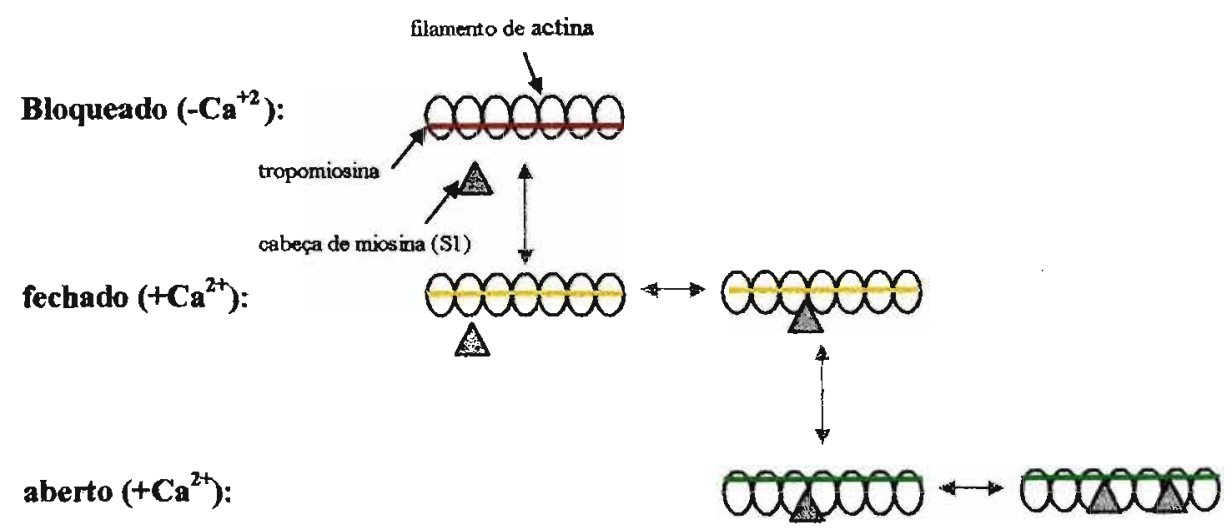

Figura 6: Esquema dos três estados (posições) da tropomiosina durante a regulação da contração muscular. As posições que a tropomiosina pode ocupar no filamento fino e as transições entre os estados são discutidas no texto acima. 
A forma alongada da TnT (White et al., 1987) e o conjunto de suas interações dependentes e independentes de $\mathrm{Ca}^{2+}$ no filamento fino (Figura 7) (para revisão, ver Perry, 1998) sugerem sua importância no controle da posição da tropomiosina no filamento fino, portanto resultando no controle da contração muscular.

Como a TnT isolada é insolúvel em força iônica fisiológica, a maior parte dos estudos sobre as interações da $\operatorname{TnT}$ no filamento fino foi realizado com fragmentos solúveis de $\mathrm{TnT}$.

Experimentos realizados utilizando fragmentos de TnT obtidos a partir de digestão com quimiotripsina (fragmento T1 e fragmento T2, Figura 7 e 8) (Ohtusuki, 1979) demonstraram que o fragmento $\mathrm{T} 1$ interage fortemente com a tropomiosina independentemente de $\mathrm{Ca}^{2+}$ (Mak e Smillie, 1981; Pearlstone e Smillie, 1982). A afinidade pela tropomiosina é atribuída principalmente à presença do fragmento CB2 dentro do fragmento T1 (Jackson et al., 1975). Embora a participação da região $\mathrm{NH}_{2}$-terminal adjacente ao fragmento $\mathrm{CB} 2$ (correspondente ao fragmento CB3) na regulação da contração não esteja ainda definida claramente, acredita-se que ela interaja com a região de sobreposição "cabeça-cauda" de tropomiosinas adjacentes (Pato et al., 1981).

A região $\mathrm{COOH}$-terminal da $\mathrm{TnT}$, correspondente ao fragmento T2, liga-se ao dímero $\mathrm{TnC} / \mathrm{TnI}$ e à tropomiosina (Pearlstone e Smillie, 1977, 1982, 1985, Tanokura et al, 1984). A interação desse fragmento com a tropomiosina na presença de TnI e TnC é uma interação sensível à variações na concentração de $\mathrm{Ca}^{2+} . \mathrm{Na}$ ausência de $\mathrm{Ca}^{2+}$, o fragmento $\mathrm{T} 2$ liga-se à região próxima ao resíduo 191 da tropomiosina (Mak e Smillie, 1981). Na presença de $\mathrm{Ca}^{2+}$, acredita-se que ocorram modificações nas interações do complexo binário TnC/TnI com essa região da TnT, que resultariam no seu desligamento da tropomiosina (Pearlstone e Smillie, 1983; Malnic et al., 1998). 


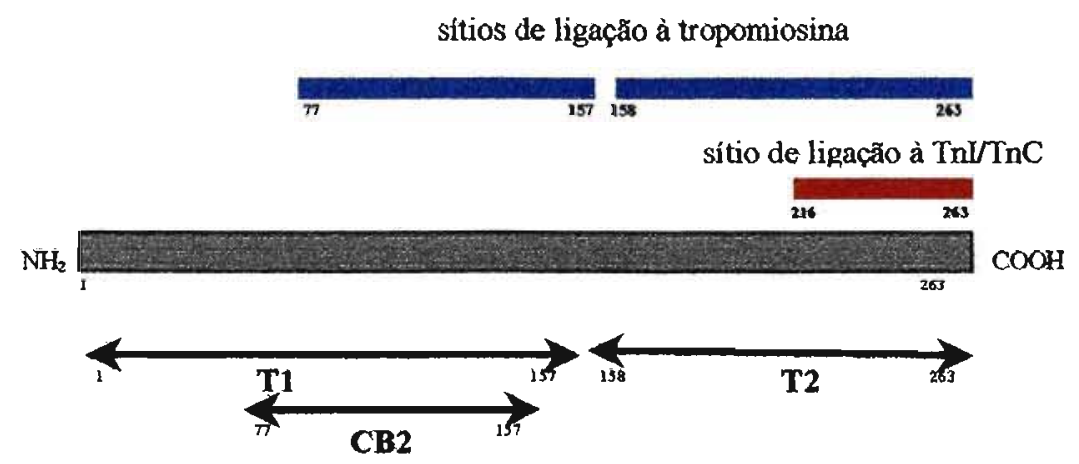

Figura 7: Interações da TnT. Acima da representação esquemática da isoforma 3 de TnT de músculo esquelético de galinha, estão indicados os sítios de interação com as demais proteínas do filamento fino. Abaixo, estão indicadas as regiốes correspondentes aos fragmentos trípticos e de brometos de cianogênio obtidos a partir de TnT de músculo esquelético de coelho.

Uma série de estudos também comprova que a TnT possui a propriedade de aumentar a afinidade da tropomiosina pela actina (Hill et al., 1992; Dahiya et al., 1994; Fisher et al., 1995). A TnT recupera a habilidade de tropomiosinas nãopolimerzáveis de se ligarem à actina (Heeley et al., 1987). Essas observações experimentais sugerem que a interação da TnT com a tropomiosina aumentaria a afinidade da tropomiosina pela actina e/ou a putativa ligação da TnT à actina. Não existe nenhuma evidência clara, na literatura, da interação direta da TnT com a actina. 


$\frac{\text { T1 }}{\mathrm{CB1}}$

Coelho

Galinha

Boi

SD - EEVEHVEEQ- - - YEEEEEAQEEAPSPAEVHEPAPEVHVPEEVHEDALEDMREEE SDT-EEVEHGEEE- - - YEEEAHEAEEVH-EEEVHEPAPP---PEEAPE- - - - - - E SDVEEAVEEYEEQEEAAEEEHEEAVEEEAGGEAEAGEPCTAEDGEEEEGREAEDG-PVE

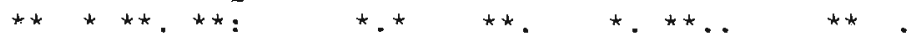

EEEEKPR---PKLTAPKIPEGEKVDEDDIQKKRQNKDLMELQALIDSHEEARKKEEEELV E--EKPR---IKLTAPKI PEGEKVDFDDIQKKRQNKDLIELQALIDSHFEARRKEEEELV EFKPKPRP FMPNLVPPKI DDGERVDEDDI HRKRMEKD INELQTLIEAHFENRKKEEEELV

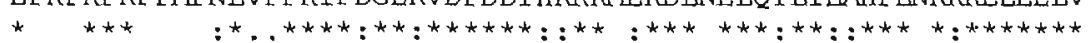

Coelho Galinha Boi

Coelho Galinha Boi
Coelho Galinha Boi
QLETDKEEFGEKLKRQKY D IMNVRARVEMLAKESKKAGTTAKGKVGGRWK QLQTEKYDEAEQTKRKKYEIVTLRNRI DQA.QKHSKKAG--AKGKVGGRWK DLEAEKEDLQEKEKQQKYE INVLRNRINDNQKVSKTRG---KAKVTGRWK

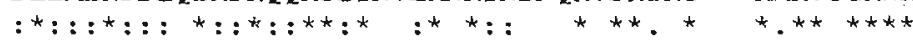

ALKERIEKRRAERAEOORIRAEKERERONRIAEEKARREEEDAKRRAEEDLKKKKALSSM AIKERIEKRRAERAEQQRIRAEKEKERQARLAEEKARREEEDAKRKAEDDLKKKKALSSM SLKDRIEKRRAERAEQQRIRAEREKERQTRIAEERARREEEESRRKAEDEARKKKALSNM

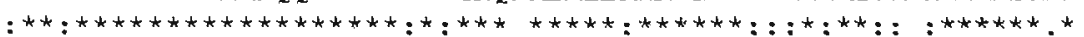

$\mathrm{T} 2$

GANYSSYLAKADOKR--GKKOTAREMKKKI LAERRKPLNIDHLSDEKLRDKAKELWDTLY GASYSSYLAKADQKR--GKKQTARETKKKVIAERRKPINIDHLNEDKLRDKAKEIWDWLY -MHEGGY IQKAQTERKSGKRQTEREKKKKI IAERRKVIAI DHLNEDQLREKAKELWOMIY

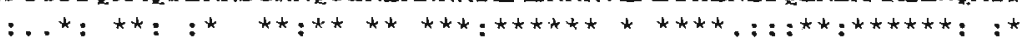

T1
$\mathrm{T} 2$

\begin{tabular}{|lllll|}
\hline $\mathrm{CB3}$ & $\mathrm{CB} 2$ & $\mathrm{CB} 5$ & $\mathrm{CB} 4$ & $\mathrm{CB} 6$ \\
\hline
\end{tabular}

Figura 8: Alinhamento das sequiências de TnT esquelética de coelho (SWISS-PROT: P02641), TnT-3 esqulética de galinha (SWISS-PROT: P12620) e TnT cardiaca bovina (SWISS-PROT: P13789). A similaridade entre os aminoácidos e a posição de alguns fragmentos obtidos após a clivagem da TnT esquelética de coelho com quimiotripsina (T) e brometo de cianogênio (CB) estão indicadas ao longo do alinhamento das sequiências. $\mathrm{O}$ alinhamento foi feito utilizando o programa CLUSTAL W (Thompson et al., 1994; http://www2.ebi.ac.uk/embnet. news/vol4 3/clustalw1.html). O alinhamento das três sequiências é mostrado para facilitar a compreensão de comparações entre resultados prévios obtidos com essas TnTs. 
Embora as interações da TnI e da TnC no filamento fino desempenhem um papel central na regulação da contração muscular, tem-se tornado cada vez mais evidente na literatura que, além do papel de ancoragem do complexo troponina no filamento fino (através de interações com todas as outras proteínas do filamento fino), a TnT desempenha uma função importante no controle da regulação muscular (para revisão, ver Perry, 1998). Foi demonstrado que a presença da TnT é necessária para a observação da sensibilidade (reversão da inibição da atividade ATPásica na presença de $\mathrm{Ca}^{2+}$ ) do complexo troponina ao $\mathrm{Ca}^{2+}$ em proporções equimolares dos três componentes do complexo troponina e em proporcões fisiológicas de actina e tropomiosina $(7: 1)$ in vitro (Sheng et al., 1992). Para a observação da inibição máxima da atividade ATPásica da acto-miosina na ausência de $\mathrm{Ca}^{2+}$, a presença de TnT também é requerida (Farah et al., 1994; Malnic e Reinach, 1994; Potter et al., 1995). Potter e colaboradores (1995) demonstraram que o processo de ativação da atividade ATPásica da acto-miosina, em músculos esqueléticos, não é um processo gerado exclusivamente pela neutralização do efeito inibitório da TnI resultante da ligação de $\mathrm{Ca}^{2+}$ à $\mathrm{TnC}$. Eles propuseram que a ativação da atividade ATPásica é uma propriedade da TnT que é deflagrada pela ligação de $\mathrm{Ca}^{2+}$ à $\mathrm{TnC}$ e que requer a presença das outras duas subunidades do complexo troponina.

A propriedade intrínseca da TnT de ativar a atividade ATPásica da actomiosina foi confirmada em nosso laboratório utilizando fragmentos recombinantes de TnT (Malnic et al., 1998) (Figura 9). Foi demonstrado que, na ausência de TnC e TnI, o fragmento correspondente aos primeiros 191 aminoácidos de TnT de músculo esquelético de galinha (fragmento TnT1-191) é capaz de ativar a atividade ATPásica, enquanto que a TnT tipo selvagem inteira isolada não é capaz de ativar. $O$ aumento da atividade ATPásica da acto-miosina observado foi de aproximadamente $30 \%$, um valor similar aos valores observados em experimentos realizados na presença do complexo troponina e de $\mathrm{Ca}^{2+}$. Esses resultados demonstraram que a região da TnT compreendida entre os aminoácidos 1-191 
contém o domínio que tem a função de ativar a atividade ATPásica da actomiosina. Essas observações experimentais levaram à proposta de um modelo mais refinado, baseado no modelo de dois sítios proposto originalmente por Pearlstone et al. (1983), para as interações das proteínas do filamento fino na presença e na ausência de $\mathrm{Ca}^{2+}$ (Malnic et al., 1998) (Figura 9).

De acordo com esse novo modelo proposto pelo nosso grupo, a TnT estaria divida em três domínios funcionais: i) o domínio ativatório, localizado na parte $\mathrm{NH}_{2}$-terminal da TnT; ii) o domínio inibitório, que estaria localizado adjacentemente ao ativatório e cuja integridade seria necessária para a observação da inibição máxima causada pelas interações da TnI com o filamento fino na ausência de $\mathrm{Ca}^{2+}$; iii) o domínio de ancoragem do dímero $\mathrm{TnC} / \mathrm{TnI}$, que estaria localizado na região COOH-terminal da TnT. A ligação de $\mathrm{Ca}^{2+}$ à $\mathrm{TnC}$ promoveria a dissociação do domínio globular da troponina (formado pela $\mathrm{TnC}$, $\mathrm{TnI}$ e região COOH-terminal da TnT) do filamento fíno. Após a liberação dessas interações que promoveriam a inibição, a região $\mathrm{NH}_{2}$-terminal da TnT desempenharia seu papel de ativação da atividade ATPásica da acto-miosina. 

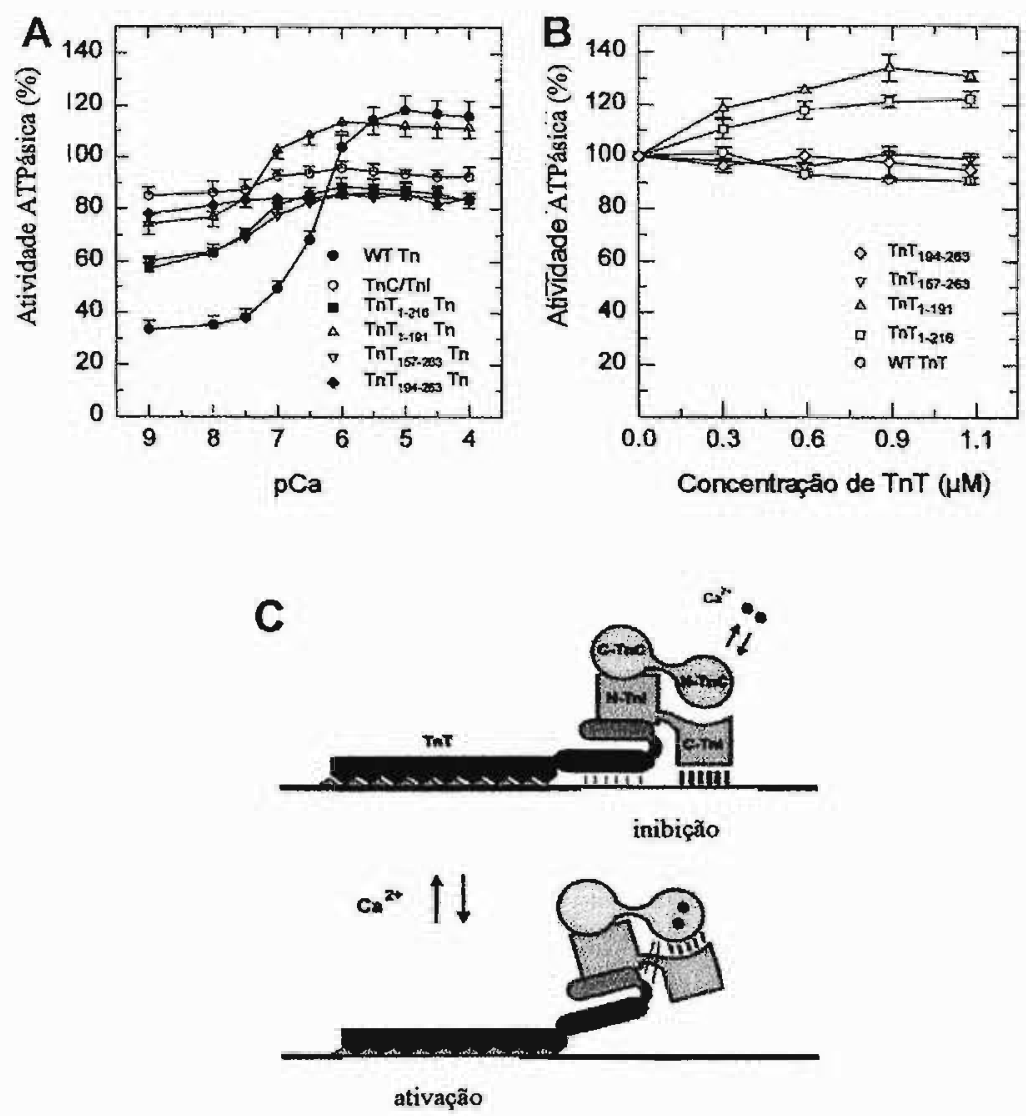

Figura 9: Ativação da atividade $\mathbf{M g}^{2+}$-ATPásica da acto-miosina pela TnT. A. Regulação $\mathrm{Ca}^{2+}$-dependente da atividade $\mathrm{Mg}^{2+}$-ATPásica da acto-miosina pelos complexos troponinas reconstituidos com fragmentos recombinantes de TnT (Malnic et al., 1998). 100\% de atividade $=$ atividade observada na presença de tropomiosina e na ausência de $\operatorname{Tn} \mathrm{I} / \mathrm{TnC}$. B. Efeito de fragmentos de TnT sobre a atividade atividade $\mathrm{Mg}^{2+}$-ATPásica da acto-miosina (Malnic et al., 1998). Em titulações da atividade $\mathrm{Mg}^{2+}$-ATPásica da acto-miosina na presença de tropomiosina e na ausência de $\mathrm{Tn} / \mathrm{TnC}$, o fragmento recombinante TnT1-191 ativou a atividade ATPásica enquanto a TnT tipo selvagem (TnTwt) não provocou nenhum efeito significativo. C. Modelo das mudanças conformacionais, induzidas pelo $\mathrm{Ca}^{2+}$, no complexo troponina (Malnic et al., 1998). A TnT está dividida em três domínios: o domínio ativatório, o inibitório e o que ancora o dímero $\mathrm{TnC} / \mathrm{TnI}$. Na ausência de $\mathrm{Ca}^{2+}$, a região $\mathrm{COOH}$-terminal da TnI e a região inibitória da TnT estão fortemente ligadas ao filamento fino, inibindo a atividade ATPásica da acto-miosina. $\mathrm{Na}$ presença de $\mathrm{Ca}^{2+}$, essas interações são substituidas por uma forte interação entre a $\mathrm{TnC}$ e a TnT, resultando na remoção da região inibitória da TnT do filamento fino, levando à ativação da atividade ATPásica da acto-miosina. 


\section{OBJETIVO}

Este trabalho teve como objetivo mapear o dominio ativatório da $\operatorname{TnT}$ ao longo da sua estrutura primária e estudar as interações desse domínio com as proteínas do filamento fino.

Com o objetivo de mapear o dominio ativatório, fragmentos da isoforma 3 de TnT de músculo esquelético de galinha correspondente aos resíduos 1-157 (TnT1-157), 1-76 (TnT1-76), 77-157 (TnT77-157), 77-191 (TnT77-191) e 158191 (TnT158-191) foram construídos. O mapeamento foi realizado analisando o efeito desses fragmentos sobre a atividade $\mathrm{Mg}^{2+}$-ATPásica da acto-miosina.

As interações desses fragmentos com a actina e com a tropomiosina foram estudadas com o objetivo de compreender quais são as interações da TnT envolvidas no processo de ativação da atividade $\mathrm{Mg}^{2+}$ - ATPásica da acto-miosina. 


\section{MATERIAS E MÉTODOS}

Produção dos Vetores de Expressão dos Fragmentos TnT1-157, TnT1-76, TnT77157 e $\operatorname{Tn} T 77-191$

Os fragmentos TnT1-157, TnT1-76 e TnT77-157 foram construídos utilizando M13mp18-TnT-3 (vetor contendo o cDNA da isoforma 3 de músculo esquelético de galinha, número de acesso no GenBank: M22156) como molde para mutagênese sítio dirigida mediada por oligonucleotídeo conforme o método descrito por Kunkel e colaboradores (1987). DNA fita simples do fago M13mp18TnT-3 foi produzido na linhagem E. coli CJ236 (Kunkel et al., 1987). O DNA fita simples uridinilado produzido, isolado e purificado foi utilizado como molde para a extensão de fitas contendo as mutações desejadas a partir de oligonucleotídeos mutagênicos. Os oligonucleotídeos 5'-AAAGACCTGATTTAACTGCAGGC-3' e 5'-TGTCCTCCATGTGAGCCTCATACAG-3' foram usados, respectivamente, para trocar os codons $\mathrm{Glu}^{77}$ e $\mathrm{Gly}^{158}$ por códons de terminação, produzindo M13mp18-TnT-3-1-76 e M13mp18-TnT-3-1-157 respectivamente. Utilizando o oligonucleotídeo 5'-GAACAAAGACCATATGGAACTGCAGG-3' e M13mp18TnT-3-1-157 como molde, um sítio de restrição NdeI foi criado nos códons 75 and 76, produzindo M13mp18-TnT-3-77-157.

A seleção dos clones mutantes foi feita pelo sequenciamento da região mutada do DNA fita simples. O sequenciamento total das regiões codificadoras também foi realizado para verificar se não houve nenhuma outra mutação adicional no DNA. O sequenciamento dos DNAs fita simples foi realizado de acordo com o método de terminação de cadeia por didesoxinucleotídeo descrito por Sanger (1977). O KIT Sequenase version 2.0 (United States Biochemical) foi utilizado conforme o protocolo fornecido pelo fabricante.

Os clones selecionados foram produzidos em larga escala na forma replicativa do bacteriófago (RF) M13, extraídos pelo método de lise alcalina e purificados por gradiente de $\mathrm{CsCl}_{2}$ como descrito por Sambrook et al. (1989). 
O vetor pET-3a (Studier et al., 1990) foi utilizado para a expressar os fragmentos de TnT. As formas replicativas (RFs) dos vírus M13 contendo as seqüências codificadoras dos fragmentos foram digeridas com as enzimas $N d e I$ e EcoRI (New England Biolabs). Os fragmentos NdeI/EcoRI contendo as seqüências codificadoras dos fragmentos de TnT foram subclonados entre os mesmos sítios de restrição em pET-3a. A subclonagem foi realizada como descrito em Sambrook et al. (1989).

O DNA codificante do fragmento TnT77-191 foi produzido em uma reação de PCR utilizando os oligonucleotídeos 5'GAACAAAGACCATATGGAACTGCAGG-3 e 5'CATTAACCTATAAAAATAGGCG-3' e o vetor de expressão do fragmento TnT1-191 (vetor pET-TnT1-191 descrito por Malnic et al., 1998) como molde. O produto da reação foi digerido com as enzimas NdeI e EcoRI (New England Biolabs) e clonado em pET-3a previamente clivado com NdeI e EcoRI. A autenticidade do plasmídeo de expressão do fragmento TnT77-191 foi confirmada por seqüenciamento.

Os vetores de expressão obtidos foram usados para transformar células competentes da linhagem E coli HMS174 (Studier et al., 1990). A preparação de plasmídeo em pequena escala a partir de colônias isoladas foi realizada como descrito por Sambrook et al. (1989). Os plasmídeos que, após serem clivados com NdeI e EcoRI, liberaram insertos com pesos moleculares esperados foram selecionados. Os plasmídeos selecionados foram utilizados para transformar $E$. coli BL21(DE3) pLysS (Studier et al. 1990) utilizando o método descrito por Hanahan (1985). A indução da expressão dos fragmentos em pequena escala (Studier et al., 1990) foi realizada para selecionar o melhor vetor de expressão de cada fragmento. A produção dos plasmídeos selecionados em larga escala foi realizada como descrito por Sambrook et al. (1989). 
Expressão e Purificação dos Fragmentos TnT1-157, TnT1-76, TnT77-157e TnT77-191

Cultivos de $E$. coli BL21(DE3) pLysS (Studier et al., 1990) transformadas com os plasmídeos em 4 litros de meio de cultura $2 \times T Y$ contendo carbenicilina $(200 \mu \mathrm{g} / \mathrm{ml})$ e clorafenicol $(200 \mu \mathrm{g} / \mathrm{ml})$ foram feitos. A indução da expressão foi realizada em $\mathrm{A}_{600}=0,8$ com isopropil- $\beta$-D-tiogalactopiranosídeo (IPTG) (concentração final: $0,4 \mathrm{mM}$ ). Após 3 horas de incubação $\left(37^{\circ} \mathrm{C}, 220 \mathrm{rpm}\right.$ ), as culturas foram centrifugadas (4.000 rpm, 15 minutos, $4^{\circ} \mathrm{C}$, rotor Sorvall GSA), os sobrenadantes descartados e as bactérias recuperadas foram ressuspendidas em $100 \mathrm{ml}$ de uma solução Tris-HCl (pH 8,0) $50 \mathrm{mM}$, EDTA $1 \mathrm{mM}$, uréia $6 \mathrm{M}$ e $\beta$ mercaptoetanol 1,4 mM, e lisadas (French Press, 16000 psi). O lisado foi centrifugado $\left(75.800 \mathrm{Xg}, 1\right.$ hora, $\left.4^{\circ} \mathrm{C}\right)$ e o sobrenadante aplicado em uma coluna DEAE-Sepharose Fast-Flow XK 16/70 equilibrada com o mesmo tampão em que as células foram ressuspendidas. Os fragmentos de $\operatorname{TnT}$ foram eluídos da coluna com um gradiente de $\mathrm{NaCl} 0-400 \mathrm{mM}$. As frações contendo os fragmentos foram selecionadas e dialisadas contra acetato de sódio (pH 5,0) $50 \mathrm{mM}$, EDTA $1 \mathrm{mM}$, uréia $6 \mathrm{M}$ e $\beta$-mercaptoetanol $1,4 \mathrm{mM}$ (2 trocas de 2 litros). Após as diálises, as frações foram aplicadas em uma coluna CM-Sepharose Fast-Flow XK 16/40 equilibrada com o mesmo tampão da diálise. Os fragmentos de TnT foram eluído da coluna com um gradiente de $\mathrm{NaCl}$ 0-400 mM. As proteínas eluídas e purificadas foram dialisadas contra Tris- $\mathrm{HCl}(\mathrm{pH} 8,0) 50 \mathrm{mM}$, EDTA $1 \mathrm{mM}, \mathrm{KCl}$ $1 \mathrm{M}$ e DTT $1 \mathrm{mM}$ ( 4 trocas de 2 litros). As proteínas foram estocadas à $-70^{\circ} \mathrm{C}$. A autenticidade dos fragmentos foi confirmada por análise da composição de aminoácidos e por degradação de Edman. A concentração dos fragmentos foi determinada como descrito por Hartree (1972), utilizando como padrão albumina bovina cuja concentração foi determinada pelo seu coeficiente de extinção molar $\left(E 280^{1 \mathrm{mg} / \mathrm{ml}}=\mathrm{A}_{280}-\mathrm{A}_{320}=0,667\right)$. Algumas amostras de proteínas foram concentradas utilizando célula de ultrafiltração AMICON. 
A síntese química do fragmento TnT158-191 e sua marcação com a sonda fluorescente extrínsica $\mathrm{ABZ}$ (ácido orto-aminobenzóico) foram realizadas pelo Prof. Dr. Clóvis R. Nakaie (Departamento de Biofísica, Universidade Federal de São Paulo) como descrito em Oliveira et al. (2000).

\section{Proteinas Musculares}

$\alpha$-Tropomiosina foi purificada a partir de coração de galinha como descrito por Smillie et al. (1982). Actina (Pardee e Spudich, 1982) e miosina (Reinach et al., 1982) foram preparadas a partir dos músculos pectoralis maior e menor de galinha. A purificação e a expressão de TnT recombinante e dos fragmentos TnT1-191 e TnT157-263 foram realizadas como descrito por Malnic et al. (1998). A TnC e a TnI recombinates de músculo de galinha foram expressadas e purificadas como descrito em Quaggio et al. (1993). As reconstituições do complexo troponina com TnT recombinante e com TnT157-263 foram feitas como descrito por Farah et al. (1994).

Dicroismo Circular dos Fragmentos de TnT

Medidas de dicroísmo circular dos fragmentos de $\operatorname{TnT}$ (concentrações entre 3 e $10 \mu \mathrm{M}$ ) em sódio-fosfato ( $\mathrm{pH} 7,0) 10 \mathrm{mM}, \mathrm{KCl} 100 \mathrm{mM}$ e DTT $1 \mathrm{mM}$ à $20^{\circ} \mathrm{C}$ foram realizadas utilizando celas de $0,05 \mathrm{~cm}$ de caminho óptico em espectropolarimetros JASCO 720 e Jobin-Yvon CD6. As estimativas da porcentagem de cada estrutura secundária a partir dos espectros de dicroísmo circular foram realizadas utilizando os programa de decomposição de espectros K2d (Andrade et al., 1993; Merelo et al., 1994) e CONTIM (Provencher, 1982a e b). 
As medidas da atividade ATPásica da acto-miosina foram realizadas combinando actina $(4 \mu \mathrm{M})$, tropomiosina $(0,57 \mu \mathrm{M})$, TnT ou os fragmentos de TnT (as concentrações estão indicadas nas legendas das Figuras), miosina $(0,2$ $\mu \mathrm{M})$ em imidazol-HCl (pH 7,0) $20 \mathrm{mM}, \mathrm{MgCl}_{2} 3,5 \mathrm{mM}$, EGTA 0,5 mM, $\mathrm{NaN}_{3}$ 0,01\%, KCl $60 \mathrm{mM}$, EDTA $1 \mathrm{mM}$ e DTT $1 \mathrm{mM}$ como descrito previamente pelo nosso grupo (Malnic e Reinach, 1994; Malnic et al, 1998). Alguns ensaios foram realizados na ausência de tropomiosina e de actina (para especificações, ver legendas das Figuras e Tabelas). As amostras foram incubadas durante 15 minutos a $25^{\circ} \mathrm{C}$ antes da adição de $2 \mathrm{mM} \mathrm{Na}_{2} \mathrm{ATP}(\mathrm{pH} \mathrm{7,0)}$, o que inicializava a reação. As reações ATPásicas eram interropidas após 15 minutos. A atividade ATPásica foi determinada utilizando um ensaio colorimétrico de detecção de fosfato inorgânico liberado (Heinonem e Lahti, 1981).

\section{Ensaios de Co-sedimentação}

O estudo da ligação dos fragmentos de TnT à actina e à tropomiosinaactina foi relizado em ensaios de co-sedimentação. Nesses ensaios, actina (20 $\mu \mathrm{M})$, $\alpha$-tropomiosina e os fragmentos de TnT (as concentrações estão indicadas nas legendas das Figuras) foram combinados em imidazol- $\mathrm{HCl}(\mathrm{pH} \mathrm{7,0)} 20 \mathrm{mM}$, $\mathrm{MgCl}_{2} 3,5 \mathrm{mM}$, EGTA 0,5 mM, $\mathrm{NaN}_{3}$ 0,01\%, $\mathrm{KCl} 60 \mathrm{mM}$, EGTA 0,5 mM e DTT $1 \mathrm{mM}$ como descrito por Malnic et al. (1998). As amostras foram homogeneizadas e centrifugadas $\left(315.000 \mathrm{Xg}\right.$ ) por 20 minutos a $4^{\circ} \mathrm{C}$. Os precipitados formados após a ultracentrifugação foram gentilmente lavados 3 vezes e ressuspendidos em um volume equivalente do mesmo tampão. Nos ensaios qualitativos, a ligação foi detectada analisando volumes equivalentes de amostras coletadas antes da ultracentrifugação e amostras correspondentes ao sobrenadante e ao precipitado após a ultracentrifugação em SDS-PAGE 15\% (Laemmli, 1970) ou Tricina/SDSPAGE 12,5\% (Shaegger e von Jagow, 1987). 
Ensaios quantitativos de ligação do fragmento TnT158-191 marcado fluorescentemente (ABZTnT158-191) foram realizados como descrito acima, exceto pela substituição de imidazol- $\mathrm{HCl}(\mathrm{pH} 7,0) 20 \mathrm{mM}$ por MOPS $(\mathrm{pH} 7,0) 25$ $\mathrm{mM}$. A ligação foi determinada por medidas da intensidade da fluorescência das amostras antes da ultracentrifugação e das amostras correspodentes ao sobrenadante e ao precipitado diluídas para volume final de $1,5 \mathrm{ml}$ e ajustadas para uma concentração final $\mathrm{KCl} 1 \mathrm{M}$. As medidas foram realizadas utilizando o espectrofluorímetro F-4500 Hitachi a $25^{\circ} \mathrm{C}$. As amostras foram excitadas a $319 \mathrm{~nm}$ e a leitura da emissão foi feita a $418 \mathrm{~nm}$ com uma fenda de excitação de $5 \mathrm{~nm}$.

Estudo do Efeitos da Presença de Actina e a-Tropomiosina no Espectro de Emissão de ABZTnT158-191

$\mathrm{O}$ efeito da presença de actina $(1 \mu \mathrm{M})$ e de $\alpha$-tropomiosina $(1 \mu \mathrm{M})$ no espectro de emissão de ABZTnT158-191 (1 $\mu \mathrm{M}$ ) em MOPS (pH 7,0) $20 \mathrm{mM}$, $\mathrm{MgCl}_{2} 3,5 \mathrm{mM}, \mathrm{KCl} 60 \mathrm{mM}$ ou $1 \mathrm{M}$ (a concentração salina está especificada nas legendas das Figuras), EDTA $1 \mathrm{mM}$ e DTT $1 \mathrm{mM}$ foi monitorado nas mesmas condições descritas acima. Os efeitos das diluições nas concentrações foram corrigidos.

Estudo dos Efeitos do Complexo Troponina e dos Fragmentos de TnT no Espectro de Emissão das Tropomiosinas 5OH263W e 5OH122W

Os efeitos da presença da actina, dos fragmentos de TnT e do complexo troponina no espectro de emissão da $\mathrm{Tm} 5 \mathrm{OH} 263 \mathrm{~W}$ (Oliveira et al., 2000) e Tm5OH122W (Farah e Reinach, 1999) em MOPS (pH 7,0) 25 mM, NaCl 60 mM, $\mathrm{MgCl}_{2} 5 \mathrm{mM}$ e DTT $1 \mathrm{mM}$ foram estudados. Os espectros de fluorescência foram obtidos em fluorímetro Hitachi F-4500 a $25^{\circ} \mathrm{C}$. As concentrações de proteínas utilizadas são indicadas nas legendas das Figuras. As amostras foram excitadas à $312 \mathrm{~nm}$ e a fluorescência detectada entre 320 e $420 \mathrm{~nm}$ com uma fenda de excitação de $5 \mathrm{~nm}$. Paralelamente, ensaios de co-sedimentação dos fragmentos de 
TnT e complexos troponina com $\mathrm{Tm} 5 \mathrm{OH} 263 \mathrm{~W}$-actina foram realizados. Os ensaios de co-sedimentação foram realizados como descrito acima exceto pela substituição de imidazol-HCl $(\mathrm{pH} 7,0) 20 \mathrm{mM}$ por MOPS $(\mathrm{pH} 7,0) 25 \mathrm{mM}$.

\section{Gel Filtração}

Ensaios de gel filtração com $\alpha$-tropomiosina e ABZ-TnT158-191 em coluna Superose 6HR 10/30 (Pharmacia Biotech) foram realizados utilizando um sitema FPLC (AKTA-Pharmacia). A coluna foi equilibrada com $\mathrm{KCl} 100 \mathrm{mM}$, MOPS $(\mathrm{pH} \mathrm{7,0)} 20 \mathrm{mM}$ e DTT $1 \mathrm{mM}$ à temperatura ambiente. Amostras de $1 \mathrm{ml}$ contendo $\alpha$-tropomiosina $3 \mu \mathrm{M}, \mathrm{ABZTnT} 158-1913 \mu \mathrm{M}$ e uma mistura de $\alpha$ tropomiosina $3 \mu \mathrm{M}$ e ABZTnT158-191 $3 \mu \mathrm{M}$ foram aplicadas na coluna e eluídas com o mesmo tampão utilizado para equilibrar a coluna. A presença de tropomiosina nas frações eluídas foi monitorada em SDS-PAGE 15\%. A presença de ABZTnT158-191 foi monitorada por medidas da intensidade de fluorescência. Essas medidas foram realizadas como descrito anteriormente. 


\section{RESULTADOS}

Fragmentos de TnT

O mapeamento do domínio ativatório ao longo da seqüência de aminoácidos 1-191 da TnT foi realizado utilizando os cinco fragmentos de TnT de músculo esquelético de galinha contruídos nesse trabalho. Esses fragmentos estão esquematicamente representados na Figura 10. Todos os fragmentos construídos nesse trabalho não possuem o sítio de ligação ao dímero TnI/TnC. Nós decidimos produzir 3 destes fragmentos baseados em fragmentos obtidos a partir de clivagem de TnT esquelética de coelho com brometo de cianogênio, fragmentos CB1, CB2 e CB3 (TnT1-157, TnT77-157 e TnT1-76, respectivamente) (Pearlstone et al., 1976). Os fragmentos TnT77-191 e TnT158-191 foram contruídos para completar o mapeamento ao longo da seqüência 1-191.

Os fragmentos TnT1-157, TnT77-157, TnT1-76 e TnT77-191 foram expressos em E. coli BL2(DE3) pLysS (Studier et al., 1990). Esses fragmentos foram purificados e apresentaram rendimento médio final de aproximadamente 5 mg por litro de cultura induzida. O fragmento TnT158-191 foi sintetisado quimicamente devido a dificuldade de produzir um fragmento recombinante pequeno.

Ao contrário da TnT isolada tipo selvagem (TnTwt), todos os cinco fragmentos construídos nesse trabalho mostraram-se solúveis em baixa força iônica ( $\mathrm{KCl} 60 \mathrm{mM}$ ), permitindo o estudo de suas interações com os outros componentes do filamento fino em concentrações salinas próximas das fisiológicas. 


TnT
TnT157-263 (T2)
TnT1-191
TnT1-157 (T1)
TnT1-76 (CB3)
TnT77-157 (CB2)
TnT77-191
TnT158-191
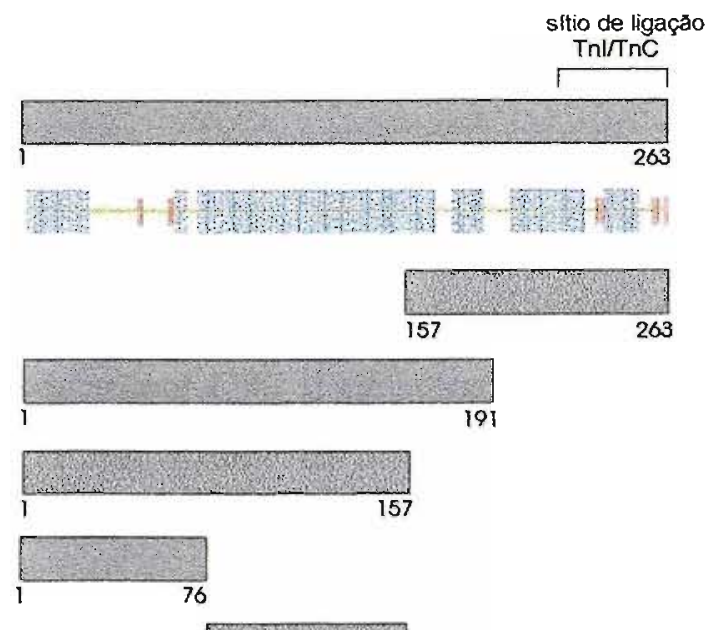

191
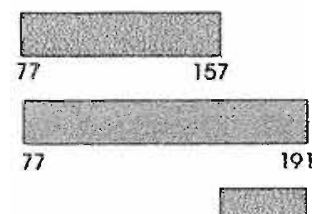

$158 \quad 19$

Predição da Estrutura Secundária da TnT.

\begin{tabular}{|c|c|c|}
\hline Estrutura Secundária & $\begin{array}{l}\text { Número de Aminoácidos em } \\
\text { Cada Estrutura }\end{array}$ & $\begin{array}{c}\text { Porcentagem de Aminoácidos em } \\
\text { Cada Estrutura }\end{array}$ \\
\hline$\alpha$-Hélice (h) & 183 & $69,58 \%$ \\
\hline Eolha-beta $\ggg)$ & 14 & 5,328 \\
\hline Randômica ( ) & 66 & $25,10 \%$ \\
\hline
\end{tabular}

$\begin{array}{lcccc}10 & 20 & 30 & 50 & 70 \\ \text { I } & 1 & 1 & \mid & 1\end{array}$

Figura 10: Representação esquemática dos fragmentos da isoforma 3 de TnT esquelética de galinha utilizados nesse estudo. A TnT recombinante tipo selvagem (TnTwt) e os fragmentos recombinantes TnT1-191 e TnT157-263 foram descritos anteriormente pelo nosso grupo (Malnic et al., 1998). Os fragmentos recombinates TnT1-157, TnT1-76, TnT77-157, TnT77-191, o fragmento sintético TnT158-191 e TnT158-191 com a sonda fluorescente ABZ (ácido o-aminobenzóico) ligado a sua extremidade $\mathrm{NH}_{2}$-terminal (ABZTnT158-191) foram construídos para esse estudo. O fragmento $\mathrm{TnT} 157-263$ corresponde aproximadamente ao fragmento quimiotríptico T2 de TnT esquelética de coelho (Pearlstone et al., 1976; Figura 8). TnT1-157, TnT77-157 e TnT1-76, respectivamente, correspondem aos fragmentos CB1, CB2 e CB3 de TnT esquelética de coelho obtidos após clivagem com brometo de cianogênio (Pearlstone et al., 1976; Figura 8). A predição da estrutura secundária da TnTwt foi obtida utilizando 0 método GOR IV (http://pbil.ibcp.fi/cgibin/npsa_automat.pl?page=npsa_gor4.html; Garnier et al., 1996). 
O espectro de dicroísmo circular UV dos fragmentos de TnT estão mostrados na Figura 11 e seus conteúdos estimados de estrutura secundária calculados estão sumarizados na Tabela 1. De acordo com resultados previamente obtidos com o fragmento não recombinante CB2 (Pearlstone e Smillie, 1977), TnT77-157 apresentou um alta elipticidade e conteúdo estimado de alfa-hélice em torno de 70\% (Tabela 1). Essa região da TnT, segundo resultados anteriormente descritos na literatura e de acordo com a predição da estrutura secundária da TnT (Figura 10), representa a região com maior conteúdo de alfa-hélice de toda a seqüência da TnT. TnT1-57 e TnT1-76 também apresentaram elipticidade molar residual e conteúdo de alfa-hélice comparáveis aos que foram previamente descritos para o fragmentos não-recombinates CB1 e CB3 de músculo esquelético de coelho (Tabela 2) (Pearlstone e Smillie 1977; Pearlstone e Smillie, 1985).

Embora as porcentagens de estrutura secundária estimada pelos dois métodos utilizados (CONTIN e K2D) para a desconvolução de um mesmo espectro sejam numericamente diferentes, os resultados obtidos utilizando os dois métodos estão em concordância de uma maneira geral. De acordo com esses resultados, como TnT1-76 e TnT158-191 possuem baixa elipticidade molar residual, os conteúdos de $\alpha$-hélice estimados para TnT1-191 TnT1-157 e TnT77191 (em torno de 30\%, 40\% e 50\%, respectivamente) originam-se da contribuição da região 77-157 que apresenta um alto conteúdo de alfa-hélice. 


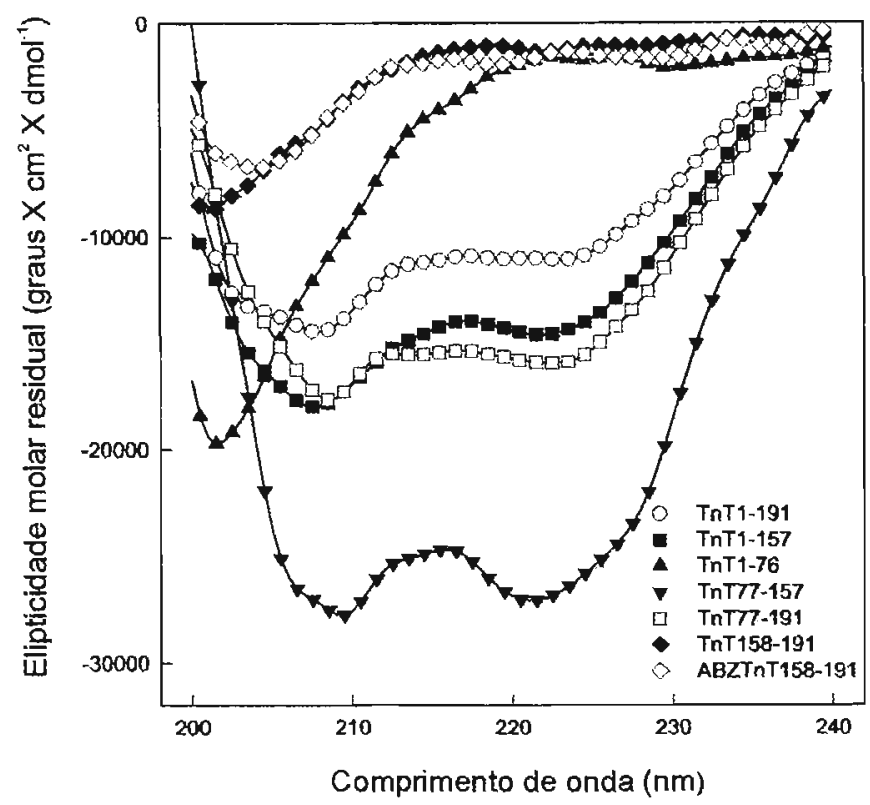

Figura 11: Espectros de dicroísmo circular (UV) dos fragmentos de TnT. Os espectros foram obtidos a partir de proteínas em tampão fosfato $(\mathrm{pH} 7,0) 10 \mathrm{mM}, \mathrm{KCl} 100 \mathrm{mM}$ e DTT 1 $\mathrm{mM}$. Os espectros foram obtidos como descrito em Materias e Métodos. Espectros típicos são apresentados.

Tabela 1: Estrutura secundária estimada dos fragmentos de TnT.

\begin{tabular}{lllllll}
\hline & \multicolumn{3}{c}{ Programa CONTIN } & \multicolumn{3}{c}{ Programa K2D } \\
\hline & $\alpha$-Hélice & Folha $\beta$ & Outras* & $\alpha$-Hélice & Folha $\beta$ & Outras* \\
TnT1-191 & $30 \%(57)$ & $26 \%(50)$ & $44 \%(84)$ & $29 \%(55)$ & $14 \%(27)$ & $57 \%(109)$ \\
TnT1-157 & $44 \%(69)$ & $17 \%(27)$ & $39 \%(61)$ & $37 \%(58)$ & $14 \%(22)$ & $49 \%(77)$ \\
TnT77-191 & $50 \%(57)$ & $11 \%(13)$ & $39 \%(45)$ & $56 \%(64)$ & $8 \%(9)$ & $35 \%(40)$ \\
TnT77-157 & $68 \%(55)$ & $0 \%(0)$ & $32 \%(26)$ & $83 \%(67)$ & $0 \%(0)$ & $17 \%(14)$ \\
TnT1-76 & $9 \%(7)$ & $47 \%(36)$ & $44 \%(33)$ & $9 \%(6)$ & $29 \%(22)$ & $63 \%(48)$ \\
TnT158-191 & $2 \%(1)$ & $53 \%(18)$ & $45 \%(15)$ & $7 \%(2,5)$ & $50 \%(17)$ & $43 \%(14,5)$ \\
ABZTnT158-191 & $9 \%(3)$ & $47 \%((16)$ & $44 \%(15)$ & $7 \%(2,5)$ & $50 \%(17)$ & $43 \%(14,5)$ \\
\hline
\end{tabular}

As estruturas secundárias foram estimadas utilizando os espectros de CD apresentados na Figura 11. Entre parentêses, está indicado o número de aminoácidos em cada estrutura. *: Para a análise utilizando o programa CONTIN (Provencher, 1982a e b), "outras" é definido como a soma das prediçóes para $\beta$ alça e "demais" estruturas. Para o programa K2D (Andrade et al., 1993; Merelo et al., 1994), "outras" é definido como a predição para estrutura randômica. 
Tabela 2: Comparação entre as elipticidades molar redidual ( $\theta)$ dos fragmentos de TnT.

\begin{tabular}{|l|c|c|}
\hline \multirow{2}{*}{} & \multicolumn{2}{|c|}{ O a 220 nm X 10-3 $\left(\mathrm{grau.cm}^{2} . \mathrm{dmol}^{-1}\right)$} \\
\cline { 2 - 3 } & $\begin{array}{c}\text { Pearlstone e Smillie (1977 } \\
\text { e 1985) }\end{array}$ & Nossos resultados \\
\hline T1/TnT1-157 & $-10,5(35,2 \%)$ & $-14,3(44 \%, 37 \%)$ \\
\hline CB2/TnT77-157 & $-24,1(77,9 \%)$ & $-26,8(68 \%, 83 \%)$ \\
\hline CB3/ TnT1-76 & $-2,9(10,5 \%)$ & $-2,1(9 \%, 9 \%)$ \\
\hline
\end{tabular}

Os espectros obtidos por Pearlstone e Smillie (1977 e 1985) foram obtidos nas seguintes condições: $\mathrm{NaCl} 100 \mathrm{mM}$, Tris $10 \mathrm{mM}$ (pH7,0), DTT $1 \mathrm{mM}$, azida sódica 0,01\% e EGTA 1 $\mathrm{mM}$.

Entre parênteses, estão os resulatdos estimados de conteúdo de alfa hélice obtidos por Pearlstone e Smillie (1977) utilizando a equação descrita por Chen et al. (1974) e a médias das estimativas para os nossos resultdos obtidas com o programas CONTIM (Provencher, 1982a e b) e K2D (Andrade et al., 1993; Merelo et al.,1994). 
$\mathrm{O}$ efeito dos fragmentos de TnT sobre a atividade $\mathrm{Mg}^{2+}$-ATPásica da actomiosina foi estudado na presença de tropomiosina e na ausência de TnI e TnCI (Figura 12). Os ensaios de titulação da atividade $\mathrm{Mg}^{2+}$-ATPásica da acto-miosina com os fragmentos de $\operatorname{Tn} T$ confirmaram que TnT1-191 tem a propriedade de ativar a atividade $\mathrm{Mg}^{2+}$-ATPásica da acto-miosina para níveis mais altos que os observados somente na presença de tropomiosina (atividade $=100 \%$ ). A mesma ativação, que representa um aumento de aproximadamente $40 \%$ sobre a atividade $\mathrm{Mg}^{2+}$-ATPásica basal, foi observada na titulação com TnT77-191. A ativação máxima foi observada numa razão molar aproximada de 1,5 fragmento de TnT/tropomiosina. Diferentemente, não foi observada ativação nas titulações com TnTwt, TnT1-76, TnT1-157, TnT77-157 e TnT158-191, nem mesmo com uma combinação dos fragmentos TnT158-191 e TnT1-157 ou TnT77-157. Esses resultados demonstram que o domínio ativatório está localizado entre a seqüência de aminoácidos 77-191 da TnT.

Para melhor compreender a propriedade ativatória da $\operatorname{TnT}$, realizamos ensaios de ATPase com TnT77-191 e TnT1-191 na ausência de tropomiosina e de actina (Figura 13 e Tabela 3). Os resultados obtidos não mostraram uma ativação causada pela presença de TnT1-191 e TnT77-191 nessas condições. Em vez de ativação da atividade $\mathrm{Mg}^{2+-}$ ATPásica da acto-miosina, foi observada uma diminuição da atividade nos ensaios na ausência de tropomiosina. Essa inibição observada teve a mesma intensidade (aproximadamente 30\%) que a inibição causada pela presença de tropomiosina e de TnT isolada. Para excluir a possibilidade de que os fragmentos TnT77-191 e TnT1-191 estariam causando um efeito inespecífico sobre a atividade $\mathrm{Mg}^{2+}$-ATPásica, analisamos a influência direta de TnT77-191 e TnT1-191 sobre a atividade $\mathrm{Mg}^{2+}$-ATPásica da miosina. Nos ensaios realizados na ausência de actina e de tropomiosina, os fragmentos que contêm o domínio ativatório da TnT não afetaram a atividade $\mathrm{Mg}^{2+}$-ATPásica da miosina (Figura 13 e Tabela 3). Esses resultados demonstram claramente que o 
processo de ativação da atividade $\mathrm{Mg}^{2+}$-ATPásica da acto-miosina pela $\operatorname{TnT}$ depende da presença de tropomiosina.

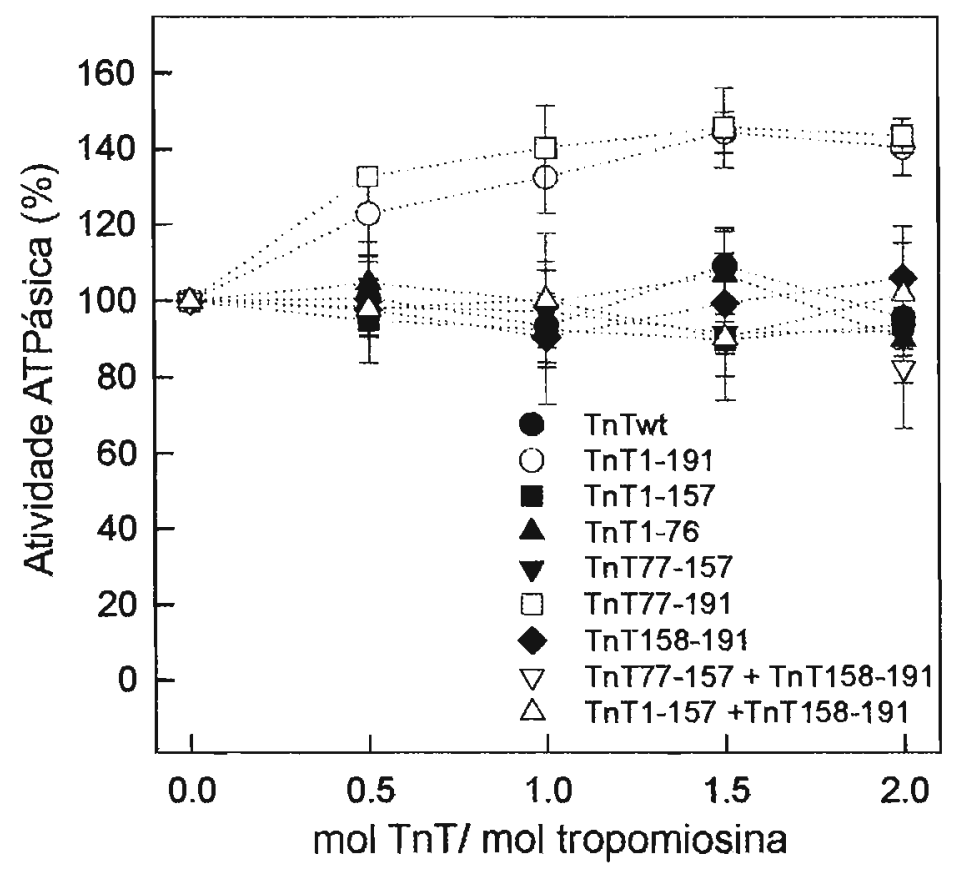

Figura 12: Efeito dos fragmentos de $\mathrm{TnT}$ sobre a atividade $\mathrm{Mg}^{2+}$-ATPásica da tropomiosina-acto-miosina na ausência de TnC e TnI. A atividade ATPásica foi determinada com concentrações crescentes de fragmentos de TnT conforme indicado na abscissa. Os resultados estão expressos como porcentagem da atividade ATPásica da tropomiosina-actina-miosina obtidos na ausência de troponina (100\% de atividade ATPásica). Os dados apresentados são médias acompanhadas dos respectivos desvios padrões de pelo menos 5 determinações independentes para cada concentração de TnT ou fragmentos de $\operatorname{TnT}$, exceto os dados referentes à combinação dos fragmento TnT77-157 e TnT158-191 que são médias de apenas 3 determinações. Os ensaios foram realizados como descrito em Materiais e Métodos nas seguintes condições: actina $(4 \mu \mathrm{M})$, $\alpha$-tropomiosina $(0,57 \mu \mathrm{M})$ e miosina $(0,2$ $\mu \mathrm{M}$ ) em imidazol- $\mathrm{HCl}(\mathrm{pH} 7,0) 20 \mathrm{mM}, \mathrm{MgCl}_{2} 3,5 \mathrm{mM}$, EGTA $0,5 \mathrm{mM}, \mathrm{KCl} 60 \mathrm{mM}$, EDTA $1 \mathrm{mM}$, DTT $1 \mathrm{mM}$ e Na 2 ATP $2 \mathrm{mM}$. 
A. Miosina

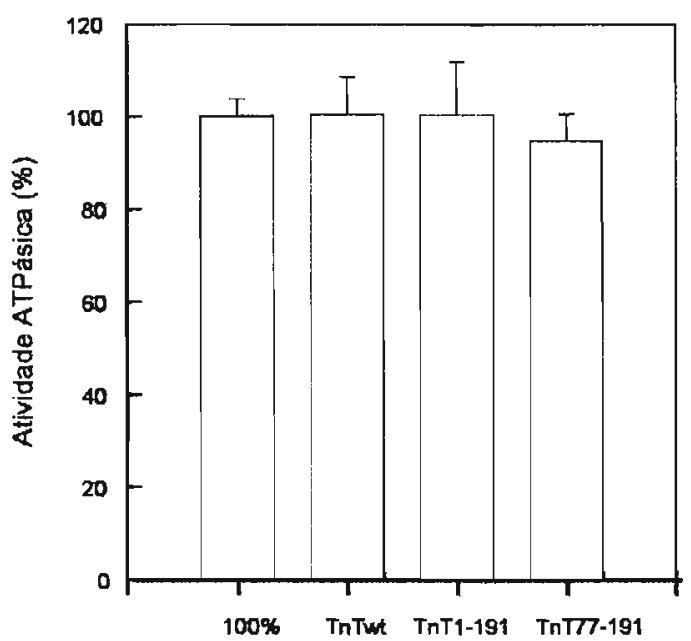

B. Acto-miosina

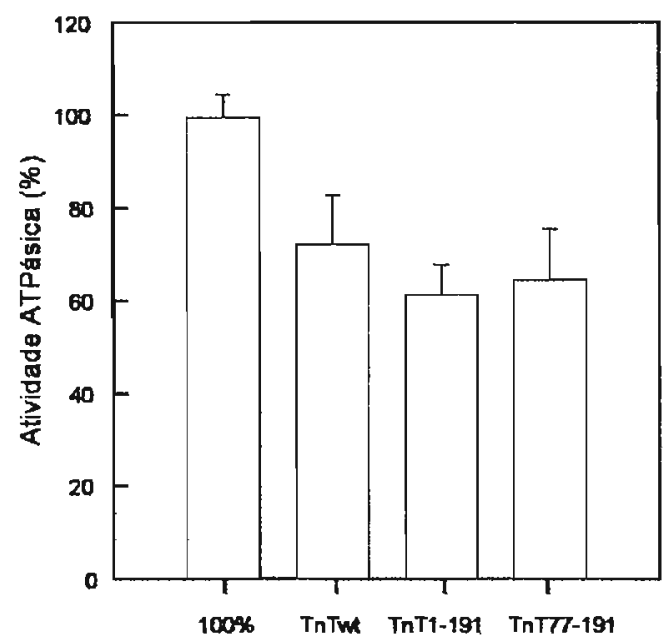

Figura 13: Efeito da TnT isolada e dos fragmentos TnT1-191 e TnT77-191 sobre a atividade $\mathrm{Mg}^{2+}$-ATPásica da miosina e da acto-miosina. $\mathrm{A}$. Os resultados (médias de cinco determiną̧ões independentes \pm desvio padrão) estão expressos como porcentagem da atividade $\mathrm{Mg}^{2+}$-ATPásica da miosina na ausência de actina, tropomiosina e $\mathrm{TnC} / \mathrm{TnI}$ (atividade 100\%). Condições dos ensaios: TnT tipo selvagem e fragmentos de $\operatorname{TnT}(1,14 \mu \mathrm{M})$ e miosina $(0,2 \mu \mathrm{M})$ nas mesmas condições descritas na Figura 12. B. O efeito dos fragmentos TnT1-191 e TnT77-191 e da TnT tipo selvagem sobre a atividade ATPásica da acto-miosina foi analisado como descrito em $A$, exceto pela presença de actina (4 $\mu \mathrm{M})$. Os resultados estão expressos como porcentagem da atividade $\mathrm{Mg}^{2+}$-ATPásica da acto-miosina. 
Tabela 3: Efeito da TnT isolada e dos fragmentos TnT1-191 e TnT77-191 sobre a atividade $\mathrm{Mg}^{2+}$-ATPásica da miosina, da acto-miosina e da tropomiosina-acto-miosina.

\begin{tabular}{|c|c|c|c|c|}
\hline & Ausência de TnT & TnTwt & TnT1-191 & Tn'T7-191 \\
\hline $\begin{array}{l}\text { Tropomiosina-acto- } \\
\text { miosina }\end{array}$ & $100 \pm 8,9$ & $95,6 \pm 10,1$ & $140,5 \pm 7,4$ & $143,6 \pm 4,6$ \\
\hline Acto-miosina & $106,4 \pm 14,8$ & $72,7 \pm 9,9$ & $61,4 \pm 6,1$ & $68,5 \pm 10,5$ \\
\hline Miosina & $11,4 \pm 2,8$ & $11,5 \pm 0,9$ & $11,4 \pm 1,3$ & $10,8 \pm 1.2$ \\
\hline
\end{tabular}

Os dados são apresentados (normalizados) como porcentagem da atividade $\mathrm{Mg}^{2+}$-ATPásica observada para tropomiosina-acto-miosina (atividade 100\%). Condições dos ensaios: 1,14 $\mu \mathrm{M}$ de TnT ou TnT1-191 ou TnT77-191, 0,57 $\mu \mathrm{M}$ de $\alpha$-tropomiosina (quando presente), $4 \mu \mathrm{M}$ de actina (quando presente) e $0,2 \mu \mathrm{M}$ de miosina em imidazol- $\mathrm{HCl}(\mathrm{pH} 7,0) 20 \mathrm{mM}, \mathrm{MgCl}_{2} 3,5$ $\mathrm{mM}, \mathrm{KCl} 60 \mathrm{mM}$, EDTA $1 \mathrm{mM}$ e DTT $1 \mathrm{mM}$. 
A observação experimental de que a TnT tipo selvagem isolada é uma proteína solúvel apenas em alta força iônica (aproximadamente $\mathrm{NaCl} 400 \mathrm{mM}$ ) dificulta o estudo das interações da TnT com o filamento fino através de cosedimentação com F-actina e com $\alpha$-tropomiosina-actina. Como todos os fragmentos construídos neste trabalho são solúveis em baixa concentração salina $(\mathrm{KCl} 60 \mathrm{mM}$ ), foi possível analisar a ligação desses fragmentos à actina e à tropomiosina-actina em condições próximas das fisiológicas por ensaios cosendimentação (Figura 14).

Observamos que o fragmento TnT1-76 não se liga à $\alpha$-tropomiosina-actina, confirmando que a região correspondente aos resíduos de aminoácidos 1-76 não se liga à tropomiosina. Nos nossos ensaios, confirmamos também que TnT77-157 (correspondente à região $\mathrm{CB} 2$ da $\mathrm{TnT}$ ) e TnT1-157 (correspondente ao fragmento CB1) ligam-se à tropomiosina-actina de acordo com resultados prévios que demostraram a ligação da região 77-157 (CB2) à tropomiosina (Jackson et al., 1975; Pearlstone e Smillie, 1977; Pearlstone e Smillie, 1982). Nós também observamos que TnT1-76, TnT77-157 e TnT1-157 não se ligam à actina. Interessantemente, observamos que TnT77-191 e TnT158-191 ligam-se à actina. Esses resultados indicam a existência de um sítio de ligação à actina entre os aminoácidos 158-191 da TnT.

Figura 14: Interações dos fragmentos $\mathrm{NH}_{2}$-terminais de $\mathrm{TnT}$ com actina e $\alpha$-tropomiosinaactina analisadas qualitativamente em ensaios de co-sedimetação. A solubilidade dos fragmentos nas condições dos ensaios, e suas interações com actina e com $\alpha$-tropomiosinaactina foram analisadas em Tricina/SDS-PAGE 12,5\%. As mesmas quantidades de amostras antes da ultracentrifugação (M), do sobrenadantes (S) e do precipitado (P) após a ultracentrifugação foram analisadas. Condições dos ensaios: actina $(20 \mu \mathrm{M}), \alpha$-tropomiosina $(2,86 \mu \mathrm{M})$, TnT158-191 e ABZTnT158-191 $(8,58 \mu \mathrm{M})$ e demais fragmentos de $\operatorname{TnT}(2,86 \mu \mathrm{M})$ em imidazol- $\mathrm{HCl}(\mathrm{pH} 7,0) 20 \mathrm{mM}, \mathrm{KCl} 60 \mathrm{mM}, \mathrm{MgCl}_{2} 3,5 \mathrm{mM}, \beta$-mercaptoetanol $2 \mathrm{mM} \mathrm{e}$ EDTA $1 \mathrm{mM}$.

Próxima página 


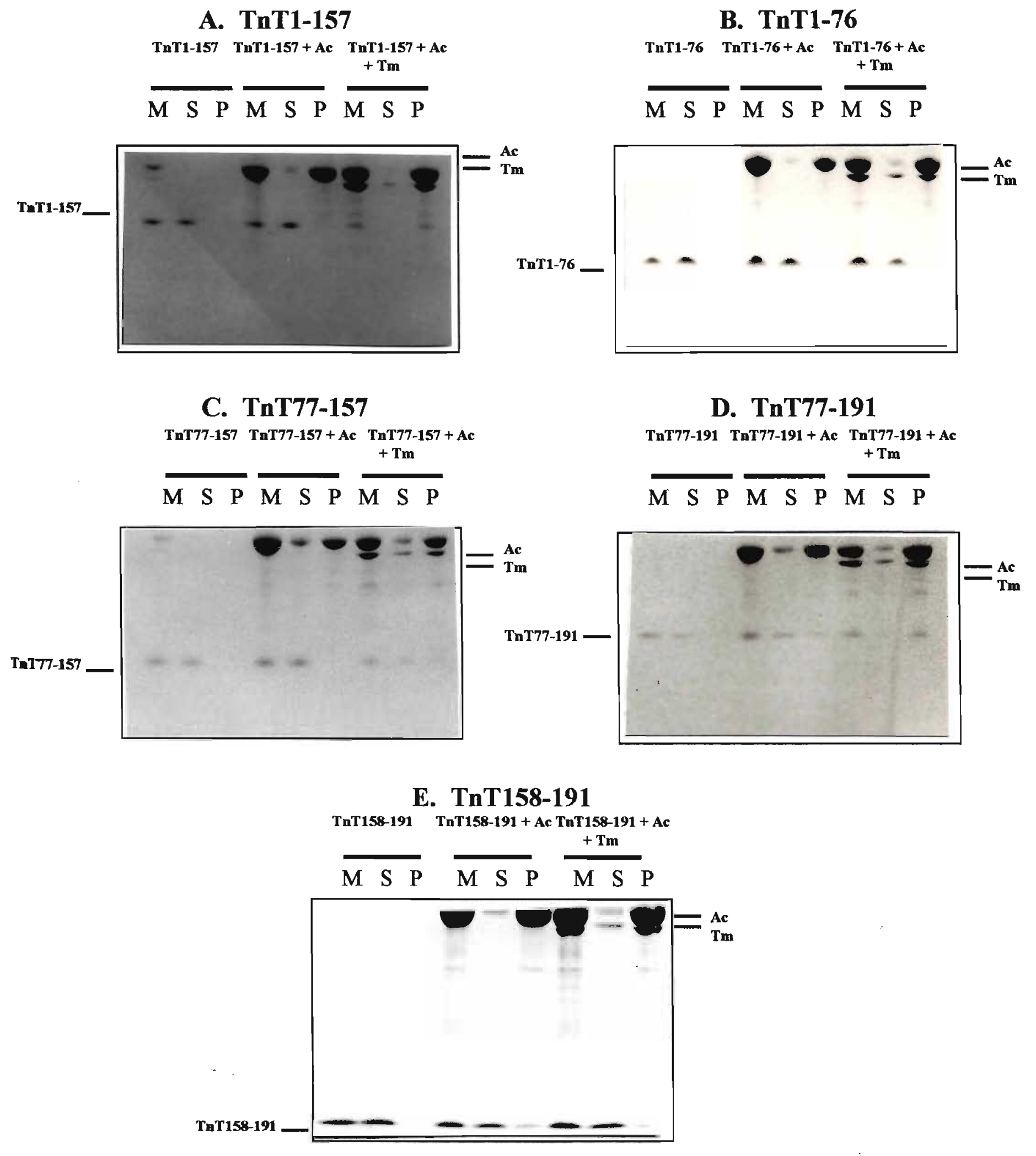


Para estudar a interação do fragmento TnT158-191 com a F-actina, nós produzimos o fragmento ABZTnT158-191 que é marcado com a sonda fluorescente extrínseca $\mathrm{ABZ}$ (ácido o-aminobenzóico) em sua extremidade $\mathrm{NH}_{2}$ terminal. Esse fragmento marcado aparentemente teve o mesmo comportamento que TnT158-191 não marcado em ensaios qualitativos de co-sedimentação e também apresentou o mesmo conteúdo de estruturas secundárias (Tabela 1), indicando que a adição da sonda não alterou muito a estrutura e o sítio de interação com a actina que esse fragmento originalmente possui. Confirmando nossos resultados obtidos em ensaios de co-sedimentação, a Figura 15 mostra que o espectro de emissão de ABZTnT158-191 é significantemente influenciado pela presença de actina. Nenhuma alteração no espectro de ABZTnT158-191 foi observada na presença de tropomiosina (Figura 15).

Para excluir a possibilidade de ligação direta do fragmento TnT158-191 com a tropomiosina, realizamos ensaios de gel filtração (Figura 15). Nesses ensaios não observamos interação entre o fragmento TnT158-191 e a tropomiosina. Esses dados estão de acordo com o resultados previamente obtidos por Jackson et al. (1975) que demonstraram que um fragmento de TnT correspondente ao aminoácidos 159-227 de TnT de coelho não era capaz de se ligar à tropomiosina imobilizada.

Para investigar melhor a ligação do fragmento TnT158-191 à actina e à actina-tropomiosina, realizamos ensaios quantitativos de co-sedimentação (Figura 16). No experimento controle realizado com o fragmento ABZTnT158-191 sozinho, não foi detectada a presença deste fragmento no precipitado. Assumindo que a ligação de TnT158-191 ocorre em uma razão molar 1:1, a constante de dissociação (Kd) de ligação à actina calculada foi de $8,1 \times 10^{-6} \mathrm{M}^{-1}$. Interessantemente, a forma de $\mathrm{S}$ das curvas mostradas na Figura 16 sugere um processo de ligação cooperativo. O coeficiente de cooperatividade de Hill calculado a partir dos dados obtidos foi de 2,1. A curva de ligação desse fragmento à tropomiosina-actina é similar à de ligação à actina. 

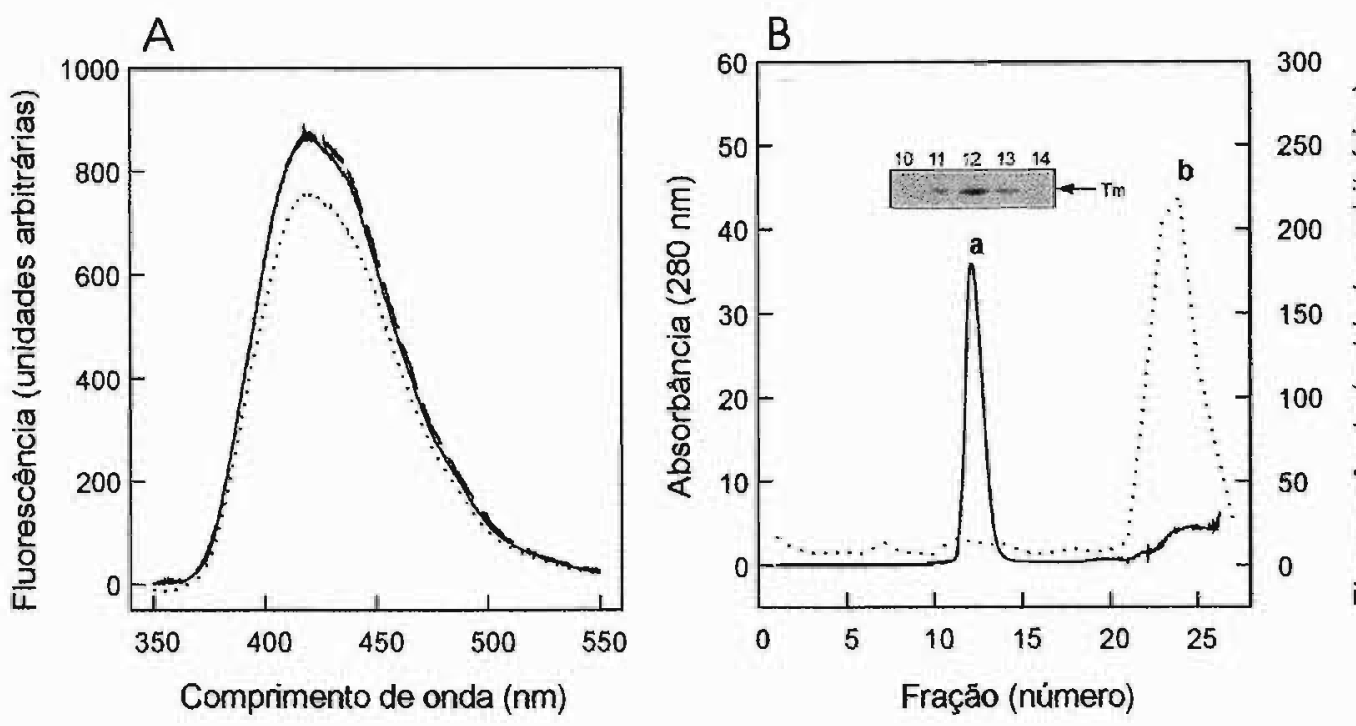

Figura 15: A. Efeito da actina e da tropomiosina no espectro de emissão do fragmento ABZTnT158-191. Espectros de emissão típicos de TnT158-191 fluorescentemente marcado

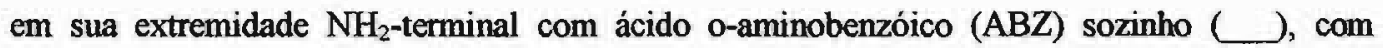
actina (...) e com tropomiosina $\left(C_{-}\right)$obtidos após excitação a $319 \mathrm{~nm}$ são apresentados. Condições do ensaio: ABZTnT158-191 $1 \mu \mathrm{M}, \alpha$-tropomiosina $1 \mu \mathrm{M}$ (quando presente) e actina $1 \mu \mathrm{M}$ (quando presente) em MOPS (pH 7,0) $20 \mathrm{mM}, \mathrm{KCl} 60 \mathrm{mM}, \mathrm{MgCl}_{2} 3,5 \mathrm{mM}$, EDTA $1 \mathrm{mM}$ e DTT $1 \mathrm{mM}$.

B. Ensaio de gel filtração com $\alpha$-tropomiosina e ABZTnT158-191. Os ensaios foram relizados em coluna Superose $6 \mathrm{HR}$ (Pharmacia Biotech) (volume total $=23,56 \mathrm{ml}$ ) equilibrada com MOPS (pH 7,0) $25 \mathrm{mM}, \mathrm{KCl} 60 \mathrm{mM}$ e DTT $1 \mathrm{mM}$ à temperatura ambiente. A presença do ABZTnT158-191 e de tropomiosina nas frações coletadas foi monitorada por medidas da intensidade de fluorescência e em géis SDS-PAGE 15\% (gel inserido), respectivamente. A linha contínua indica a absorbância a $280 \mathrm{~nm}$. A linha descontinua indica a emissão de fluorescência de ABZTnT158-191. Os pontos a e b, respectivamente, indicam as frações onde a $\alpha$-tropomiosina (Tm) e ABZTnT158-191 foram eluidas. Em ensaios realizados, nas mesmas condições, com $\alpha$-tropomiosina e com ABZTnT158-191 isolados, as eluições também ocorreram nos mesmos pontos a e b, respectivamente. 

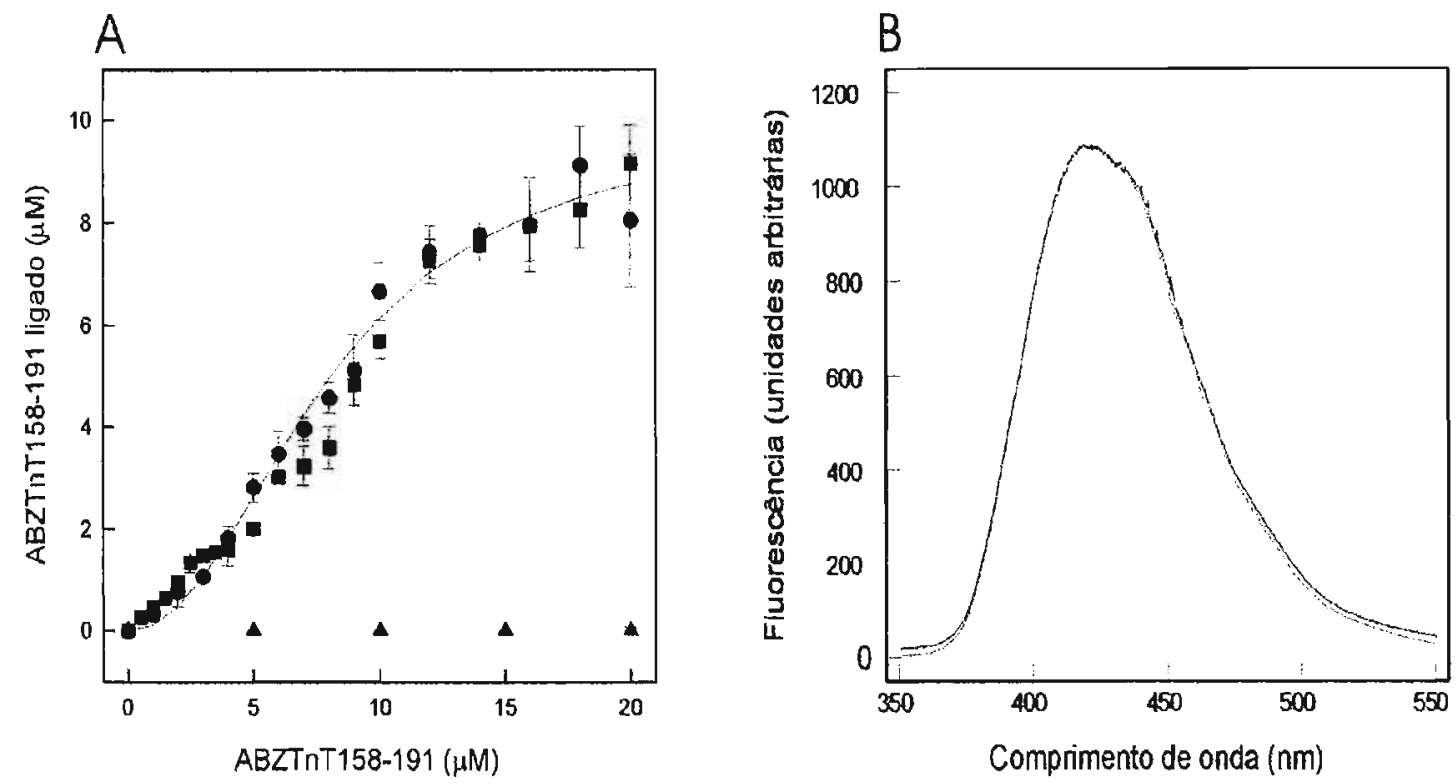

Figura 16: Ligação do fragmento TnT158-191 à actina e à a-tropomiosina-actina. A. Os dados das curvas de ligação de ABZTnT158-191 à actina $(10 \mu \mathrm{M})$ (esferas) e à $\alpha$ tropomiosina-actina (1,4 $\mu \mathrm{M}$ de $\alpha$-tropomiosina e $10 \mu \mathrm{M}$ de actina) (quadrados) foram obtidos em ensaiois de co-sedimentação com concentrações crescentes de ABZTnT158-191 realizados como descrito em Materiais e Métodos. Condições do ensaio: imidazol- $\mathrm{HCl}$ (pH 7,0) $20 \mathrm{mM}, \mathrm{MgCl}_{2} 3,5 \mathrm{mM}, \mathrm{KCl} 60 \mathrm{mM}$, EGTA $0,5 \mathrm{mM}$ e DTT $1 \mathrm{mM}$. Os dados apresentados são médias de pelo menos três determinações independentes acompanhadas pelos respectivos desvios-padrões. A abscissa indica a concentração total de TnT158-191, e a ordenada indica TnT158-191 ligado por actina. A linha representa o melhor ajuste ("curve fitting") obtido a partir dos dados de ligação à actina utilizando a equação de Hill: $\mathrm{Y}=\mathrm{C}^{\mathrm{n}} / \mathrm{C}^{\mathrm{n}}+$ $K_{D}{ }^{n}$, onde $Y$ é a ligação fracional de TnT158-191, C é a concentração de TnT158-191 e $K_{D}$ é a constante de dissociação. Experimentos controles foram relizados na ausência de actina (triângulos). B. O gráfico mostra a influência de actina $(1 \mu \mathrm{M})$ e tropomiosina $(1 \mu \mathrm{M})$ no espectro de emissão do fragmento ABZTnT158-191 (1 $\mu \mathrm{M})$ nas mesmas condições descritas em $\mathbf{A}$, mas em $\mathrm{KCl} 1 \mathrm{M}$, demonstrando que nas condições em que as medidas de fluorescência foram realizadas (concentração final $\mathrm{KCl} 1 \mathrm{M}$ ) (detalhes em Materiais e Métodos), a presença de actina não influencia a intensidade de fluorescência da sonda $A B Z$. Linhas: ABZTnT158-191, ABZTnT158-191 e actina, ABZTnT158191 e $\alpha$-tropomiosina. 
É interessante notar que somente os dois fragmentos que foram capazes de ativar a atividade $\mathrm{Mg}^{2+}$-ATPásica da acto-miosina (TnT1-191 e TnT77-191) preservam tanto o sítio de ligação à actina como o sítio de ligação à tropomiosina (Tabela 4).

Tabela 4. Sumário das propriedades dos fragmentos de TnT estudados nesse trabalho.

\begin{tabular}{llcc}
\hline & Ligação à tropomiosina & Ligação à actina & $\begin{array}{c}\text { Ativação da } \\
\text { ATPase* }^{*}\end{array}$ \\
\hline TnT1-191 & $\operatorname{sim}$ & $\operatorname{sim}$ & $\operatorname{sim}$ \\
TnT1-157 & $\operatorname{sim}$ & não & não \\
TnT1-76 & não & não & não \\
TnT77-157 & $\operatorname{sim}$ & não & não \\
TnT77-191 & $\operatorname{sim}$ & $\operatorname{sim}$ & sim \\
TnT158-191 & não & sim & não \\
\hline
\end{tabular}

*: Ativação da ATPase refere-se à capacidade dos fragmentos de ativar a atividade da actomioisna na presença de tropomiosina e na ausência de TnI e TnC. 
Efeito do Complexo Troponina e Fragmentos de TnT no Espectro de Emissão de Tm5OH263W

Para estudar as interações da TnT com a tropomiosina e mapear a região da tropomiosina que interage com a região correspondente ao fragmento T1 da TnT (aminoácidos 1-157), realizamos ensaios de fluorescência com Tm5OH263W. Tm5OH263W é uma tropomiosina recombinante com uma sonda intrínseca (5hidroxitriptofano) substituindo a glutamina que originalmente na tropomiosina tipo selvagem ocupa a posição 263 na seqüência primária (Figura 17). Embora Tm5OH263W ligue-se à actina em ensaios de co-sedimentação (Figura 18), Tm5OH263W não tem seu espectro de emissão alterado pela adição de actina sozinha (Figura 17). Entretanto, a adição do complexo troponina causa um decréscimo significante na intensidade de fluorescência do espectro de emissão de Tm5OH263W. Nenuma alteração no espectro de emissão de Tm5OH263W foi observado em ensaios realizados com complexo troponina reconstituído com TnT157-263 (Figura 17). Assim sendo, a fluoresência de Tm5OH263W pôde ser utilizada como uma sonda específica para o estudo das interações entre tropomiosina e a parte $\mathrm{NH}_{2}$-terminal da $\mathrm{TnT}$ correspondente a região $\mathrm{T} 1$.

Os ensaios de ligação do complexo troponina, complexo troponina reconstituído com TnT157-263 e fragmentos de TnT são mostrados na Figura 17 e resumidos na Tabela 5. Os resultados dos ensaios de fluorescência apresentados na Figura 17 podem ser confrontandos com os resultados obtidos em ensiaos de cosedimentação nas mesmas condições (Figura 18). Esses ensaios demonstram que apesar da ligação com actina não alterar o espectro de $\operatorname{Tm} 5 \mathrm{OH} 263 \mathrm{~W}$, o decréscimo na fluorescência da sonda em função da adição do complexo troponina, de TnT1-191 e de TnT157-191, quando a tropomiosina está ligada à actina, é mais significativo $(\sim 20 \%)$ do que quando não há actina no sistema $(\sim 12 \%)$, indicando provavelmente uma interação mais forte na presença de actina do que na sua ausência. Entretanto, TnT1-157 promove um decréscimo de aproximadamente $20 \%$ no sinal de fluorescência da sonda de forma independente da ligação de actina. Observamos também que a emissão de Tm5OH263W não 
varia em função da adição do complexo troponina com deleção do fragmento $\mathrm{T} 1$, indicando que a variação na fluorescência observada é específica para interações com T1, já que ensaios de co-sedimentação demonstram que TnT157-263 liga-se ao mutante de tropomiosina (Figura 18). De acordo com os nossos resultados anteriores, observamos que o fragmento TnT1-76 não promove nenhum efeito na fluorescência da sonda. Todos os fragmentos que contêm a região CB2 (TnT1191, TnT1-157, TnT77-157 e TnT77-191) foram capazes de ligar-se à Tm5OH263W-actina em ensaios de co-sedimentação. Interessantemente, com exceção do próprio fragmento $\mathrm{CB} 2$, todos eles promoveram um decréscimo no sinal de fluorescência da sonda. Esses dados, aparentemente conflitantes, sugerem que o fragmento TnT77-157 (CB2) liga-se à tropomiosina-actina, mas essa interação é modulada pelas seqüências vizinhas na estrutura primária da TnT. Somente na presença dessas seqüências, observamos alteração na fluorescência de $\mathrm{Tm} 5 \mathrm{OH} 263 \mathrm{~W}$. 
Tabela 5: Efeito da troponina e dos fragmentos de TnT sobre a intensidade de fluorescência do espectro de emissão de Tm5OH263W.

\begin{tabular}{lcccc}
\hline & \multicolumn{2}{c}{+ Actina } & \multicolumn{2}{c}{ - Actina } \\
& - Tn & + Tn & - Tn & + Tn \\
\hline TnTwt + TnI + TnC & $100 \%$ & $81 \%$ & $100 \%$ & $88 \%$ \\
TnT157-263 + TnI +TnC & $100 \%$ & $108 \%$ & $100 \%$ & $99 \%$ \\
TnT1-191 & $100 \%$ & $80 \%$ & $100 \%$ & $89 \%$ \\
TnT1-157 & $100 \%$ & $76 \%$ & $100 \%$ & $82 \%$ \\
TnT1-76 & $100 \%$ & $101 \%$ & $100 \%$ & $98 \%$ \\
TnT77-157 & $100 \%$ & $97 \%(96 \%)^{*}$ & $100 \%$ & $96 \%(97 \%)^{*}$ \\
TnT77-191 & $100 \%$ & $79 \%$ & $100 \%$ & $92 \%$ \\
TnT158-191 & $100 \%$ & $102 \%$ & $100 \%$ & $98 \%$ \\
\hline
\end{tabular}

Os dados foram obtidos a partir dos espectros apresentados na Figura 17 (razão molar Tn:Tm5OH263W:actina $=3: 1: 7$ ) que representam resultados típicos obtidos a partir de pelo menos dois ensaios independentes. $0^{*}$ : resultados referentes a ensaios realizados com $10 \mu \mathrm{M}$ de TnT77-157, ou seja, razão molar 10:1:7 de TnT77-157, Tm5OH263W e actina.

Figura 17: Efeito das proteínas do filamento fino sobre o espectro de fluorescência da tropomiosina 50H263W. A. São mostrados espectros típicos (de um total de pelo menos dois espectros obtidos para cada ensaio) de emissão da tropomiosina Tm5OH263W na presença de actina, do complexo troponina, de complexo troponina reconstituído com o fragmento TnT157-263 e com os fragmentos de TnT construidos nesse projeto. Os espectros foram obtidos como descrito em Materiais e Métodos nas seguintes condições: MOPS $(\mathrm{pH}$ 7,0) $25 \mathrm{mM}, \mathrm{NaCl} 60 \mathrm{mM}, \mathrm{MgCl}_{2} 5 \mathrm{mM}$ e DTT $1 \mathrm{mM}$ a $25^{\circ} \mathrm{C}$. Concentração das proteínas: 1 $\mu \mathrm{M}$ de Tm5OH263W, $3 \mu \mathrm{M}$ de troponina ou dos fragmentos de TnT, $7 \mu \mathrm{M}$ de actina, cálcio 1 mM ou EGTA $1 \mathrm{mM}$. Os espectros estão representados pelas seguintes linhas:

Tm5OH263W; Tm5OH263W e troponina; Tm5OH263W, troponina e $\mathrm{Ca}^{2+} ; \quad$ Tm5OH263W e actina; Tm5OH263W, actina e troponina;

Tm5OH263W, actina, troponina e $\mathrm{Ca}^{2+}$. A intensidade de fluorescência está expressa em unidades arbitrárias.

Próxima página 
Ausência de Actina

Tn

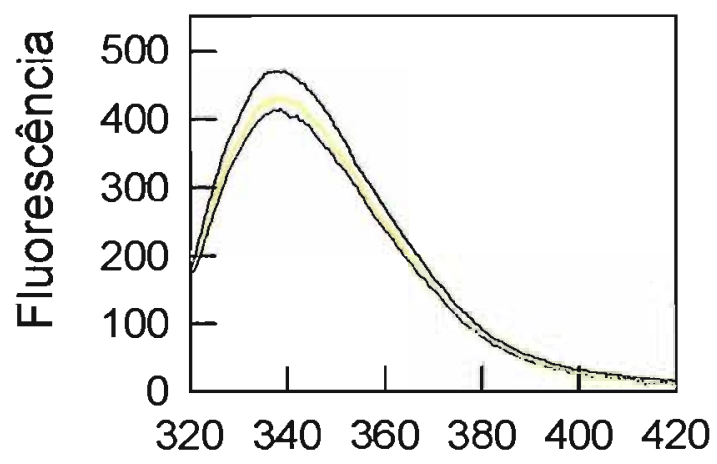

$\operatorname{Tn}(\operatorname{TnT157-263)}$

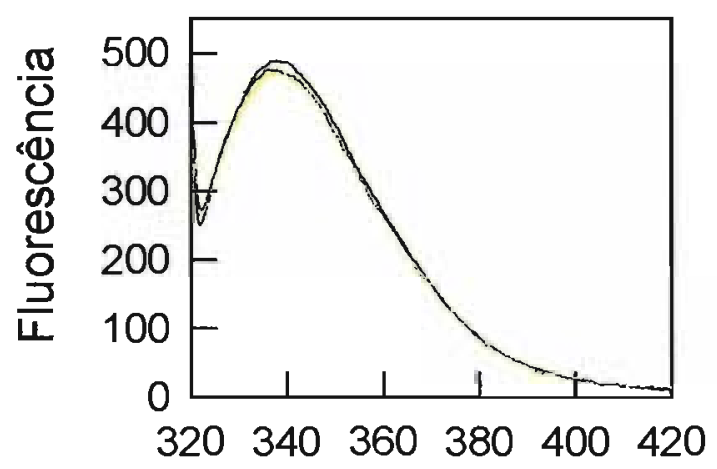

TnT1-191

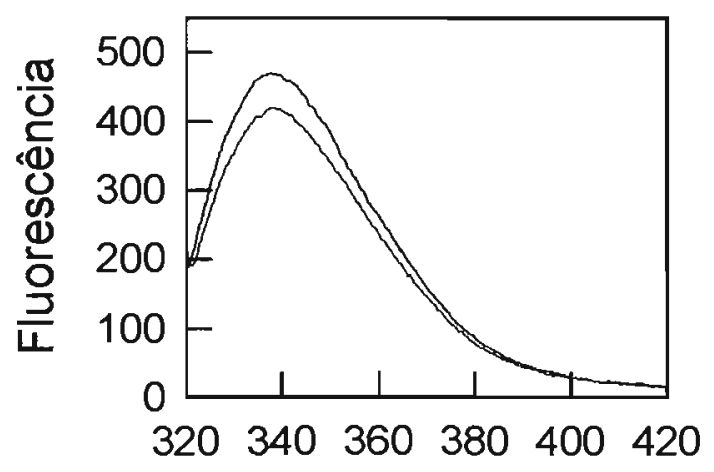

TnT1-157

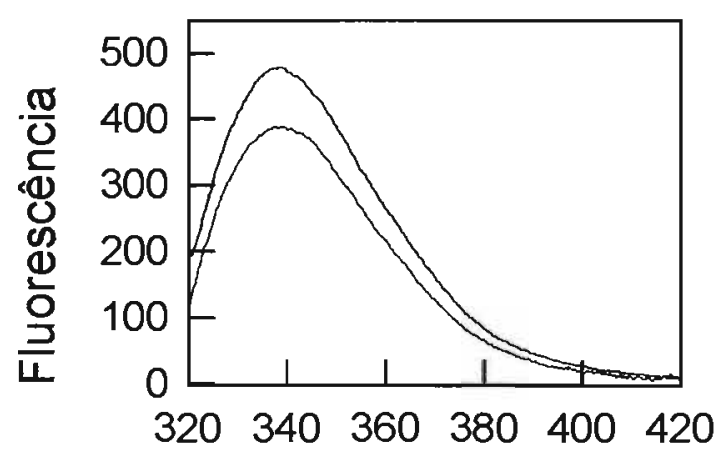

Comprimento de onda $(\mathrm{nm})$
Presença de Actina

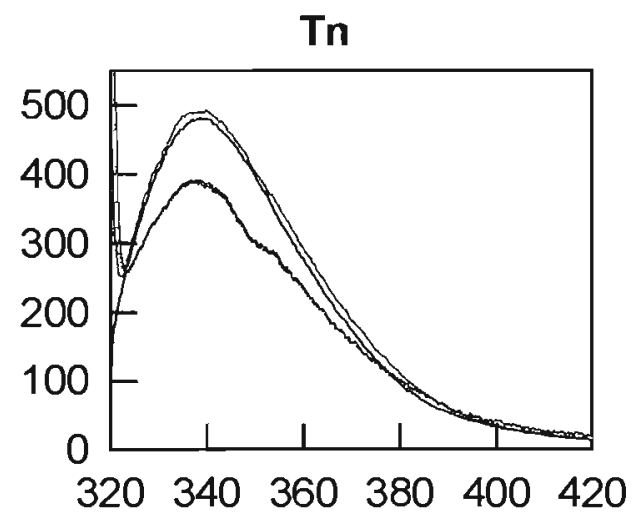

$\operatorname{Tn}(\operatorname{TnT157-263)}$

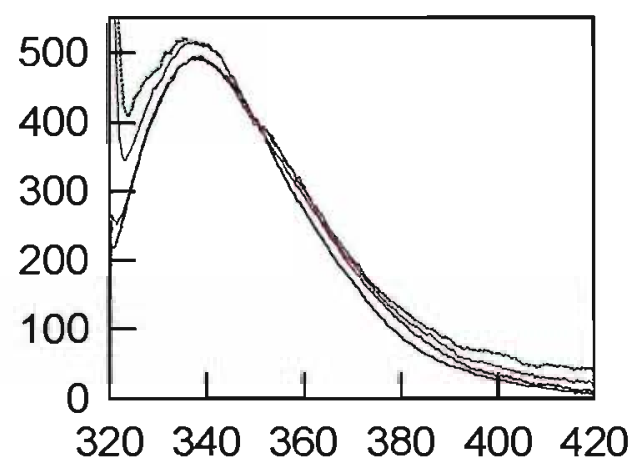

TnT1-191

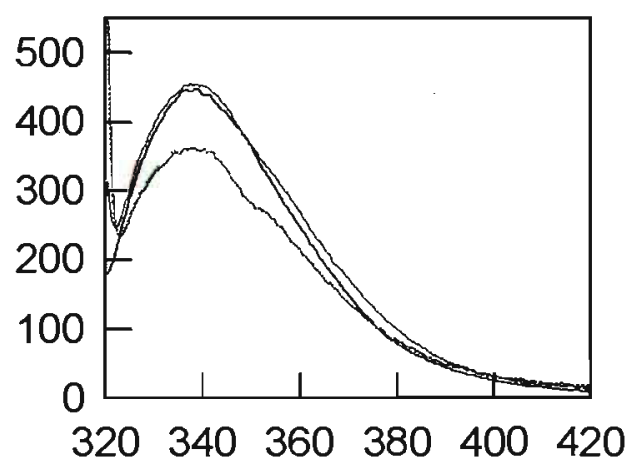

TnT1-157

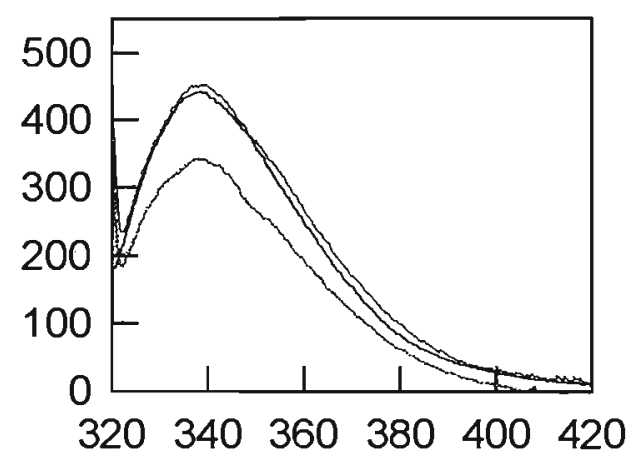

Comprimento de onda $(\mathrm{nm})$ 
Ausência de Actina

TnT77-191

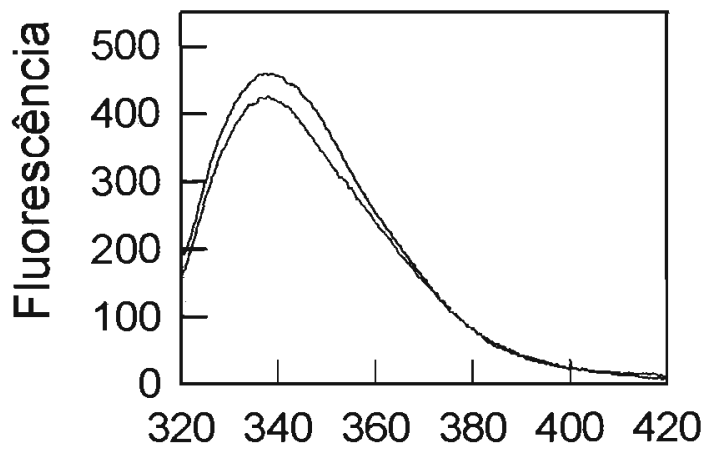

TnT1-76

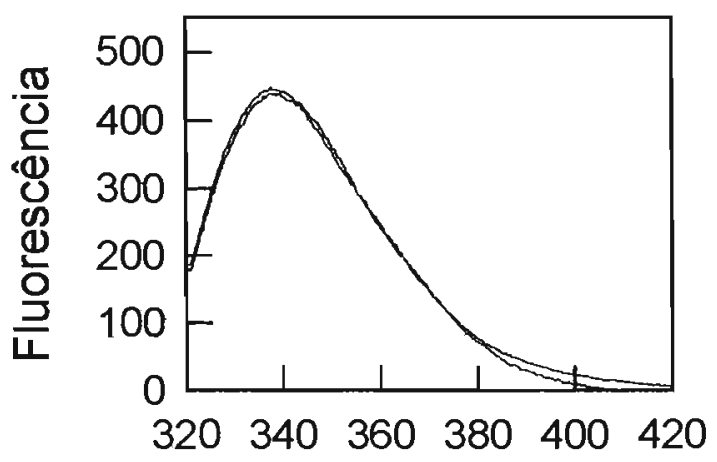

TnT77-157

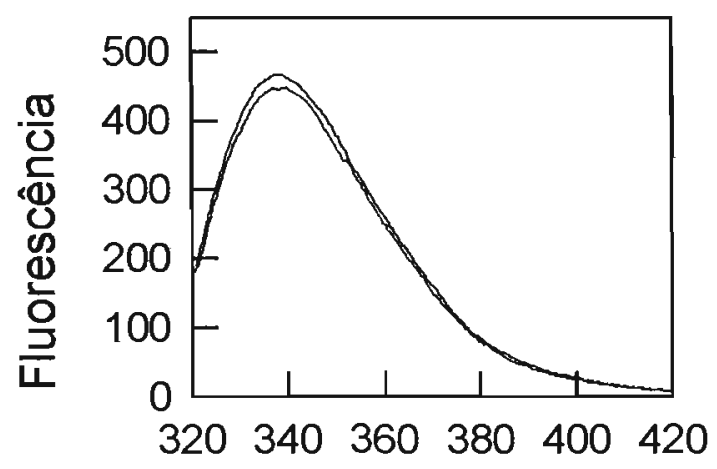

TnT158-191

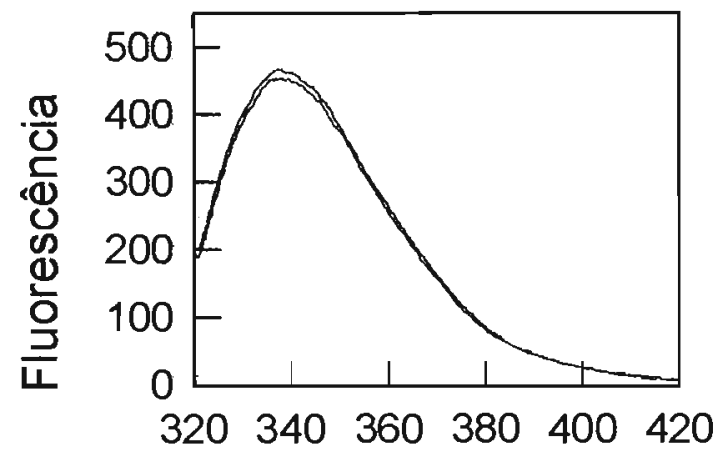

Comprimento de onda $(\mathrm{nm})$
Presença de Actina

TnT77-191

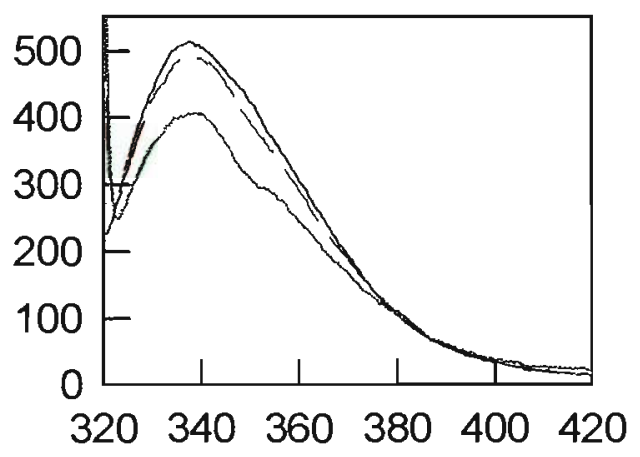

TnT1-76

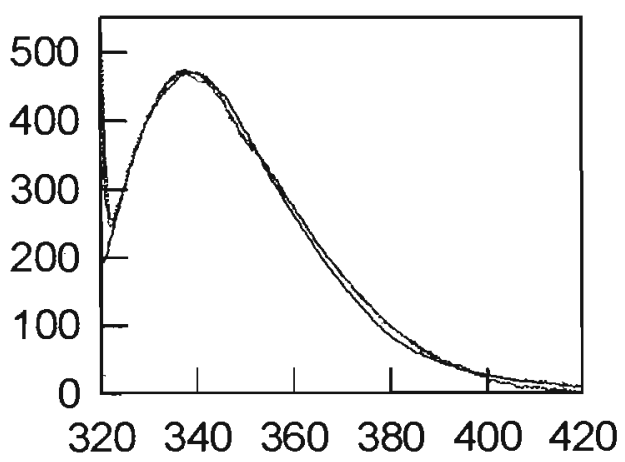

TnT77-157

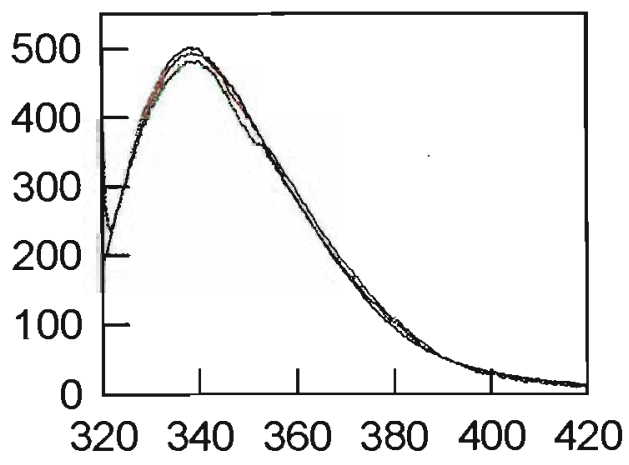

TnT158-191

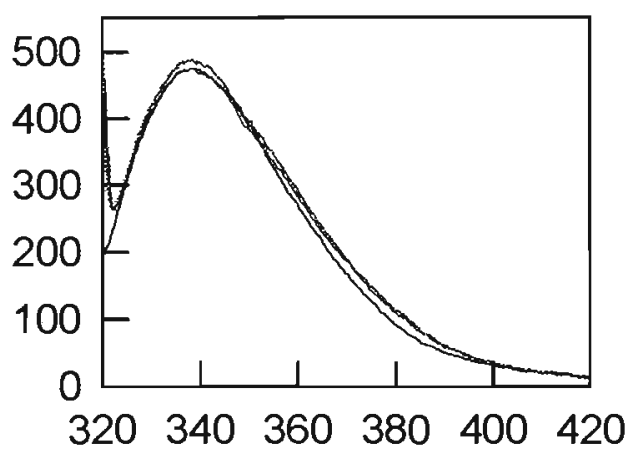

Comprimento de onda $(\mathrm{nm})$ 

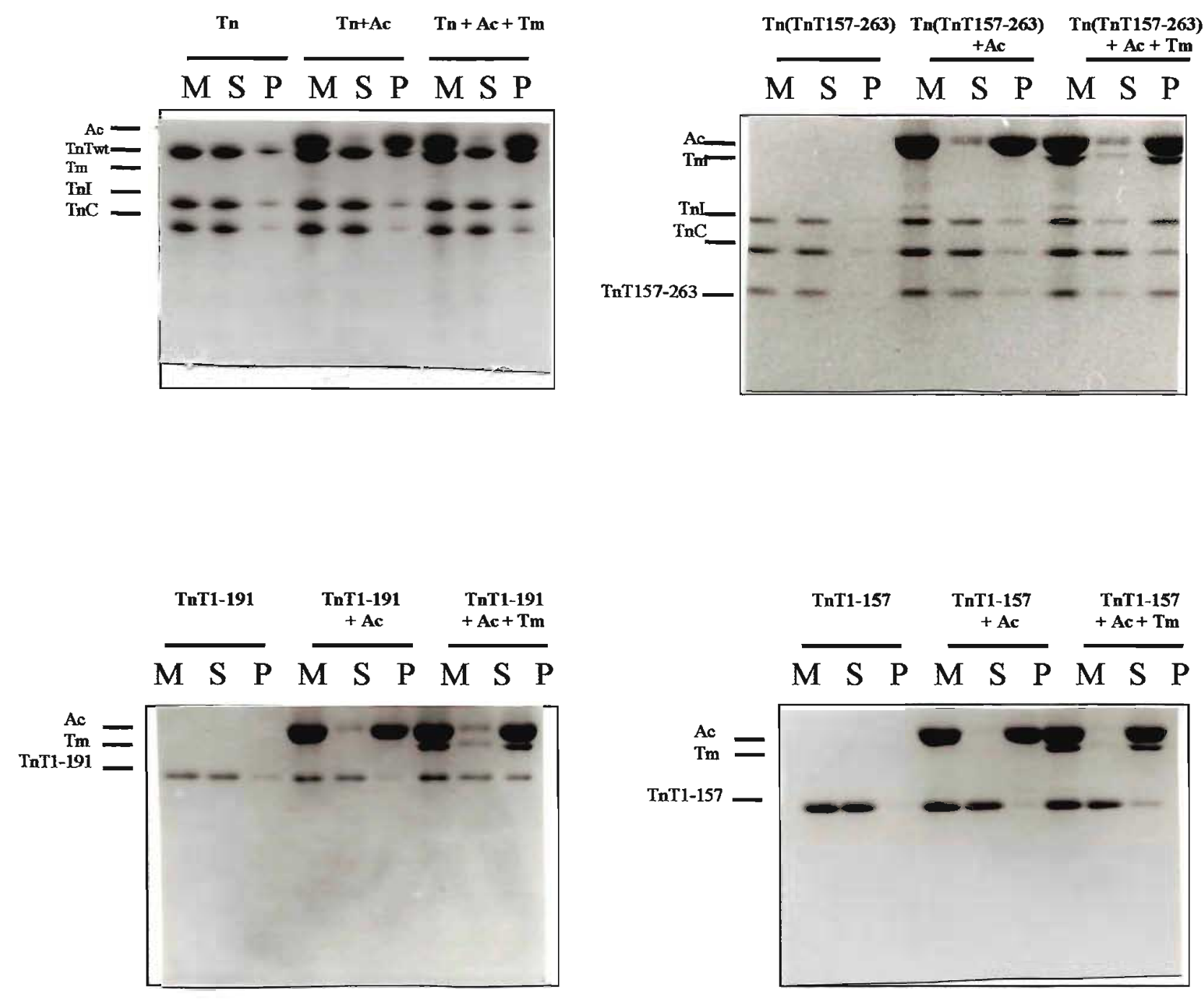

Figura 18: Ensaios de co-sedimentção do complexo troponina, do complexo troponina reconstituído com TnT157-263 e dos fragmentos de TnT com Tm50H263W-actina. Os ensaios foram relizados como descrito em Materias e Métodos e nas mesmas condições em que os espectros mostrados na Figura 17 foram obtidos. A solubilidade dos fragmentos nas condições dos ensaios e suas interações com actina e com Tm5OH263W-actina foram analisadas em Tricina/SDS-PAGE $12,5 \%$. As mesmas quantidades de amostras antes da ultracentrifugação (M), do sobrenadante (S) e do precipitado (P) após a ultracentrifugação foram analisadas.

Continuação na próxima página. 
.Figura 18 - parte II
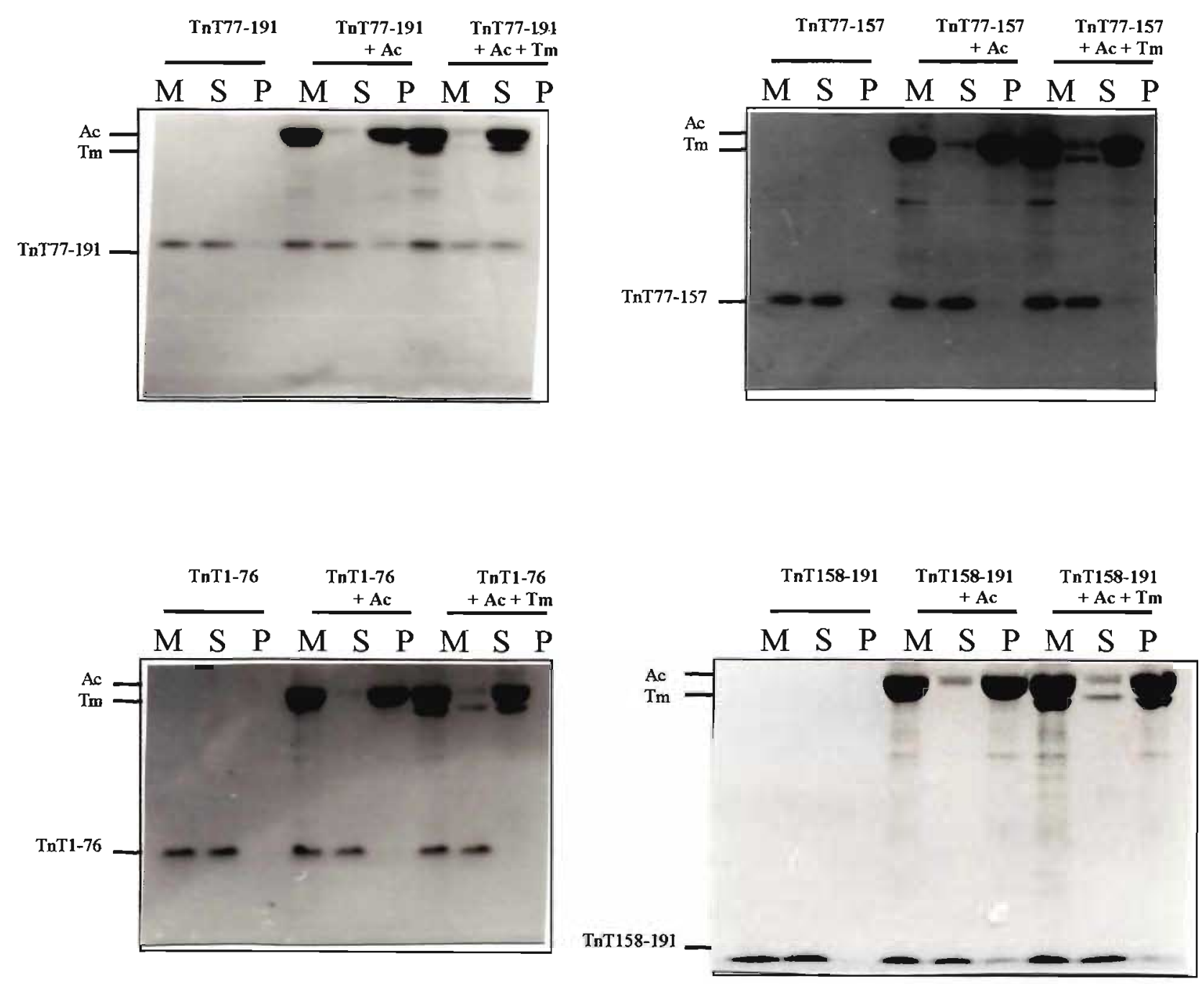
Uma tropomiosina recombinante com uma sonda intrínseca localizada na posição 122 ( $\mathrm{Tm} 5 \mathrm{OH} 122 \mathrm{~W}$ ) da estrutura primária foi construída e caracterizada pelo nosso grupo anteriormente (Farah e Reinach, 1999). A sonda 5hidroxitriptofano presente na posição 122 da tropomiosina, localizada na parte externa da estrutura coiled coil da tropomiosina, é uma sonda sensível à ligação de actina, à ligação do complexo troponina e à ligação de $\mathrm{Ca}^{2+}$ no complexo troponina (Farah e Reinach, 1999 e Figura 19). Acredita-se que o sítio de ligação do complexo troponina está situado entre os aminoácidos 150 e 284 da tropomiosina, portanto essa sonda não estaria interagindo diretamente com o complexo troponina (White $e t a l$, 1987). Dessa forma, essa sonda parece ser sensível à alterações da interação da actina com a tropomiosina provocada pela ligação de $\mathrm{Ca}^{2+}$ no complexo troponina, o que levaria a tropomiosina a ocupar uma outra posição no filamento de actina.

Para analisarmos se os fragmentos de $\operatorname{TnT}$, que são capazes de ativar a atividade ATPásica da acto-miosina, causam a mesma alteração no espectro de emissão da Tm5OH122W que a provocada pelo ligação de $\mathrm{Ca}^{2+}$ no complexo troponina, observamos o efeito dos fragmentos de TnT no espectro dessa sonda na presença de actina. A Figura 19 mostra alguns desses espectros. Nesses ensaios, observamos que a presença do complexo troponina causa um decréscimo pequeno na intensidade de fluorescência da sonda $5 \mathrm{OH} 122 \mathrm{~W}$ e a adição de $\mathrm{Ca}^{2+}$ no sistema provoca um aumento de aproximadamente $10 \%$ na intensidade de fluorescência da sonda conforme previamente descrito (Farah e Reinach, 1999). Observamos que a adição de $\mathrm{Ca}^{2+}$ ao sistema com comlexo troponina reconstituído com TnT157-263 não causa nenhum efeito na intensidade de fluorescência. A adição dos fragmentos TnT1-157, TnT1-76, TnT77-157, TnT1-157 + TnT158-191 também não causa nenhum efeito no espectro da sonda (Figura 19 e dados não apresentados). Somente a adição dos fragmentos TnT1-191 e TnT77-191, que preservam o domínio ativatório (aminoácidos 77-191), provocou um aumento da intensidade de fluorescência da sonda. $\mathrm{O}$ aumento provocado por esses fragmentos foi similar ao 
aumento provocado pela adição de $\mathrm{Ca}^{2+}$ na presença do complexo troponina. Esses resultados sugerem que o domínio ativatório da $\operatorname{TnT}$ altera a posição da tropomisona no filamento fino assim como a ligação de $\mathrm{Ca}^{2+}$ no complexo troponina.

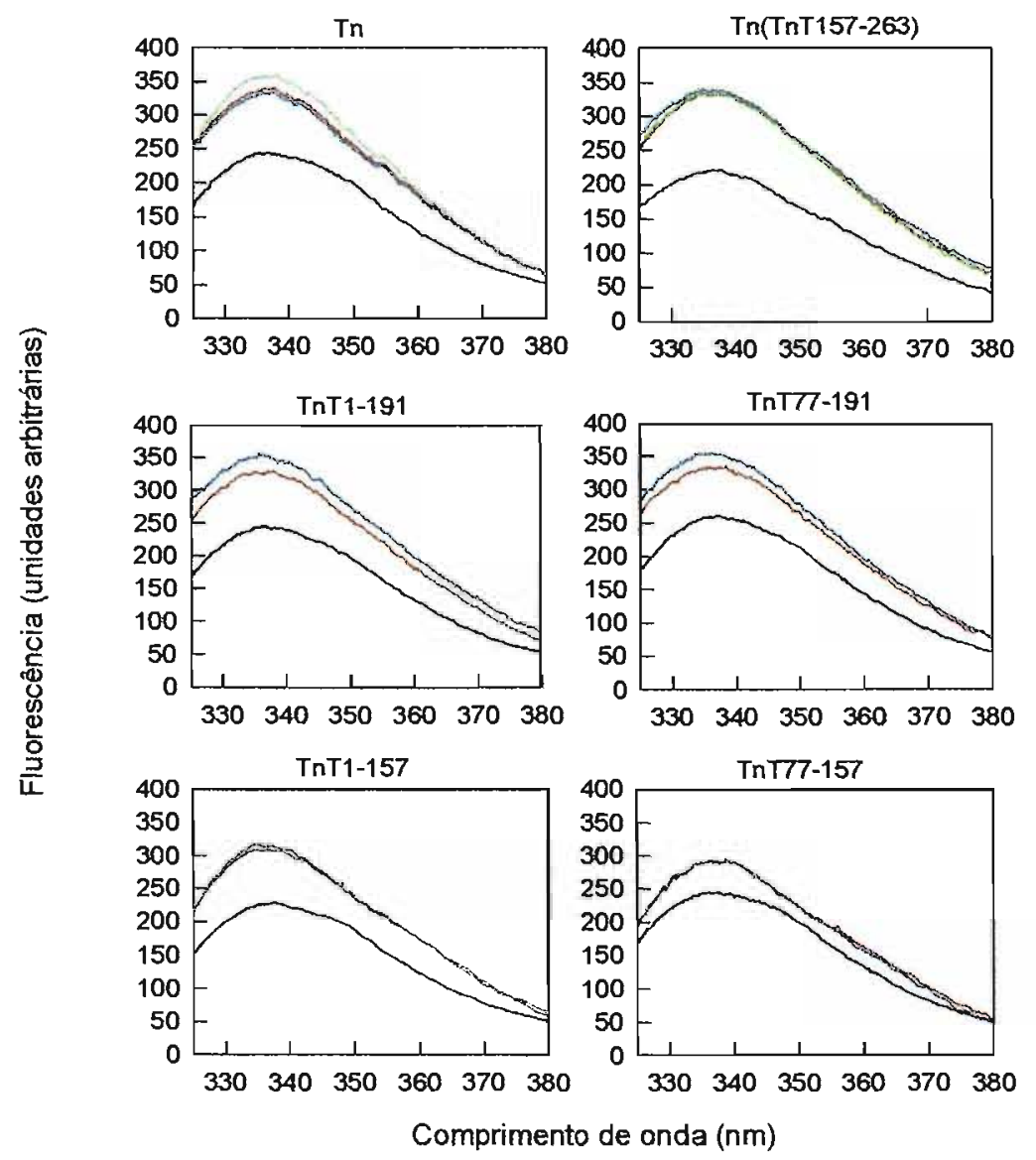

Figura 19: Variaçẽes na intensidade de fluorescência do espectro de emissão de Tm50H122W. Espectros típicos de emissão da Tm5OH122W são mostrados. Os espectros foram obtidos como descrito em Materiais e Métodos nas seguintes condições: MOPS ( $\mathrm{pH}$ $7,0) 25 \mathrm{mM}, \mathrm{NaCl} 60 \mathrm{mM}, \mathrm{MgCl}_{2} 5 \mathrm{mM}$ e DTT $1 \mathrm{mM}$ a $25^{\circ} \mathrm{C}$. Concentração das proteinas: 1 $\mu \mathrm{M}$ de $\mathrm{Tm} 5 \mathrm{OH} 122 \mathrm{~W}, 3 \mu \mathrm{M}$ de troponina ou dos fragmentos de $\mathrm{TnT}, 7 \mu \mathrm{M}$ de actina, cálcio 1 mM ou EGTA $1 \mathrm{mM}$. Os espectros estão representados pelas seguintes linhas:

$\mathrm{Tm} 5 \mathrm{OH} 122 \mathrm{~W}$; Tm5OH122W e actina; Tm5OH122W, actina e tropanina, $\mathrm{Tm} 5 \mathrm{OH} 122 \mathrm{~W}$, actina, troponina e $\mathrm{Ca}^{2+}$. A razão molar entre actina, tropomiosina e complexo troponina ou fragmentos de TnT é 7:1:3. 


\section{DISCUSSÃo}

Para melhor compreender o processo de ativação da atividade $\mathrm{Mg}^{2+}$ ATPásica da acto-miosina, estudamos as propriedades dos fragmentos de TnT que abrangiam a região correspondente aos aminoácidos 1-191.

Os resultados obtidos nesse trabalho: i) comprovam que a $\operatorname{TnT}$ é a subunidade do complexo troponina responsável pelo fenômeno de ativação da atividade ATPásica da acto-miosina; ii) demonstram que o dominíos ativatório está compreendido entre os aminoácidos 77-191 da TnT; iii) demonstram que a região correspondente aos aminoácidos 158-191 é um sítio de ligação à actina; iiii) demonstram que o aminoácido 263 da tropomiosina interage com a região correspondente ao fragmento $\mathrm{CB} 2$ da $\mathrm{TnT}$.

\section{Estrutura da TnT}

A característica mais marcante na estrutura primária da TnT é o alto conteúdo de resíduos de aminoácidos polares com cargas. Cerca de $50 \%$ dos aminoácidos da TnT são positiva ou negativamente carregados em $\mathrm{pH}$ neutro. A análise mais detalhada mostra que a distribuição dessas cargas não é randômica ao longo da seqüência da TnT. A região $\mathrm{NH}_{2}$-terminal é formada predominantemente por aminoácidos ácidos, enquanto a região COOH-terminal é formada predominantemente por aminoácidos básicos. No restante da seqüência da $\operatorname{TnT}$, observa-se que existe uma ausência de regiões formadas por aminoácido apolares e que existe uma tendência a formação de pequenos agregados de mesma carga. Essa observação da estrutura primária da TnT indica que a TnT apresenta-se de forma aberta de modo a permitir interações com solvente e outras proteínas Estudos de microscopia eletrônica (Flicker et al., 1982) também indicam que a TnT possui uma estrutura aberta. Essa estrutura da TnT é consistente com a suscetibilidade da TnT isolada e de fragmentos de TnT à degradação proteolítca durante o processo de purificação, observada nesse trabalho e também relatada por vários laboratórios. O fato da TnT apresentar essa estrutrura "aberta" torna 
conviniente o estudo de suas regiões ou de seus domínios utilizando-se fragmentos proteolíticos ou recombinantes, como nesse trabalho.

Os dados de dicroísmo circular obtidos com fragmentos recombinantes de TnT, que indicam que região 77-157 apresenta um alto conteúdo de alfa-hélice, estão de acordo com a predição da estrutura secundária da TnT e com resultados prévios obtidos com fragmentos proteolíticos de TnT (Pearlstone e Smillie 1977; Pearlstone e Smillie, 1985). Contudo, esses resultados devem ser analisados com cautela, uma vez que eles foram obtidos com fragamentos de TnT isolados em solução. Fica impossível, portanto, prever os efeitos, na estrutura secundária dos fragmentos de $\mathrm{TnT}$, decorrentes de suas interações com a tropomiosina e actina.

Interações da Região $\mathrm{NH}_{2}$-Terminal da Troponina $\mathrm{T}$

A solubilidade dos fragmentos de $\mathrm{TnT}$ a $60 \mathrm{mM} \mathrm{KCl}$ permitiu que fosse realizado um mapeamento das interações da região $\mathrm{NH}_{2}$-terminal da TnT. Nossos resultados estão de acordo com os resultados obtidos previamente que demonstraram que a região correspondente aos aminoácidos 77-157 da TnT é o sítio de ligação da TnT à tropomiosina (Jackson et al., 1975; Pearlstone e Smillie, 1977). Entretanto, nosso estudo da interação dos fragmentos de TnT com TmQ263(5OH)W demonstram que essa interação é modulada pelas seqüências vizinhas na estrutura primária da TnT. A hipótese de que a região CB2 (aminoácidos 77-157) interage inespecificamente com tropomiosina e que CB3 (aminoácidos 1-76) confere especificidade à essa interação foi anteriormente relatada por Brisson et al. (1986). Eles observaram que o fragmento CB2 interage mais fracamente com tropomiosina que o fragmento T1; e que a interação de CB2 com tropomiosina, ao contrário da de $\mathrm{T} 1$, é uma interação inespecífica. Nosso trabalho sugere que a seqüência de aminoácidos 158-191 tem o mesmo efeito estrutural que a seqüência 1-76 na modulação da interação da região CB2 da TnT com a tropomiosina.

Devido à insolubilidade da TnT, a interação direta da TnT com actina sempre foi um ponto obscuro no estudo das interações do filamento fino. Uma 
série de estudos demonstrou que a TnT aumenta a afinidade da tropomioina pela actina (Fisher et al., 1995; Hill et al., 1992; Heeley et al, 1987). O estudo realizado por Hill et al. (1992) demonstrou que a deleção dos primeiros 69 aminoáciodos da TnT cardíaca não afeta essa propriedade da TnT de aumentar a afinidade da tropomiosina pela actina, mas que essa afinidade era significantemente reduzida quando os primeiros 158 resíduos de aminoácidos eram deletados (o que corresponde aos primeiros 135 aminoácidos da TnT de músculo esquelético de galinha). Estudos realizados anteriormente em alta força iônica $(400 \mathrm{mM} \mathrm{KCl})$ indicaram uma fraca interação entre a TnT e a actina (Potter e Gergely, 1974; Hitchcock, 1975). Através de ensaios de co-sedimentação com fragmentos trípticos e com TnT inteira, Heeley et al. (1988) demonstraram que a região da $\mathrm{Tn} \mathrm{T}$ representada pelo fragmento $\mathrm{T} 2$ interage com actina e que essa interação é insensivel à concentração de $\mathrm{Ca}^{2+}$. Como esses ensaios foram realizados em condições salinas em que a TnT e o fragmento T2 não são totalmente solúveis (150 mM KCl), a interação direta da TnT com actina ainda permanecia inconclusiva. Nesse trabalho, demonstramos que entre os aminoácidos 158-191 da TnT existe um sítio de ligação à actina e que, interessantemente, a ligação de TnT à actina é um processo cooperativo. Esses resultados evidenciam a participação da $\mathrm{TnT}$ na ancoragem da tropomiosina no filamento de actina através de interações com a tropomiosina e com a actina.

A curva de ligação desse fragmento com tropomiosina-actina (razão molar 1:7) também demonstra que, mesmo com a presença de tropomiosina no sistema, a saturação continua ocorrendo numa proporção $1 \mathrm{~mol}$ TnT158-191/ $1 \mathrm{~mol}$ actina. Estudos realizados anteriormente (Jackson et al. 1975) e os apresentados nesse trabalho falharam em demonstrar qualquer tipo de interação dessa região da TnT com a tropomiosina. Em adição, os nossos dados também não sugerem que a ligação da tropomiosina no filamento de actina possa interferir significantemente na afinidade da TnT pela actina.

Ativação da Atividade ATPásica da Acto-miosina pela TnT 
As primeiras evidências do papel ativatório da TnT surgiram junto com a observação de que o processo de ativação da atividade ATPásica da acto-miosina, em altas concentrações de $\mathrm{Ca}^{2+}$, ocorre apenas quando a TnT está presente no complexo troponina (Bremel et al., 1972; Haselgrove, 1973; Malnic e Reinach, 1994; Malnic et al., 1998; Farah et al., 1995). Nosso grupo (Malnic et al., 1998) foi o primeiro a demonstrar que um fragmento isolado de $\mathrm{TnT}$ correspondente aos resíduos de aminoácidos 1-191 tem a função de ativar a atividade ATPásica da acto-miosina na presença de tropomiosina e na ausência das outras duas subunidades da TnT para níveis similares aos observados na presença de todo complexo troponina e $\mathrm{Ca}^{2+}$.

Nesse trabalho, estudando o efeito dos fragmentos de TnT na atividade ATPásica da acto-miosina, observamos que somente os fragmentos TnT1-191 e TnT77-191 possuiam a capacidade de ativar a atividade ATPásica. Observamos que somente os fragmentos que preservavam os sítios de interação com a tropomiosna (aminoácidos 77-157) (Jackson et al., 1975; Pearlstone e Smillie, 1977) e o sítio de interação com a actina (aminoácidos 77-191) possuiam a capacidade de ativar a atividade ATPásica. Esses resultados indicam a importância dessas interações da TnT e que os primeiros 76 aminoácidos da TnT não estão envolvidos no processo de ativação

Desde que foi proposto que existe uma região de sobreposição cabeça cauda entre tropomiosinas adjacentes (MacLachlan e Stewart, 1975; Phillips et al., 1980) e que a região da TnT correspondente ao fragmento CB3 estaria em contato com essa região de sobreposição (White et al. , 1987), muitas especulações foram feitas sobre o papel dessa região da TnT na transmissão do processo de ativação ao longo do filamento fino. Walsh et al. (1984) demonstram que a remoção dos primeiros 11 aminoácidos da tropomiosina não altera o grau de cooperatividade da ativação da atividade ATPásica da acto-miosina mediada por $\mathrm{Ca}^{2+}$. Essa observação foi interpretada como uma evidência de que a região correspondente à CB3 desempenharia um papel principal na cooperatividade presente no processo de ativação da atividade ATPásica e que, portanto, o papel da região CB3 seria 
desempenhado através de interações dessa região com duas tropomiosinas adjacentes.

Entretanto, estudos realizados por Hinkle et al. (1999) e Pan et al. (1991), através de ensaios com complexo troponina reconstituídos respectivamente com TnT cardíaca com os primeiros 94 removidos e com TnT esquelética de coelho com os primeiros 45 aminoácidos removidos, demonstraram que a remoção da extremidade $\mathrm{NH}_{2}$-terminal da TnT não causa um efeito significativo no processo cooperativo de ativação da ATPásica da acto-miosina mediado por $\mathrm{Ca}^{2+}$. Como os fragmentos de TnT estudados nesse trabalho apresentam a região de ancoragem de TnI/TnC (aminoácidos 216-263) (Malnic et al., 1998) removida, não foram realizados ensaios de ativação com complexo troponina reconstituído com os fragmentos de TnT. Contudo, nossos resultados de titulação da atividade ATPásica com fragmentos de TnT também indicam que a região CB3 da TnT não desempenha um papel significativo no processo de ativação. Uma possibilidade é que a cooperatividade da ativação possa ser transmitida entre unidades regulatórias vizinhas via moléculas de actina.

A importância da interação do complexo troponina com a actina para o processo de ativação da atividade ATPásica da acto-miosina foi também sugerida recentemente por Korman e Tobacman (1999). Utilizando mutantes de actina com mutações pontuais no subdomínio 3 da actina, esses autores observaram que, na presença do complexo troponina e de $\mathrm{Ca}^{2+}$, essas mutações comprometiam exclusivamente o processo de ativação da atividade ATPásica sem afetar a afinidade da actina por troponina.

Os nossos resultados de ligação do fragmento TnT158-191 à actina sugerem que a ligação de TnT à actina é um processo cooperativo, indicando que a ligação de TnT alteraria a estrutura do filamento fino. Essa observação indica um possível papel dessa interação da $\operatorname{TnT}$ com a actina no processo de cooperatividade da ativação da atividade ATPásica.

Embora os nossos resultados tenham deixado claro a importânica das interações da região 77-191 da TnT no processo de ativação, o mecanismo dessa ativação ainda não é claro. Acredita-se que que a ligação de $\mathrm{Ca}^{2+}$ nos sítios de 
regulatórios da $\mathrm{TnC}$ produza uma interação entre a região $\mathrm{NH}_{2}$-terminal da $\mathrm{TnC}$ e a região $\mathrm{COOH}$-terminal da $\mathrm{TnT}$, causando a dissociação ou enfraquecimento da interação da parte COOH-terminal da TnT com a tropomiosina. (Pearlstone e Smillie, 1982). Essa alteração na interção da região COOH-terminal da TnT com a tropomiosina leva à ativação da atividade ATPásica da acto-miosina. Uma possibilidade é que as interações da região 77-191 da TnT alterem a conformação da actina e suas interações com a miosina.

O Domínio Ativatório da Troponina T Altera a Posição da Tropomiosina no Filamento Fino

Acredita-se que o sítio de ligação do complexo troponina está situado entre os aminoácidos 150 e 284 da tropomiosina, portanto a sonda $50 H 122 W$ não estaria interagindo diretamente com o complexo troponina (White et al., 1987). Dessa forma, essa sonda (que é sensível à ligação de actina, à ligação de complexo troponina e à ligação de $\mathrm{Ca}^{2+}$ no complexo troponina), parece responder à mudanças na interação da actina com a tropomiosina provocada pela ligação de $\mathrm{Ca}^{2+}$ no complexo troponina. No contexto do modelo do bloqueio estérico (Huxley, 1972; Haselgrove,1972), essas alterações no espectro de emissão de Tm5OH122W presumivelmente refletem alterações da posição da tropomiosina no filamento de actina durante a regulação da contração muscular. Uma dessas posições deve ser a mesma posição que a tropomiosina ocupa no filamento fino durante o processo de ativação da atividade ATPásica da acto-miosina provocada pelo ligação de $\mathrm{Ca}^{2+}$ no complexo troponina.

Para estudarmos o mecanismo de ativação da atividade ATPásica por TnT1-191 e TnT77-191, analisamos o efeito desses fragmentos no espectro de emissão da tropomiosina $5 \mathrm{OH} 122 \mathrm{~W}$ na presença de actina. $\mathrm{O}$ aumento provocado pelos fragmentos TnT1-191 e TnT77-191 foi similar ao aumento provocado pela adição de $\mathrm{Ca}^{2+}$ na presença do complexo troponina. Esses resultados reforçam as nossas conclusões, obtidas a partir dos ensaios da atividade ATPásica da actomiosina, de que a região da $\operatorname{TnT}$ compreendida entre os aminoácidos 77-191 
(domínio ativatório da TnT) é responsável pela ativação da atividade ATPásica deflagrada pela ligação e $\mathrm{Ca}^{2+}$ no complexo troponina. Também evidenciam que o domínio ativatório da TnT é responsável pela alteração da posição da tropomisona no filamento fino observada em nos músculos estriados em altas concentrações de $\mathrm{Ca}^{2+}$. O papel da TnT seria o de prender a tropomiosina no filamento de actina por meio de suas interações com a tropomiosina e a actina numa posição que levaria à ativação. $O$ domínio ativatório da TnT desempenharia o seu papel de uma forma análoga mas oposta ao domínio inibitório da TnI, que durante a inibição, mantém a tropomiosina numa determinada posição no filamento fino por meio de interações com a actina e com a tropomiosina.

Interação da Região 77-157 da TnT com a Tropomiosina

A porção COOH-terminal da tropomiosina interage com a região correspondente ao fragmento $\mathrm{T} 1$ (aminoácidos 1-157) da TnT (Flicker et al., 1982). Estudos anteriores mostraram que a região envolvida com a interação com essa região da TnT está delimitada entre os resíduos 190-284 (Pato e Smillie, 1981). Alguns estudos sugerem que essa região de interação da tropomiosina com a troponina seja responsável por uma diferenciação funcional entre as muitas isoformas de tropomiosina (para revisão, ver Less-Miller e Helfman, 1991). De fato, a região entre os aminoácidos 158-284 é codificada por um éxon alternativo específico para músculos esqueléticos: éxon 9a para o gene $\alpha$ (Ruiz-Opazo et al. 1985) e 7 para genes $\beta$ (Helfman e Ricci, 1989), e tecidos não musculares e músculos lisos não possuem complexo troponina. Estudos demonstraram que os primeiros 18 resíduos $(258-275)$ codificados por esse éxon são decisivos para a interação da troponina com a tropomiosina no filamento fino através de quimeras e mutantes de deleção de $\alpha$-tropomiosinas não acetiladas de músculos estriados de ratos (Hammell e Hitchcock-DeGregori, 1996). Sabe-se que a integridade das porções $\mathrm{NH}_{2}$ e $\mathrm{COOH}$-terminal é indispensável para a manutenção da capacidade de polimerização das tropomiosinas e sua ligação com actina (Lewis et al., 1983; Mak et al., 1983; Cho et al., 1990) e que a ausência de acetilação em 
tropomiosinas de músculo esquelético recombinantes (produzidas em bactérias) acarreta a diminuição dessas propriedades, em ausência de troponina (Mak et al., 1983; Monteiro et al., 1994). Utilizando uma tropomiosina recombinante funcional (propriedades regulatórias e físicas) (Monteiro et al, 1994), nosso trabalho confirma os resultados obtidos com tropomiosina não acetilada por Hammell \& Hitchcock-DeGregori (1996) e, adicionalmente, indica um resíduo (263) que interage especificamente com a região CB2 da troponina. Foram contornados, nesse trabalho, alguns problemas experimentais que cercam os estudos das interações tropomiosina-troponina: i) o estudo de uma seqüência única de tropomiosina (geralmente as células produzem mais de uma isoforma) e funcional (devido à fusão dipeptídica) apesar de expressa em bactéria, com uma sonda intrínseca e seletiva (mutação para triptofano e incorporação de 5hidroxitriptofano); ii) o estudo das interações com troponina $\mathrm{T}$, utilizando fragmentos solúveis de TnT; utilizando o complexo troponina reconstituído com T2 como controle negativo (o que exclui a hipótese da sonda ser sensível à T2, TnC ou TnI).

É interessante notar que o resíduo 263 da tropomiosina supostamente ocupa uma posição " $d$ " na estrutura "coiled-coil", caracterizada por cadeias laterais predominantemente hidrofóbicas e posicionada na interface das duas hélices da proteína (Smillie, 1979). A análise da seqüência da TnT mostra que existe uma uma região com repetições heptapeptícas entre os resíduos dentro da região CB2 da TnT (aminoácidos 77-157) portanto com alta probabilidade de formar estrutura coiled coil. Essas observações sugerem que essa região, com alto percentual de $\alpha$ hélice, talvez forme uma tripla hélice com a troponiosina. 


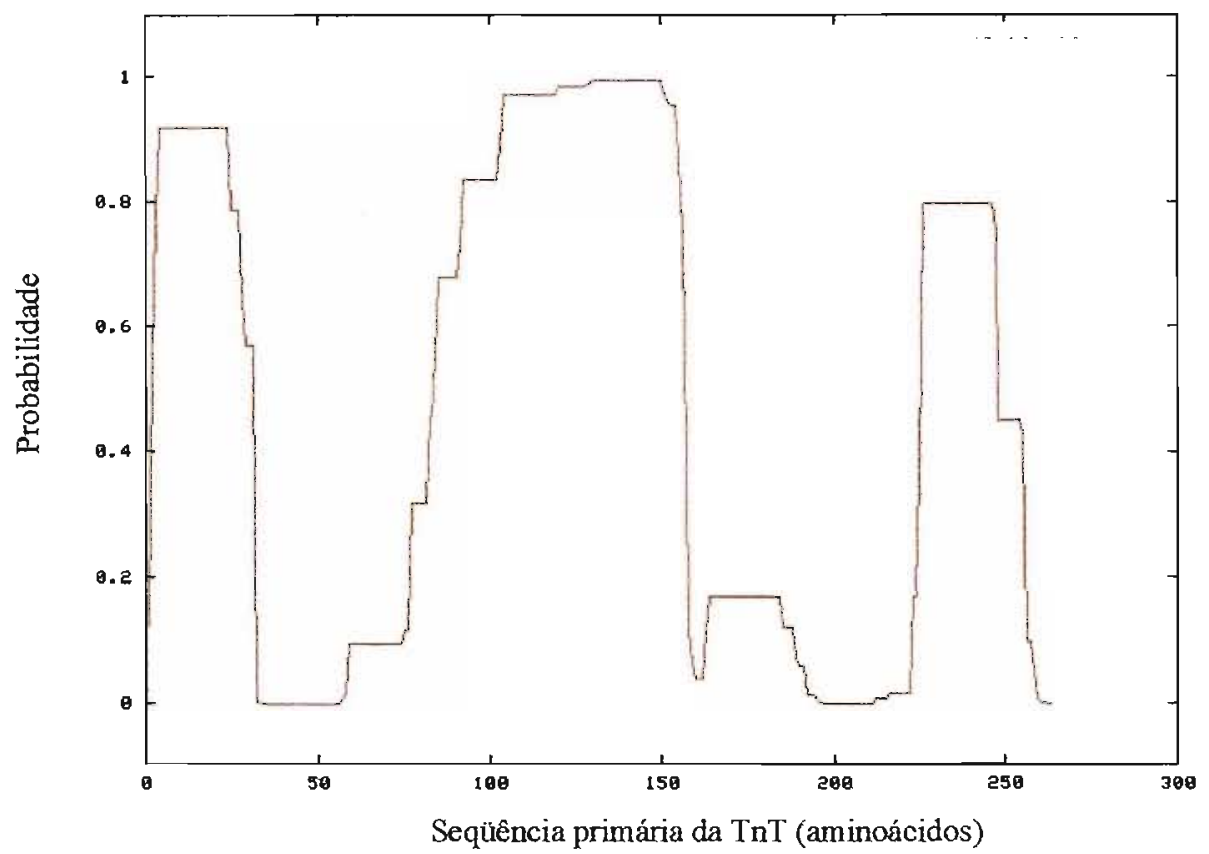

Figura 20. Probabilidade das regiões da TnT de formarem coiled coil. A predição de estrutura coiled coil a partir da sequência primária da TnT foi feita como descrita por Lupas et al. (1991). Essa predição indica duas regiôes com alta probabilidade de fonação de coiled coil: a região correspondente ao fragmento $\mathrm{CB} 2$ e a região $\mathrm{COOH}-$ terminal correspondente ao sitio de interação da TnT com a TnI.

O nosso trabalho claramente demosntrou que a domínio ativatório da TnT é responsável pelo processo de ativação da atividade ATPásica da acto-miosina observado após a ligação de $\mathrm{Ca}^{2+}$ no complexo troponina. Entretanto, algumas questões relacionadas ao mecanismo dessa ativação, e de toda a regulação da contração, ainda não estão esclarecidas. Uma questão é como o domínio ativatório da TnT é capaz de elevar os níveis da atividade ATPásica para níveis maiores que os observados na presença da tropomiosina na ausência do complexo troponina. 


\section{OBSERVAÇÃO}

\section{NÃO FOI AUTORIZADA A INCLUSÃO DO TRABALHO \\ NESTE ARQUIVO}

Oliveira, D.M., Nakaie, C.R., Sousa, A.D., Farah, C.S,, Reinach, F.C. (2000) - Mapping the domain of troponin T responsible for the activation of actomiosyn ATPase Activity. Identification of residues involved in binding to actin. J. Biol. Chem. 275, 2751327519. 


\section{REFERÊNCIAS BIBLIOGRÁFICAS}

Andrade, M. A., Chacon P., Merelo J. J. e Moran, F. (1993). Evaluation of secondary structure of proteins from UV circular dichroism spectra using an unsupervised learning neural network. Protein Eng. 6, 383-390.

Bagshaw, C. R (1993). Muscle contraction. Second Edition. Chapman e Hall, London, United Kingdom.

Bremel, R. D. e Weber, A. (1972). Cooperation within actin filament in vertebrate skeletal muscle. Nat New Biol. 238, 97-101.

Brisson, J. R., Golosinska, K., Smillie, L. B. e Sykes, B. D. (1986). Interaction of tropomyosin and troponin $\mathrm{T}$ : a proton nuclear magnetic resonance study.

Biochemistry 25, 4548-4555.

Bronson, D. D. e Schachat, F. H. (1982). Heterogeneity of contractile proteins.

Differences in tropomyosin in fast, mixed, and slow skeletal muscles of the rabbit.

J. Biol Chem. 257, 3937-3944.

Carlier, M. F. (1991). Actin: protein structure and filament dynamics. J. Biol.

Chem., 266, 1-4.

Chalovich, J. M. e Eisenberg, E. (1986). The effect of troponin-tropomyosin on the binding of heavy meromyosin to actin in the presence of ATP. J. Biol. Chem. 261, 5088-5093.

Chen, Y. H., Yang, J. T. e Chau, K. H. (1974). Determination of the helix and beta form of proteins in aqueous solution by circular dichroism. Biochemistry 13, 33503359. 
Cho, Y. J. e Hitchcock-DeGregori, S. E. (1991). Relationship between alternatively spliced exons and functional domains in tropomyosin. Proc. Natl. Acad. Sci. U. S. A. 88, 10153-10157.

Cummins, P. e Perry, S. V. (1973). The subunits and biological activity of polymorphic forms of tropomyosin. Biochem. J. 133, 765-777.

Dahiya, R., Butters, C. A. e Tobacman, L. S. (1994). Equilibrium linkage analysis of cardiac thin filament assembly. Implications for the regulation of muscle contraction. J Biol Chem. 269, 29457-29461.

Farah, C. S., Miyamoto, C. A., Ramos, C. H. I., Da Silva, A. C. R., Quaggio, R. B., Fujimori, K., Smillie, L. B. e Reinach, F. C. (1994). Structural and regulatory functions of the $\mathrm{NH}_{2}$ - and $\mathrm{COOH}$-terminal regions of skeletal muscle troponin I. $J$. Biol. Chem. 269, 5230-5240.

Farah, S. C. e Reinach, F. C. (1995). The troponin complex and regulation of muscle contraction. FASEB J. 9, 755-767.

Farah, S. C. e Reinach, F. C. (1999). Regulatory properties of recombinant tropomyosins containing 5-hydroxytryptophan: $\mathrm{Ca} 2+-$ binding to troponin results in a conformational change in a region of tropomyosin outside the troponin binding site. Biochemistry 38, 10543-10551.

Fisher, D., Wang, G. e Tobacman, L. S. (1995). NH2-terminal truncation of skeletal muscle troponin $\mathrm{T}$ does not alter the $\mathrm{Ca} 2+$ sensitivity of thin filament assembly. J. Biol. Chem. 270, 25455-25456.

Flicker, P. F., Phillips Jr, G. N. e Cohen, C. (1982). Troponin and its interactions with tropomyosin. An electron microscope study. J. Mol. Biol. 162, 495-501. 
Garnier, J., Gibrat, J. F. e Robson, B. (1996). GOR secondary structure prediction method version IV. Methods Enzymol. 266, 540-553.

Gazith, J., Himmelfarb, S. e Harrington, W. F. (1970). Studies on the subunit structure of myosin. J. Biol Chem. 245, 15-22.

Greaser, M. L. e Gergely, J. (1971). Reconstitution of troponin activity from three protein components. J. Biol. Chem. 246, 4226-4233.

Greaser, M. L. e Gergely, J. (1973). Purification and properties of the components from troponin. J. Biol. Chem. 248, 2125-2133.

Gordon, A. M., Homsher, E. e Regnier, M. (2000). Regulation of contraction in striated muscle. Physiol Rev. 80, 853-924.

Hanahan, D. (1985). Techniques for transformation in E. coli. In: DNA cloning: a practical approach, (Glover, D. M., ed.), 109-135, IRL Press, Oxford.

Hammell, R. L. e Hitchcock-DeGregori, S. E. (1996). Mapping the functional domains within the carboxyl terminus of alpha-tropomyosin encoded by the alternatively spliced ninth exon. J. Biol. Chem. 271, 4236-4242.

Hartree, E. F. (1972). Determination of protein: a modification of Lowry method that gives a linear photometric response. Analytical Biochemistry 48, 422-427.

Haselgrove, J. C. (1972). X-ray evidence for a conformational change in actincontaining filaments of vertebrates. Cold Spring Harbor Symp. Quant. Biol. 37, 341-352.

Heeley, D. H., Golosinska, K. e Smillie, L. B. (1987). The effects of troponin T fragments $\mathrm{T} 1$ and $\mathrm{T} 2$ on the binding of nonpolymerizable tropomyosin to $\mathrm{F}$-actin 
in the presence and absence of troponin I and troponin C. J. Biol. Chem. 262, 9971-9978.

Heinomem, J. K. e Lahti, R. J. (1981). A new and convenient colorimetric determination of inorganic orthophosphate and its application to the assay of inorganic pyrophosphatase. Anal. Biochem. 113, 313-317.

Helfman, D. M. e Ricci, W. M (1989). Branch point selection in alternative splicing of tropomyosin pre-mRNAs. Nucleic Acids Res.17, 5633-5650.

Herzberg, O. e James, M. N. (1985). Structure of the calcium regulatory muscle protein troponin-C at 2.8 A resolution. Nature 313, 653-659.

Herzberg, O., Moult, J. e James, M. N. (1986). A model for the Ca2+-induced conformational transition of troponin C. A trigger for muscle contraction. J. Biol. Chem. 261, 2638-2644.

Herzberg, O. e James, M. N. G. (1988). Refined crystal structure of troponin C from turkey skeletal myscle at 2.0 A resolution. J. Mol. Biol. 203, 761-779.

Higuchi, R. (1990). PCR Protocols: A Guide to Methods and Applications. Academic Press, London, United Kingdom.

Hill, L. E., Mehegan, J. P., Butters, C. A. e Tobacman, L. S. (1992). Analysis of troponin-tropomyosin binding to actin. Troponin does not promote interactions between tropomyosin molecules. J. Biol. Chem. 267, 16106-16113.

Hinkle, A., Goranson, A., Butters, C. A. e Tobacman, L. S. (1999). Roles for the troponin tail domain in thin filament assembly and regulation. A deletional study of cardiac troponin T. J. Biol. Chem. 274, 7157-7164. 
Hitchock, S. E. (1975). Regulation of muscle contraction: bindings of troponin and its components to actin and tropomyosin. Eur. J. Biochem. 52, 255-263.

Holmes, K. C., Popp, D., Gebhard, W. e Kabsch. W. (1990). Atomic model of the actin filament. Nature 347, 44-49.

Houdusse, A., Kalabokis, V. N., Himmel, D., Szent-Gyorgyi, A. G. e Cohen, C. (1999). Atomic structure of scallop myosin subfragment S1 complexed with MgADP: a novel conformation of the myosin head. Cell 97, 459-470.

Huxley, H. E. (1969). The mechanism of muscular contraction. Science 164, 13561365 .

Huxley, H. E. (1972). Structural changes in actin- and myosin- containing filaments during contraction. Cold Spring Harbor Symp. Quant. Biol. 37, 361-376.

Jackson, P., Amphlett, G. W. e Perry, V. (1975). The primary structure of troponin $\mathrm{T}$ and the interaction with tropomyosin. Biochem. J. 151, 85-97.

Kabsch ,W., Mannherz, H. G., Suck, D., Pai, E. F., Holmes, K. C.(1990). Atomic structure of the actin:DNase I complex. Nature 347, 37-44.

Kabsch, W. e Vandekerckhove, J. (1992). Structure and function of actin. Annu. Rev. Biophys. Biomol. Struct. 21, 49-76.

Korman, V. L. e Tobacman, L. S. (1999). Mutations in actin subdomain 3 that impair thin filament regulation by troponin and tropomyosin. J. Biol. Chem. 274, 2291-2296.

Kunkel, T. A. (1987). Rapid and efficient site-specific mutagenesis without phenotypic selection. Methods. Enzymol. 154, 367-382. 
Johnson, P. e Smillie, L. B. (1975). Rabbit skeletal $\alpha$-tropomyosin chains are in register. Biochem. Biophys. Res. Commun. 64, 1316-1322.

Laemmli, U. K. (1970). Cleavage of structural proteins during the assembly of the head of bacteriophage T4. Nature 368, 65-67.

Less-Miller, J. P. e Helfman, D. M. (1991). The molecular basis for tropomyosin isoform diversity. BioEssays 13, 1-9.

Lehman, W., Craig, R. e Vibert, P. (1994). Ca2+ induced tropomyosin movement in Limulus thin filaments revealed by three-dimensional reconstituition. Nature $368,65-67$.

Lehman, W., Vibert, P., Uman, P. e Craig, R (1995). Steric blocking by tropomyosin visualized in relaxed vertebrated thin filaments. J. Mol. Biol. 251, 191-196.

Lehrer, S. S. (1975). Intramolecular crosslinking of tropomyosin via disulfide bond formation: evidence for chain register. Proc. Natl. Acad. Sci. US A. 72, 3377-3381.

Lewis, W. G., Cote, G. P., Mak A. S. e Smillie, L. B. (1983). Amino acid sequence of equine platelet tropomyosin. Correlation with interaction properties. FEBS Lett. 156, 269-273.

Lupas A, van Dyke, M. e Stock, J. (1991). Predicting coiled coils from proteins sequences. Science 252, 1162-1164.

Malnic, B. e Reinach, F. C. (1994). Assembly of functional skeletal muscle troponin complex in Escherichia coli. Eur. J. Biochem. 222, 49-54. 
Malnic, B., Farah C. S. e Reinach, F. C. (1998). Regulatory properties of the NH2and $\mathrm{COOH}$-terminal domains of troponin $\mathrm{T}$. ATPase activation and binding to troponin I and troponin C. J. Biol. Chem. 273, 10594-10601.

Mak, A. S. e Smillie, L. B. (1981). Structural interpretation of the two-site binding of troponin on the muscle thin filament. J. Mol. Biol. 149, 541-550.

Mak, A. S., Golosinska, K. e Smillie, L. B. (1983). Induction of nonpolymerizable tropomyosin binding to $\mathrm{F}$-actin by troponin and its components. $J$ Biol Chem. 258, 14330-14334.

McKillop, D. F. A. e Geeves, M. A. (1993). Regulation of the interaction between actin and myosin subfragment 1 : evidence for three states of the thin filament. Biophys. J. 65, 693-701.

McLachlan, A. D. e Stewart, M. (1975). Tropomyosin coiled- coil interactions. Evidence for an unstaggered structure. J. Mol. Biol. 98, 293-304.

McLaughlin, P. J., Gooch, J. T., Mannherz, H. G. e Weeds, A. G. (1993). Structure of gelsolin segment 1-actin complex and the mechanism of filament severing. Nature 364, 685-92

Merelo, J.J., Andrade, M. A., Prieto, A e Morán, F. (1994). Proteinotopic Feature Maps. Neurocomputing. 6, 443-454.

Monteiro, P. B., Lataro, R. C., Ferro, J. A. e Reinach, F. C. (1994). Functional alpha-tropomyosin produced in Escherichia coli. A dipeptide extension can substitute the amino-terminal acetyl group. J. Biol. Chem. 269, 10461-10466. 
Moore, P. B., Huxley, H. E. e DeRosier, D. J. (1970). Three-dimensional reconstruction of F-actin, thin filament and decorated thin filament. J. Mol. Biol. 50, 279-295.

Ohtsuki, I. (1979). Molecular arrangement of troponin-T in the thin filament. $J$. Biochem. 86, 491-497.

Ohtsuki, I., Maruyama, K. e Ebashi, S. (1986). Regulatory and cytoskeletal proteins of vertebrate skeletal muscle. Adv. Protein Chem. 38, 1-67.

Pan, B. S., Gordon, A. M. e Potter, J. D. (1991). Deletion of the first $45 \mathrm{NH}_{2}$ terminal residues of rabbit skeletal troponin $\mathrm{T}$ strengthens binding of troponin to immobilized tropomyosin. J. Biol. Chem. 266, 12432-2438.

Pardee, J. D. e Spudich, J. A. (1982). Purification of muscle actin. Methods. Enzymol. 85, 164-182.

Pato, M. D., Mak, A. S. e Smillie, L. B. (1981). Fragments of rabbit striated muscle alpha-tropomyosin. II. Binding to troponin-T. J. Biol. Chem. 256, 602-607.

Pearlstone, J. R., Carpenter, M. R., Johnson, P. e Smillie, L. B. (1976). Aminoacid sequence of tropomyosin-binding component of rabbit skeletal muscle troponin. Proc. Natl. Acad. Sci. U.S.A. 73, 1902-1906.

Pearlstone, J. R. e Smillie, L. B. (1977). The binding site of skeletal al phatropomyosin on troponin-T. Can. J. Biochem. 55, 1032-1038.

Pearlstone, J. R. e Smillie, L. B. (1978). Troponin T fragments: physical properties and binding to troponin C. Can. J. Biochem. 56, 521-527. 
Pearlstone, J. R. e Smillie, L. B. (1982). Binding of troponin-T fragments to several types of tropomyosin. Sensitivity to $\mathrm{Ca}^{2+}$ in the presence of troponin-C. $J$. Biol. Chem. 257, 10587-10592.

Pearlstone, J. R e Smillie, L. B. (1983). Effects of troponin-I plus-C on the binding of troponin- $\mathrm{T}$ and its fragments to alpha-tropomyosin. $\mathrm{Ca}^{2+}$ sensitivity and cooperativity. J. Biol. Chem. 258, 2534-2542.

Pearlstone, J. R e Smillie, L. B. (1985). The interaction of rabbit skeletal muscle troponin-T fragments with troponin-I. Can. J. Biochem. 63, 212-218.

Perry, S. V., Cole, H. A., Head, J. F. e Wilson, J. F. (1972). Localization and mode of action of the inhibitory protein component of troponin complex. Cold spring Harbor Symp. Quant. Biol. 37, 251-262.

Perry, S. V. (1998). Troponin T: genetics, properties and function. J. Musc. Res. Cell Motil. 19, 575-602.

Phillips G. N. Jr, Fillers J. P. e Cohen, C. (1980). Motions of tropomyosin. Crystal as metaphor. Biophys. J. 32, 485-502.

Poole, K. J. V., Lorenz, M., Evans, G., Rosembau, G. e Holmes, K C. (1994). The effect of calcium on the regulated thin filament structure. Biophhys. J. 66, A347.

Potter, J. D. e Gergely, J. (1974). The calcium and magnesium binding sites on troponin and their role in the regulation of myofibrillar adenosine triphosphatase. Biochemistry 13, 2697-2703.

Potter, J. D., Sheng, Z., Pan, B. e Zhao, J. (1995). A direct regulatory role for troponin $\mathrm{T}$ and a dual role for troponin $\mathrm{C}$ in the $\mathrm{Ca} 2+$ regulation of muscle contraction. J. Biol. Chem. 270, 2557-2562. 
Provencher, S. W. (1982). A constrained regularization method for inverting data represented by linear algebraic or integral equations. Phys. Commun. 27, 213-227.

Provencher, S. W. (1982). CONTIN - A general purpose constrained regularization program for inverting noisy linear algebraic and integral equations. Phys. Commun. 27, 229-242.

Quaggio, R B., Ferro, J. A., Monteiro, P. B. e Reinach F. C. (1993). Cloning and expression of chicken skeletal muscle troponin I in Escherichia coli: the role of rare codons on the expression level. Protein. Sci. 2, 1053-1056.

Rayment, I., Rypniewski, W. R., Schmidt-Bäse, K., Smith, R., Tomchick, D. R., Benning, M. M, Winkelmann, D. A., Wesenberg, G. e Holden, H. M. (1993). Three-dimensional structure of myosin subfragment-1: A molecular motor. Science 261, 50-58.

Rayment, I., Holden, H. M., Whittaker, M., Yohn, C. B., Lorenz, M., Holmes, K. C. e Milligan, R A. (1993b). Structure of the actin-myosin complex and its implications for muscle contraction. Science 261, 58-65.

Reinach, F. C., Masaki, T., Shafiq, S., Obinata, T. e Fishman, D. A. (1982). Isoforms of $\mathrm{C}$-protein in adult chicken skeletal muscle: detection with monoclonal antibodies J. Cell Biol. 95, 78-84.

Ruiz-Opazo, N., Weinberger, J.e Nadal-Ginard, B. (1985). Comparison of alphatropomyosin sequences from smooth and striated muscle. Nature 315, 67-70.

Sambrook, J., Fritsch, E. F. e Maniatis, T. (1989). Molecular cloning: a laboratory manual. Cold Spring Harbor Laboratory Press, New York. 
Sanger, F., Nicklen, S. e Coulson, A. R. (1977). DNA sequencing with chainterminating inhibitors. Proc. Natl. Acad. Sci. U.S.A. 74, 5463-5467.

Schaeger, H. e von Jagow, G. (1987). Tricine-sodium dodecyl sulfatepolyacrylamide gel electrophoresis for the separation of proteins in the range from 1 to $100 \mathrm{kDa}$. Anal. Biochem. 166, 368-379.

Sheng, Z., Pan, B. S., Miller T. E. e Potter, J.D (1992). Isolation, expression, and mutation of a rabbit skeletal muscle cDNA clone for troponin I. The role of the $\mathrm{NH} 2$ terminus of fast skeletal muscle troponin I in its biological activity. J. Biol. Chem. 267, 25407-25413

Smillie, L. B. (1979). Structure and functions of tropomyosin from muscle and non-muscle sources. TIBS 4, 151-155.

Smillie, L. B. (1982). Preparation and identification of alpha- and betatropomyosins. Methods. Enzymol. 85, 234-241.

Smillie, L. B., Golosinska, K. e Reinach, F. C. (1988). Sequences of complete cDNAs encoding four variants of chicken skeletal muscle troponin T. J. Biol. Chem. 263, 18816-18820.

Steinmetz, M. O., Hoenger, A., Tittmann, P., Fuchs, K. H., Gross, H. e Aebi, U. (1998). An atomic model of crystalline actin tubes combining electron microscopy with X-ray crystallography. J. Mol. Biol. 278, 703-711.

Squire, J. M. (1973). General model of myosin filament structure. Molecular packing arrangements in myosin filaments. J. Mol. Biol. 77, 291-323.

Squire, J. M. e Morris, E. P. (1998). A new look at thin filament regulation in vertebrate skeletal muscle. FASEB J. 12, 761-771. 
Studier, F. W. e Moffatt, B. A. (1986). Use of bacteriophage T7 RNA polymerase to direct selective high-level expression of cloned genes. J. Mol. Biol, 189, 113130.

Studier, F. W., Rosenberg, A. H., Dunn, J. J. e Dubendorff, J. W. (1990). Use of T7 RNA polymerase to direct expression of cloned genes Methods Enzymol. 185, $60-89$.

Syska, H., Wilkinson, J. M., Grand, R. J. e Perry S. V. (1976). The relationship between biological activity and primary structure of troponin I from white skeletal muscle of the rabbit. Biochem J. 153, 375-87.

Thompson J. D., Higgins D. G. e Gibson, T. J. (1994). Clustal w: improving the sensitivity of progressive multiple sequence alignment through sequence weighting, position-specific gap penalties and weight matrix choice. Nucleic Acids Res. 22, 4673-4680.

Tobacman, L. S. (1996). Thin filament-mediated regulation of cardiac contraction Ann Rev Physiol. 58, 447-481.

Tonokura, M. e Ohtsuki, I. (1983). Chymotryptic subfragments of troponin T from rabbit skeletal muscle. Interaction with tropomyosin, troponin I and troponin C. J. Biochem. 95, 1417-1421.

Walsh, T .P., Trueblood, C. E., Evans, R. e Weber, A. (1985). Removal of tropomyosin overlap and the co-operative response to increasing calcium concentrations of the acto-subfragment-1 ATPase. J. Mol. Biol. 82, 265-269.

White, S. P., Cohen, C. e Phillips Jr., G. N. (1987). Structure of co-crystals of tropomyosin and troponin. Nature 325, 826-828. 
Zot, A. S. e Potter, J. D. (1987). Structural aspects of troponin-tropomyosin

regulation of skeletal muscle contraction. Ann. Rev. Biophys. Biophys. Chem. 16, 535-559. 